FERNANDA VITAL RAMOS DE ALMEIDA

\title{
Flora e distribuição ecológica de comunidades de macroalgas lóticas de fragmentos florestais da região noroeste do estado de São Paulo
}

Dissertação apresentada ao Instituto de Biociências do Campus de Rio Claro, Universidade Estadual Paulista Júlio de Mesquita Filho, como parte dos requisitos para obtenção do título de Mestre em Ciências Biológicas (Biologia Vegetal).

Orientador: Prof. Dr. Orlando Necchi jr.

Rio Claro

2010 


\section{MEUS AGRADECIMENTOS...}

Ao Prof. Dr. Orlando Necchi Jr., pela orientação desde o início da minha graduação, pela confiança em mim e no meu trabalho e pelos valiosos momentos de aprendizado.

Ao Prof. Dr. Luis Henrique Zanini Branco, por ter me ajudado com a identificação das amostras e pelos conselhos referentes ao meu trabalho.

À FAPESP e ao Projeto BIOTA/FAPESP, pelo apoio financeiro para a realização das coletas e equipamento fotográfico, e pela bolsa cedida durante o período de estudo.

Aos meus companheiros de laboratório, especialmente Nádia, Carmélia, Mariéllen, Jéfferson e Haruo pelos momentos de aprendizado e descontração.

Ao Jefferson e ao Marcos pelo auxílio nas coletas.

Aos meus pais, pelo amor, pela educação e pelo incentivo incondicional aos meus estudos ao longo de suas vidas.

À minha avó e aos meus tios, por me acolherem e me incentivarem sempre.

Às minhas eternas companheiras de república, Ferzinha, Martini, Minas, Vivian, Daia e Kaiser, pelos momentos inesquecíveis que passamos durante a graduação, pelo apoio e amizade.

Aos meus amigos mais do que importantes, especialmente Babu, Nandão, Ciro, Gorgon, Nego e Michel, pelo carinho, apoio e amizade sincera.

À Deus, por me dar essa oportunidade. 
"O homem argumenta; a natureza age."

Voltaire 


\section{RESUMO}

Vários estudos envolvendo flora e distribuição de comunidades de macroalgas lóticas já foram desenvolvidos na região noroeste do estado de São Paulo; entretanto, nunca foi realizada qualquer abordagem sobre macroalgas lóticas em fragmentos florestais remanescentes, aspecto mais relevante deste estudo. Foram testadas as seguintes hipóteses: (1) entre as regiões/biomas estudados no estado de São Paulo, o atual trabalho deve apresentar maior similaridade florística com Floresta Tropical, por ser mais próxima e composta também por Floresta Estacional Semidecidual; (2) características intrínsecas de cada corpo d'água devem exercer maior influência na riqueza e abundância das comunidades de macroalgas do que parâmetros mais gerais de cada fragmento, como forma, tamanho e matriz adjacente, e da ordem de grandeza do riacho e sua respectiva bacia de drenagem. Este trabalho teve como objetivo geral realizar o levantamento florístico e analisar a distribuição ecológica das comunidades de macroalgas lóticas de fragmentos florestais remanescentes de Floresta Estacional

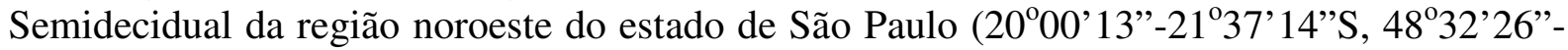
$50^{\circ} 26^{\prime} 02^{\prime \prime}$ ). Foram amostrados 17 riachos pertencentes a 12 fragmentos, no intervalo de junho a agosto de 2007 e 2008, período mais favorável para a região (estação seca). Foram identificadas 16 espécies de macroalgas, pertencentes a 14 gêneros. A maioria das espécies (69\%) foi encontrada em um único ponto. Cyanophyta e Chlorophyta foram os grupos predominantes (44 e 37,5\%), seguidos por Rhodophyta (12,5\%) e Heterokontophyta (6\%). Phormidium retzii (Cyanophyta) foi a espécie mais frequente, ocorrendo em seis pontos de amostragem. Apenas duas espécies representaram novos registros para a região: Trichocoleus sociatus (Cyanophyta) e Vaucheria pseudogeminata (Heterokontophyta); a última representa o primeiro registro para o Brasil. A flora regional assemelhou-se mais (com nove espécies em comum, 56\%) a Floresta Tropical, conforme esperado. Tanto a riqueza global (16), quanto a riqueza $(1,6 \pm 1,5)$ e a abundância $(1,8 \pm 3,1)$ de macroalgas por ponto de amostragem foram baixas. Este fato pode ser atribuído à predominância de substrato areno-argiloso (65\% dos pontos) e provavelmente à predominância de trechos sombreados (53\%), ambos desfavoráveis à colonização e manutenção de macroalgas lóticas. Estas características permitem caracterizar o ambiente como severo para estas comunidades, o que condiz com a Hipótese do Distúrbio Intermediário, a qual prevê que muitas espécies tendem a não tolerar condições de distúrbio elevado e extinguem-se do local. Características como forma e tamanho do fragmento, assim como sua matriz adjacente (cana/pastagem), ordem do riacho e sua posição no fragmento (borda/interior) e a sua respectiva bacia de drenagem, não mostraram influência nos parâmetros da comunidade de macroalgas. Estes resultados, aliados à ocorrência restrita de espécies, sugerem que as variáveis locais, especialmente substrato e sombreamento, foram as mais influentes na distribuição das comunidades de macroalgas, o que confirma a hipótese inicial. Por outro lado, considerando a escassez de trabalhos envolvendo macroalgas lóticas de ambientes associados a fragmentos florestais, recomenda-se a realização de mais estudos para melhor entendimento a respeito da distribuição destas comunidades nestes ambientes.

Palavras-chave: distribuição ecológica. flora. fragmentos florestais. Macroalgas. riachos. 


\begin{abstract}
Several studies involving the flora and distribution of lotic macroalgal communities have been carried out in the northwest region of São Paulo State, southeastern Brazil. However, the lotic macroalgae in remnant forest fragments have never been studied, the most relevant aspect of this study. The following hypotheses have been tested: 1) among the biomes/regions previously studied in São Paulo State, the flora of the northwest region is expected to reveal the highest floristic similarity with the Tropical Forest, since it is the nearest biome and also composed by semidecidual seasonal forest; 2) particular characteristics of each water body are expected to be more influential on the species richness and abundance of macroalgal communities than more general parameters of each forest fragment, such as surrounding matrix, stream order and position in the respective drainage basin. This study aimed at surveying the flora and describing the ecological distribution the of lotic macroalgal communities from remnant forest fragments composed of semidecidual seasonal forest in the

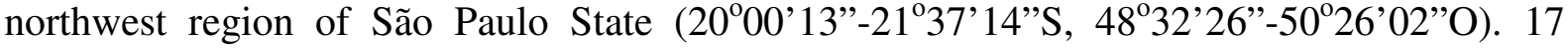
streams were sampled in 12 forest fragments from June to August of 2007 and 2008 during the typical most favorable period in the region (dry season). 16 species have been surveyed, belonging to 14 genera. $69 \%$ of species were found in a single site. Cyanophyta and Chlorophyta were the predominant algal groups (44 amd 37.5\%), followed by Rhodophyta (12.5\%) and Heterokontophyta (6\%). Phormidium retzii (Cyanophyta) was the most frequent species, occurring in six sampling sites. Only two species were new records for the region: Trichocoleus sociatus (Cyanophyta) and Vaucheria pseudogeminata (Heterokontophyta); the later represents the first report for Brazil. The regional flora was more similar (nine species in common, $56 \%$ ) with that of the Tropical Forest, as expected. Global species number (16), as well as species richness $(1.6 \pm 1.5)$ and percent cover $(1.8 \pm 3.1)$ of macroalgae per sampling site were low. This can be ascribed to the predominance of sandy-clayish stream bottom (65\% of sites) and probably to shaded stream segments $(53 \%)$, both unfavorable to the colonization and maintenance of lotic macroalgae. These attributes allow us to characterize the habitats as severe for such communities and such characteristics agree with the Intermediate Disturbance Hypothesis, which predict that most species are not capable to tolerate conditions of intense or frequent disturbances and tend to be extinct. Parameters such as fragment shape and size, as well as the surrounding matrix, stream order and its position in the fragment (border vs interior) and in the drainage basin, did not show influence on the characteristics of macroalgal communities. These results, associated with the high proportion of restrict species, suggest that local variables, particularly substratum and shading, were the most influential on the distribution of macroalgal communities, confirming the initial hypothesis. On the other hand, considering the scarcity of studies on lotic macroalgae in forest fragments, is strongly evident the need for more studies for a better understanding of such communities.
\end{abstract}

Key words: ecological distribution. Flora. forest fragments. Macroalgae. streams. 


\section{SUMÁRIO}

PÁGINAS

1. INTRODUÇÃO E MATERIAIS E MÉTODOS GERAIS ...........................................................

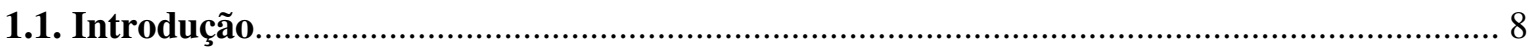

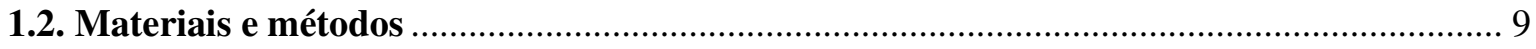

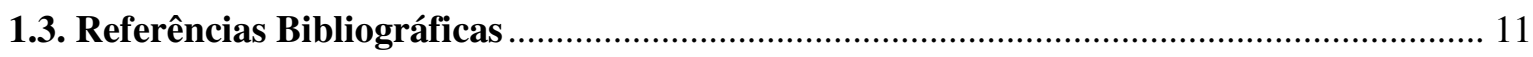

2. CAPITULO 1. FLORA DE COMUNIDADES DE MACROALGAS LÓTICAS DE FRAGMENTOS FLORESTAIS NA REGIÃO NOROESTE DO ESTADO DE SÃO PAULO ...........18

2.1. Resumo

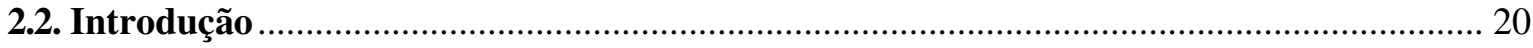

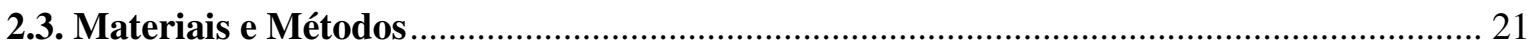

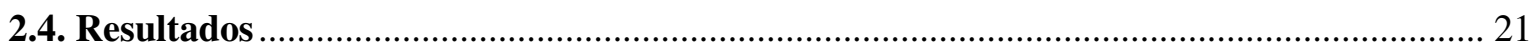

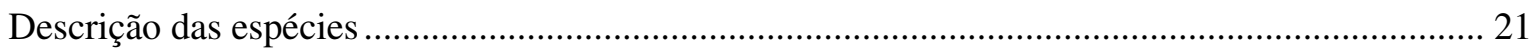

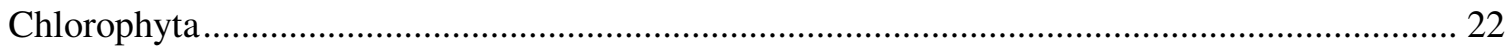

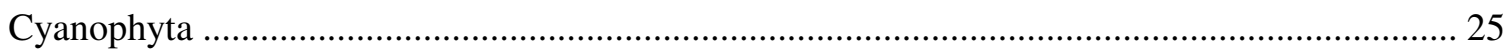

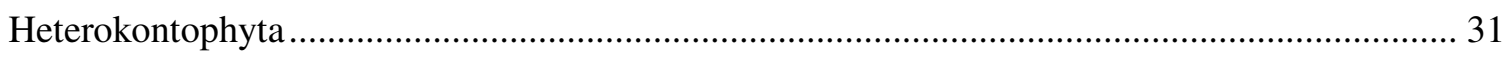

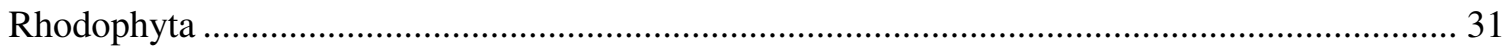

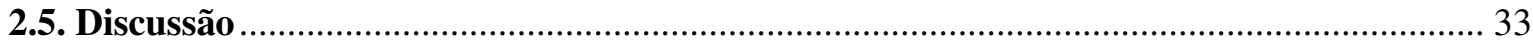

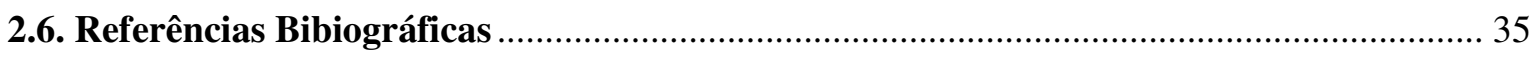

3. CAPÍTULO 2. DISTRIBUIÇÃO ECOLÓGICA DAS COMUNIDADES DE MACROALGAS LÓTICAS DE FRAGMENTOS FLORESTAIS DA REGIÃO NOROESTE DE SÃO PAULO...........44

3.1. Resumo

2.2. Introdução

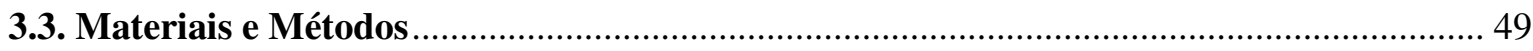

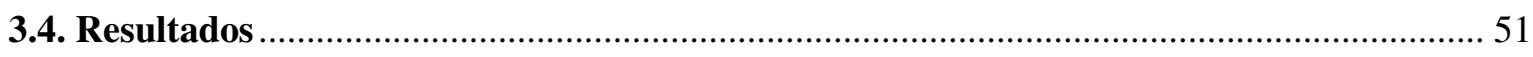

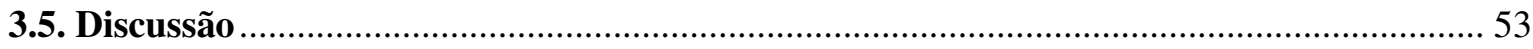

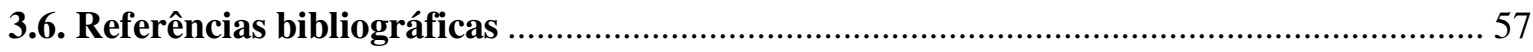

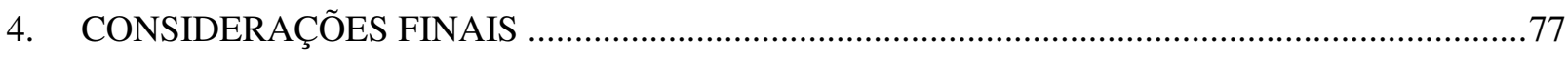

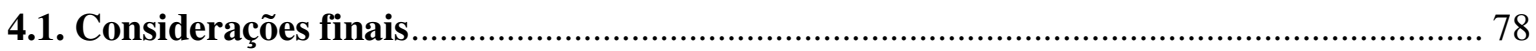

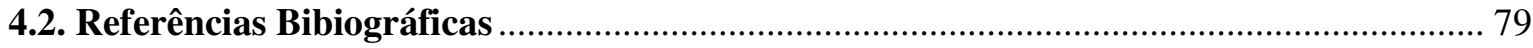




\section{INTRODUÇÃO E MATERIAIS E MÉTODOS GERAIS}




\section{Introdução}

Ambientes lóticos, como riachos e rios, são hábitats muito diferentes de outros corpos d'água, pois estão sujeitos a mudanças ao longo de seu percurso, associadas com as propriedades físicas e químicas do ambiente (p.ex., profundidade, vazão, geologia, turbidez), o que dificulta o estabelecimento e aplicação de metodologias específicas (ROUND, 1965). Riachos de pequeno porte geralmente apresentam uma grande diversidade de micro-hábitats, decorrentes dos componentes espaciais (espaço disponível) e estruturais (forma) do substrato (HACKER \& STENECK, 1990), e estes são utilizados por diferentes comunidades biológicas (STOCK \& WARD, 1991). Assim, a permanência em rios e riachos depende das adaptações de cada organismo, permitindo-lhes o estabelecimento e manutenção de populações relativamente estáveis (GILLER \& MALMKVIST, 1998).

Um componente importante destes hábitats são as algas bentônicas, que vivem em fundo de riachos e estão associadas a diferentes tipos de substrato (STEVENSON, 1996). Grande parte da flora de algas bentônicas é constituída por espécies que apresentam um evidente crescimento macroscópico (JOHN \& MOORE, 1985; SHEATH et al., 1986), as quais têm sido referenciadas em muitos trabalhos como macroalgas lóticas. Como exemplo, pode-se citar trabalhos realizados em diferentes partes do mundo (PFISTER, 1993 e LEUKART, 1995, na Europa; ENTWISLE, 1989 e 1990, na Austrália; SHEATH et al., 1986, 1989, SHEATH \& COLE, 1992, SHEATH \& MÜLLER, 1997, SHERWOOD \& SHEATH, 1999 e VERB \& VIS, 2001, na América do Norte; HU \& XIE, 2006, na China), inclusive no Brasil (BRANCO et al., 1999, NECCHI et al., 2000, 2003, KRUPEK et al., 2007, NECCHI et al., 2008 e PERES et al., 2008).

Em ambientes continentais como um todo, os estudos relacionados a algas ainda se concentram em organismos planctônicos (BICUDO et al., 1996). Para ambientes lóticos, nota-se que essa situação vem mudando nas duas últimas décadas com o crescente número de estudos realizados com algas bentônicas, inclusive no Brasil. Grande parte destes trabalhos envolvem a região noroeste do estado de São Paulo, sendo estes estudos eminentemente taxonômicos (composição florística) ou ecológicos (particularmente distribuição e sazonalidade) (NECCHI et al., 1991; NECCHI, 1993; NECCHI et al., 1994b, 1995, 1997; BRANCO \& NECCHI, 1998; NECCHI et al., 2000).

A região noroeste de São Paulo é considerada a mais desmatada e fragmentada do estado e com menor concentração de unidades de conservação, quadro que aparentemente não será revertido sem ações de manejo do meio ambiente (KRONKA et al., 1993). Por isso, é essencial a realização de estudos para o conhecimento dessas áreas, para que se reduza a perda de biodiversidade e possibilite o gerenciamento do uso sustentável dos remanescentes florestais. 
Apesar dos vários trabalhos com macroalgas que incluem a região noroeste do estado, este é o primeiro realizado em fragmentos florestais remanescentes da região, sendo este, portanto, o aspecto mais relevante deste estudo. Este trabalho integra o projeto temático "Fauna e flora de fragmentos florestais remanescentes do noroeste paulista: base para estudos de conservação da biodiversidade”, dentro do programa BIOTA/FAPESP, Instituto Virtual da Biodiversidade (PROC. 04/04820-3), mais especificamente como parte do subprojeto "Criptógamas - algas, briófitas, pteridófitas e fungos".

O objetivo geral deste trabalho foi, portanto, realizar o levantamento florístico das macroalgas lóticas de fragmentos florestais remanescentes da região noroeste do estado de São Paulo, assim como abordar aspectos referentes à distribuição ecológica destes organismos.

\section{Materiais e métodos}

O presente estudo foi realizado em fragmentos florestais remanescentes de floresta estacional semidecidual, localizados na região noroeste do estado de São Paulo (2000'13"$21^{\circ} 37^{\prime} 14^{\prime \prime S}, 48^{\circ} 32^{\prime} 26^{\prime \prime}-50^{\circ} 26^{\prime} 02^{\prime \prime} \mathrm{O}$ ), sudeste do Brasil (figura 1). Os limites da região noroeste do estado de São Paulo, conforme definida no projeto temático, incluem integralmente as Unidades de Gerenciamento dos Recursos Hídricos (UGRHIs) do TurvoGrande e São José dos Dourados e partes das UGHRIs do Baixo Pardo, Baixo Tietê e TietêBatalha (figura 2). Esta área compreende as regiões administrativas de São José do Rio Preto, Araçatuba, e parte das regiões administrativas de Bauru (porção norte) e Ribeirão Preto (porção oeste).

O esquema amostral geral do projeto foi constituído por nove fragmentos grandes (designados de G1 a G9, com áreas maiores que 200 ha) e nove pequenos (designados de P1 a P9, com áreas entre 50 e 150 ha) (figura 1). Estes foram divididos em dois blocos de nove fragmentos (que continham tanto fragmentos grandes quanto pequenos), para serem amostrados durante um ano cada (um em 2007 e outro em 2008). Dos 18 fragmentos selecionados, 12 foram efetivamente amostrados, tendo em vista que em um deles (P3) o riacho estava seco e cinco outros (P5, P8, G2, G4 e G7) não continham riachos amostráveis (ambientes lênticos, pantanosos ou muito pequenos). Por outro lado, os fragmentos P7, G1, G5, G8 e G9 continham dois riachos amostráveis cada (designados R1 e R2), totalizando 17 riachos amostrados em 12 fragmentos. Dos riachos amostrados, dez se situaram em fragmentos denominados grandes (maior que 200 ha) e sete em fragmentos pequenos (entre 50 e 150 ha). Informações sobre os fragmentos foram obtidos a partir de dados gerados no projeto temático (tabela 1 ). 
As amostragens foram realizadas no intervalo de junho a agosto de 2007 e 2008, dentro do período típico de maior abundância e riqueza de espécies de macroalgas em ambientes lóticos da região (estação seca) (NECCHI \& PASCOALOTO, 1993; BRANCO \& NECCHI, 1997), através da técnica de quadrado associada à de transeção de linha (NECCHI, 2004). Foi delimitado um trecho de 10 metros de extensão, subdividido em intervalos iguais de um metro, com o auxílio de uma corda estendida ao longo de uma das margens. Duas unidades amostrais foram distribuídas de forma eqüidistante em relação à largura sobre o leito do rio, a cada intervalo de um metro de comprimento, totalizando 20 unidades no trecho todo (figura 3). A ocorrência de macroalgas em cada unidade amostral foi observada com o auxílio de um visor subaquático com o fundo de vidro ("view box") (NECCHI, 1993). Foi adotado o conceito de macroalga proposto por Sheath \& Cole (1992).

Foram medidas as seguintes variáveis ambientais em cada ponto, conforme procedimentos gerais descritos por Necchi et al. (2000): latitude e longitude; temperatura da água, turbidez, condutividade, $\mathrm{pH}$ e oxigênio dissolvido; profundidade e velocidade da correnteza. Todas as variáveis foram medidas em campo, com o auxílio dos seguintes aparelhos (NECCHI et al., 2000): latitude e longitude - GPS Garmin eTrex "Legend"; profundidade - régua; velocidade da correnteza - fluxômetro mecânico General Oceanics 2030R; temperatura, turbidez, condutividade, pH e oxigênio dissolvido - controlador de qualidade de água Horiba U-10.

O substrato foi estimado em termos percentuais por análise visual do leito do riacho e denominado de acordo com as classes de tamanho de partículas (GORDON et al, 1992). Os dados de sombreamento foram definidos através da classificação em uma de quatro classes de sombreamento: aberto, parcialmente sombreado, sombreado e fortemente sombreado (modificado de DeNICOLA et al., 1992). Para tal classificação foi feita uma estimativa visual, sendo considerados: abertos os riachos que apresentaram ausência de floresta nas margens; parcialmente sombreados àqueles com floresta apenas nas margens, estas não cobrindo o trecho por inteiro; sombreados àqueles com a floresta cobrindo o trecho por inteiro, mas com apenas um extrato arbóreo; e fortemente sombreados os riachos que apresentaram mais de um extrato arbóreo cobrindo o trecho por completo. Foi preferível a estimativa visual em relação às medidas absolutas (p.ex. irradiância medida por quantômetro) pelo fato de não ter sido possível realizar as medições sempre no horário recomendado para esta variável (10:0014:00) (NECCHI, 2004) nos diferentes riachos. 


\section{Referências Bibliográficas}

BICUDO, C. E. M.; BICUDO, D. C.; GIANI, A. Towards assessing biodiversity in freshwater algae. In: BICUDO, C.E.M. \& MENEZES N. A. (eds.). Biodiversity in Brazil, São Paulo: Conselho Nacional de Desenvolvimento Científico e Tecnológico.. p. 4-16, 1996.

BRANCO, L. H. Z.; NECCHI, O. Jr. Seasonality of macroalgae in three tropical drainage basins in São Paulo State, southeastern Brazil. Archiv für Hydrobiologie. v. 141, p. 75-91, 1997.

BRANCO, L. H. Z.; NECCHI, O. Jr. Distribution of stream macroalgae in three tropical drainage basins of southeastern Brazil. Archiv für Hydrobiologie, v. 142, p. 241-256, 1998.

DeNICOLA, D. M.; HOGLAND, K. D.; ROEMER, S. C. Influence of canopy cover on spectral irradiance and periphyton assemblages in a prairie stream. Journal of the North American Benthological Society, v. 11, p. 391-404, 1992.

ENTWISLE, T. J. Macroalgae in Yarra River basin: flora and distribution. Proceedings of the Royal Society of Victoria, v. 101, p. 1-76, 1989.

ENTWISLE, T. J. Macroalgae in the upper Yarra and Watts River catchments: Distribution and Phenology. Australian Journal of Marine and Freshwater Research, v. 41, p. 505$522,1990$.

GILLER, P. S.; MALMQVIST, B. The Biology of Streams and Rivers: Biology of Habitat. Oxford: Oxford University Press, 1998. 296 p.

GORDON, N. D.; McMAHON, T. A.; FINLAYSON, B. L. Stream hydrology: an introduction for ecologists. Chichester: John Wiley \& Sons, 1992. 526 p.

HACKER, S. D.; STENECK, R. S. Habitat architecture and the abundance and body-size dependent habitat selection of a phytal amphipod. Ecology, v. 71, p. 2269-2285, 1990.

HU, B. F.; XIE, S. L. Effect of seasonality on distribution of macroalgae in a streamsystem (Xin `an Spring) in Shanxi Province, North China. Journal of Integrative Plant Biology, v. 48, p.889- 896, 2006

JOHN, D. M.; MOORE, J. A. Observation on phytobenthos of freshwater Thames I. The environment, floristic composition and distribution of macrophytes (principally macroalgae). Archiv für Hydrobiologie, v. 102, p. 435-459, 1985.

KRONKA, F. J. N.; MATSUKUMA, C. K.; NALON, M. A.; CALI, I. H.; ROSSI, M.; MATTOS, I. F. A.; SHIN-IKE, M. S.; PONTINHAS, A. A. S. Inventário Florestal do Estado de São Paulo. São Paulo: Instituto Florestal de São Paulo, 1993. 199 p.

KRUPEK, R. A.; BRANCO, C. C. Z.; PERES, C. K. Distribuição ecológica das comunidades de macroalgas da bacia de drenagem do rio das Pedras, região centro-sul do estado do Paraná, Sul do Brasil. Revista Brasileira de Botânica, v. 30, p. 173-182, 2007.

LAURENCE, W.F.; YENSEN, E. Predicting the impacts of edge efects in fragmented habitats. Biological Conservation, v. 55, p. 45-67, 1991. 
LEUKART, P. Studies on the macroalgal vegetation of a small soft-water stream in the Spessart mountains, Germany, with reference to algal distribution and seasonality. Algological Studies, v. 79. p. 77-92, 1995.

NECCHI, O. Jr. Distribution and seasonal dynamics of Rhodophyta in the Preto River basin, southeastern Brazil. Hydrobiologia, v. 250, p. 81-90, 1993.

NECCHI, O. Jr. Amostragem de algas bentônicas. In: BICUDO, C.E.M. \& BICUDO, D. C. (eds). Amostragem em limnologia. São Carlos: Ed. Rima, p. 167-177, 2004.

NECCHI, O. Jr.; BRANCO, C. C. Z.; BRANCO, L. H. Z. Distribution of stream macroalgae in São Paulo State, Southeastern Brazil. Archiv für Hydrobiologie: Algological Studies, v. 97, p. 43-57, 2000.

NECCHI, O. Jr.; BRANCO, C. C. Z.; SIMÃO, R. C. G.; BRANCO, L. H. Z. Distribution of stream macroalgae in the northwest region of São Paulo State, southeastern Brazil. Hydrobiologia, v. 299, p. 219-230, 1995.

NECCHI, O. Jr., BRANCO, L. H. Z., BRANCO, C. C. Z. Ecological distribution of stream macroalgal communities from a drainage basin in the Serra da Canastra National Park, Minas Gerais, southeastern Brazil. Brazilian Journal of Biology, v. 63, p.635-646, 2003.

NECCHI, O. Jr.; BRANCO, L. H. Z.; PASCOALOTO, D. Distribution of macroalgae in a tropical river basin from southeastern Brazil. Archiv für Hydrobiologie, v. 129, p. 459-471, 1994.

NECCHI, O. Jr.; BRANCO, L. H. Z.; SPEZAMIGLIO, D. N. Ecological distribution of stream macroalgal communities from "Parque Nacional de Itatiaia", states of Minas Gerais and Rio de Janeiro, Brazil. Revista Brasileira de Botânica, v. 31, p. 135-145, 2008.

NECCHI, O. Jr.; DIP, M. R.; GÓES, R. M. Macroalgae of a stream in southeastern Brazil: composition, seasonal variation and relation to physical and chemical variables. Hydrobiologia, v. 213, p. 241-250, 1991.

NECCHI, O. Jr.; PASCOALOTO, D. Seasonal dynamics of macroalgal communities in the Preto River basin, São Paulo, southeastern Brazil. Archiv für Hydrobiologie, v. 129, p. 231252, 1993.

NECCHI O. Jr.; PASCOALOTO, D.; BRANCO, C. C. Z.; BRANCO, L. H. Z. Stream macroalgal flora from the northwest region of São Paulo State, Southeastern Brazil. Algological Studies, v. 84, p. 91-112, 1997.

PERES, C. K.; BRANCO, C. C. Z.; KRUPEK, R. A. Macroalgas de riachos da Serra da Prata, leste do estado do Paraná, Sul do Brasil. Acta Botanica Brasilica, v. 22, p. 333-344, 2008.

PFISTER, P. Seasonality of macroalgal distribution pattern whitin the reach of a gravel stream (Isar, Tyrol, Austria). Archiv für Hydrobiologie, v. 129, p. 89-107, 1993.

ROUND, F. E. The biology of the algae. London: Edward Arnold, 1965. 269 p.

SHEATH, R. G.; COLE, K. M. Biogeography of stream macroalgae in North America. Journal of Phycology, v. 28, p.448-460, 1992. 
SHEATH, R. G.; HAMILTON, P. B.; HAMBROOK, J.; COLE, K. M. Stream macroalgae of the eastern boreal forest region of North America. Canadian Journal of Botany, v. 67, p. 3353-3362, 1989.

SHEATH, R. G.; MORINSON, M. O.; KORCH, J. E.; KACZMARCZYK, D.; COLE, K.M. Distribution of stream macroalgae in south-central Alaska. Hydrobiologia, v. 135, p. 259269, 1986.

SHEATH, R. G.; MÜLLER, K. M. Distribution of stream macroalgae in four high arctic drainage basins. Arctic, v. 50, p. 355-364, 1997.

SHERWOOD, A. R.; SHEATH, R. G. Seasonality of macroalgae and epilithic diatoms in spring-fed streams in Texas, U.S.A. Hydrobiologia, v. 390, p.73-82, 1999.

STEVENSON, R. J. An introduction to algal ecology in freshwater benthic habitats. In: STEVENSON R. J., BOTHWELL, M. L. \& LOWE, L. (eds). Algal ecology: Freshwater benthic ecosystems. New York: Academic Press, p. 3-30, 1996.

STOCK, M. S.; WARD, A. K. Blue-green algal mats in a small stream. Journal of Phycology, v. 27, p. 692- 698, 1991.

STRAHLER, A. N. Quantitative analysis of watershed geomorphology. American Geophysical Union Transation, v.38, p. 913-920, 1957.

VERB, R. G.; VIS, M. L. Macroalgal communities from a acid mine drainage impacted watershed. Aquatic Botany, v. 71, p. 93-107, 2001. 


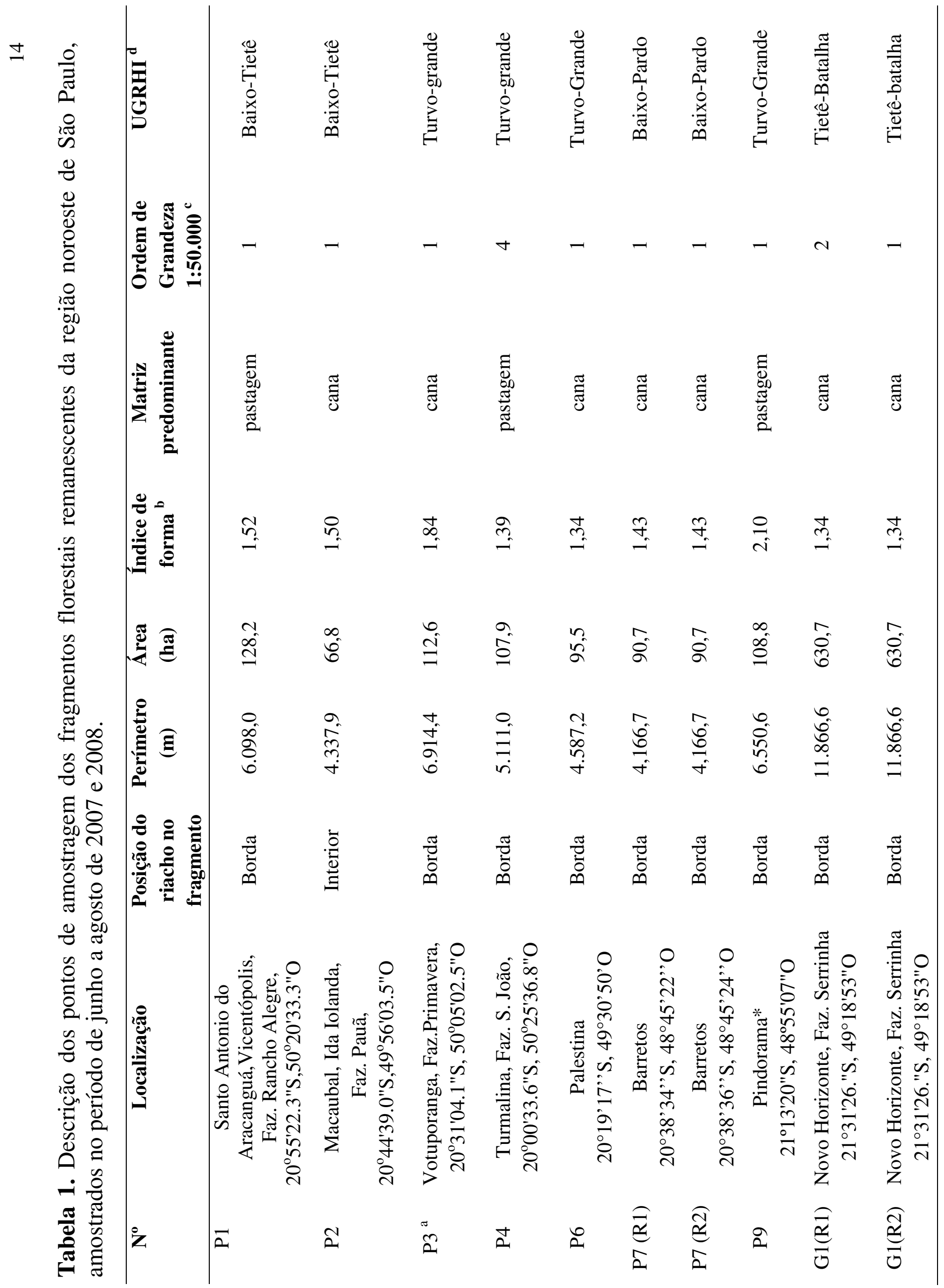




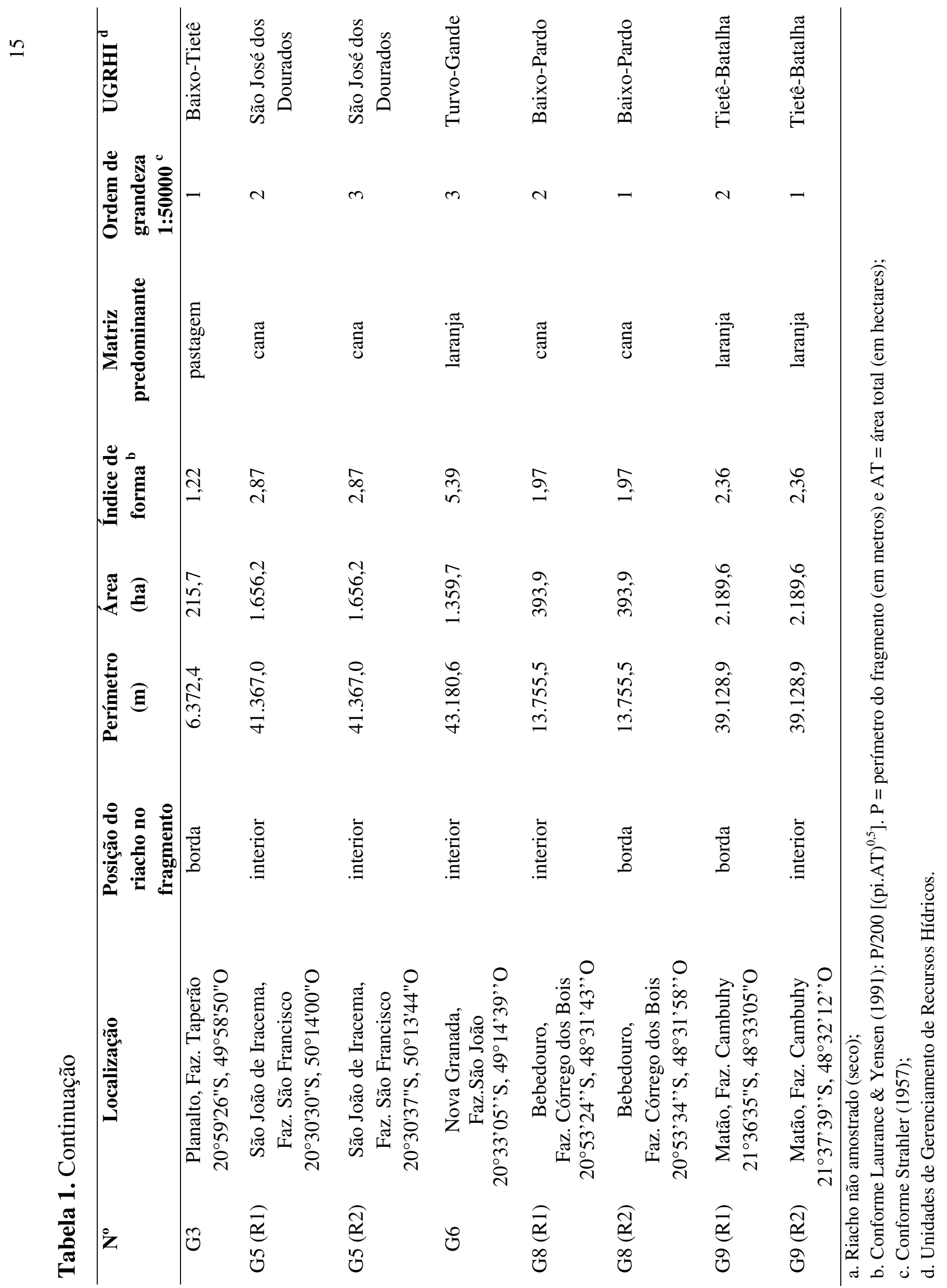




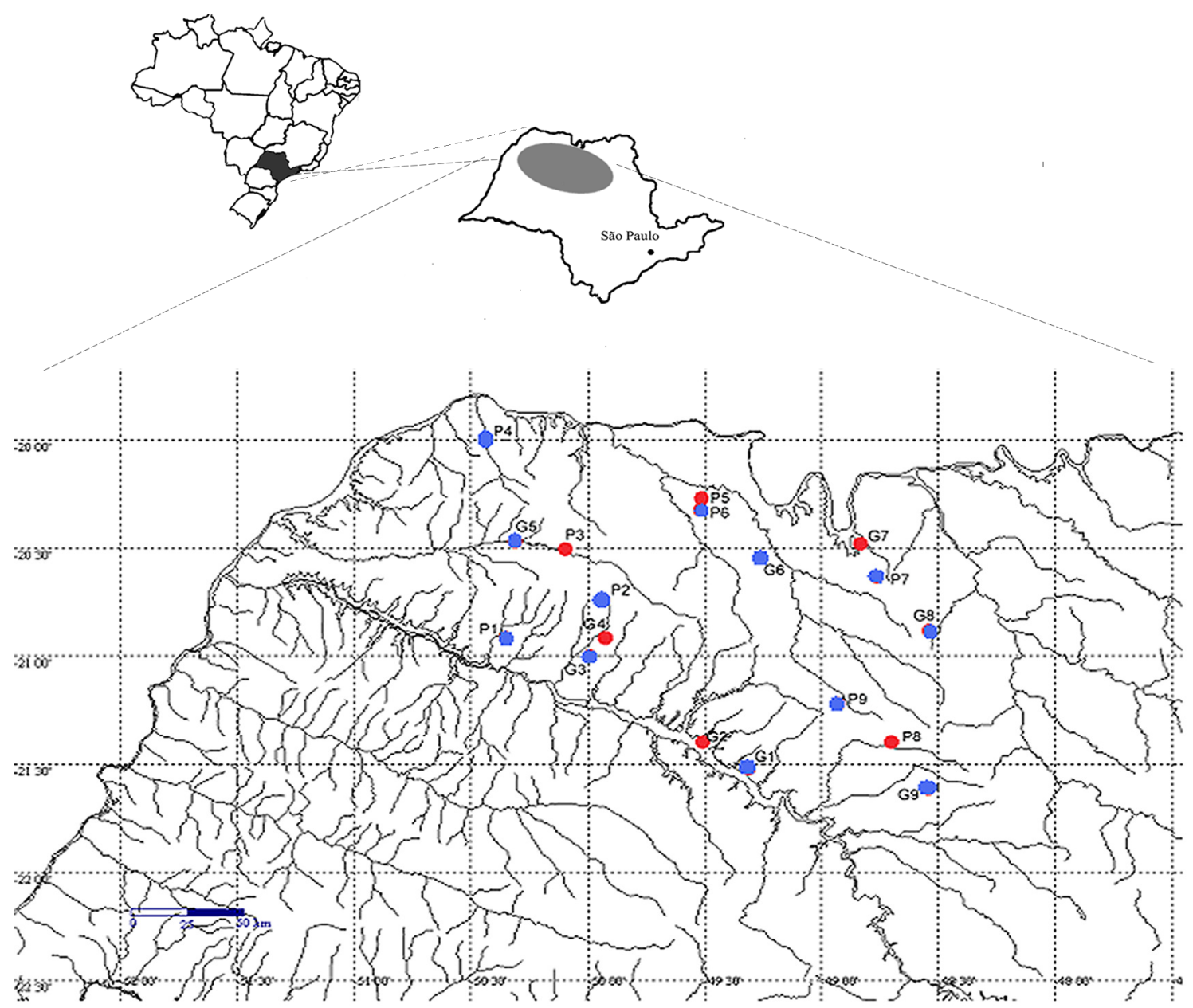

Fragmentos amostrados

Fragmentos não amostrados (ambientes secos, lênticos ou pantanosos)

Figura 1. Região noroeste do estado de São Paulo (em destaque) e a localização dos 18 fragmentos selecionados para estudo.

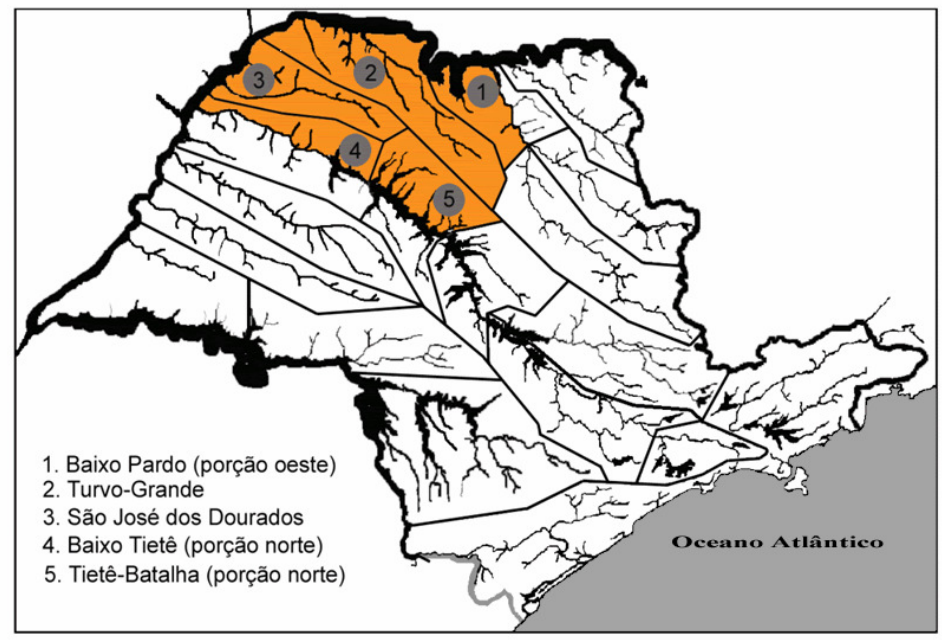

Figura 2. Região noroeste do estado de São Paulo conforme definida no projeto temático (em laranja), destacando as Unidades de Gerenciamento de Recursos Hídricos nas quais os fragmentos selecionados estão inseridos. 


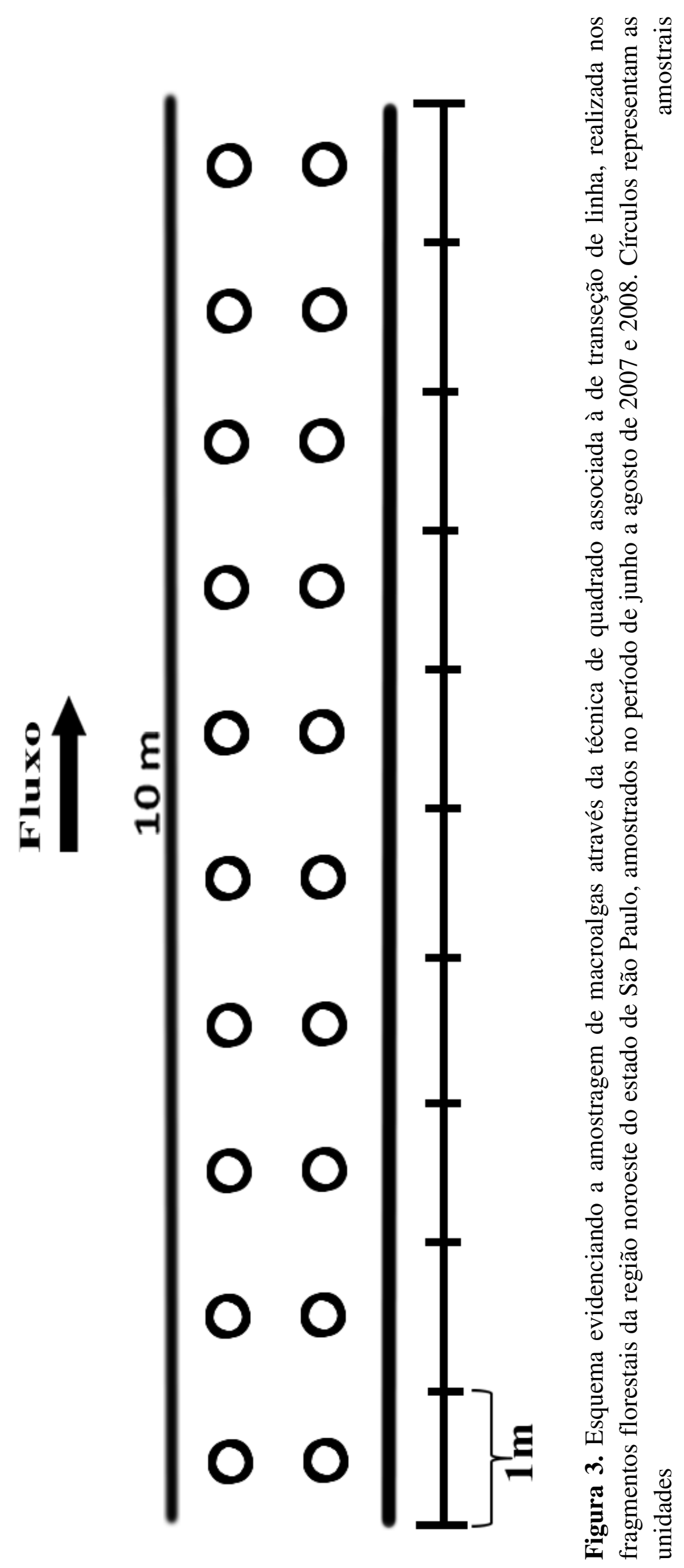


Capítulo 1

\section{FLORA DE COMUNIDADES DE MACROALGAS LÓTICAS DE FRAGMENTOS FLORESTAIS NA REGIÃO NOROESTE DO ESTADO DE SÃO PAULO}




\section{RESUMO}

Este trabalho representa a primeira abordagem realizada considerando a flora de macroalgas lóticas em fragmentos florestais remanescentes da região noroeste de São Paulo, sendo este o aspecto mais relevante do estudo. $\mathrm{O}$ objetivo deste trabalho foi realizar o levantamento florístico das comunidades de macroalgas lóticas de fragmentos florestais remanescentes de Floresta Estacional Semidecidual da região noroeste do estado de São Paulo. Entre as regiões/biomas amostrados no estado de São Paulo, presume-se que a região estudada apresente maior similaridade florística com Floresta Tropical, que se encontra mais próxima da região amostrada, além de ser composta também por Floresta Estacional Semidecidual. Foram identificadas 16 espécies de macroalgas, pertencentes a 14 gêneros. Cyanophyta e Chlorophyta foram os grupos mais representativos (44 e 37,5\%, respectivamente), seguidos por Rhodophyta (12,5\%) e Heterokontophyta (6\%). O número global de espécies foi baixo em comparação com estudos semelhantes feitos em outras regiões, provavelmente devido à predominância de substrato areno-argiloso (65\%) e de trechos sombreados (53\%). A maioria das espécies $(69 \%)$ foi encontrada exclusivamente em um único ponto de amostragem, padrão frequentemente observado para macroalgas lóticas. Phormidium retzii foi a espécie mais frequente, ocorrendo em seis pontos de amostragem. Esta espécie tem sido reportada como amplamente distribuída em vários estudos realizados no Brasil e em outras regiões do mundo. Trichocoleus sociatus (Cyanophyta) e Vaucheria pseudogeminata (Heterokontophyta), foram reportadas pela primeira vez na região, sendo que a última representa o primeiro registro de ocorrência no Brasil. A proporção dos tipos morfológicos foi: filamentos livres (46\%), emaranhados de filamentos (40\%), filamentos gelatinosos e tufos ( $7 \%$ cada). Estes dados foram bastante distintos daquelas reportados na maioria dos estudos anteriores, notadamente a frequiência bem maior neste estudo de filamentos livres ( $8 \%-15 \%$ nos anteriores), e menor de filamentos gelatinosos (11\%-13\%), além da ausência de incrustantes e colônias gelatinosas (1\%-2\% e 12\%-23\%, respectivamente). Comparando os resultados obtidos com aqueles reportados para diferentes regiões/biomas do estado de São Paulo, a flora de macroalgas de fragmentos florestais remanescentes da região noroeste assemelhou-se mais àquela de Floresta Tropical, com nove espécies em comum (56\%), o que confirmou a hipótese inicial. 


\subsection{Introdução}

Macroalgas lóticas são geralmente representadas por quatro filos: Cyanophyta, Chlorophyta, Rhodophyta e Heterokontophyta (particularmente as classes Bacillariophyceae e Xantophyceae) (VAN DEN HOEK et al., 1995). Todos estes organismos possuem talos com uma ampla variedade morfológica, sendo as mais relevantes: emaranhados de filamentos, colônias gelatinosas, filamentos gelatinosos, filamentos livres, tufos, crostas e pseudoparênquimas (SHEATH \& COLE, 1992).

Vários trabalhos relevantes envolvendo aspectos taxonômicos de comunidades de macroalgas de ecossistemas lóticos podem ser relacionados para diferentes regiões do mundo, entre elas: América do Norte (SHEATH \& BURKHOLDER, 1985; SHEATH et al., 1986; SHEATH \& COLE, 1992; SHEATH \& MÜLLER, 1997), Europa (KAWECKA, 1981; JOHANSSON, 1982; WHITTON, 1984; JOHN \& MOORE, 1985; WHITTON et al., 1991) e Australásia (BIGGS \& PRICE, 1987; ENTWIISLE, 1989, 1990). Estudos semelhantes vem sendo desenvolvidos, especialmente nas duas últimas décadas, em diferentes regiões do Brasil (BRANCO \& NECCHI, 1996; NECCHI et al., 2003; KRUPEK et al., 2007; NECCHI et al., 2008; PERES et al., 2008; BRANCO et al., 2009), sendo que muitos destes abrangem a região noroeste de São Paulo (NECCHI et al., 1991; NECCHI, 1993; NECCHI et al., 1994b, 1995, 1997; BRANCO \& NECCHI, 1998). Vários estudos abordam ainda aspectos eminentemente taxonômicos de macroalgas lóticas. Entre estes constam trabalhos realizados no Brasil, especialmente nos estados do Paraná (BRANCO et al., 2008, 2009; KRUPEK et al., 2008; PERES et al., 2008), e no estado de São Paulo (BRANCO \& NECCHI, 1996, na Mata Atlântica e NECCHI et al, 1997, na região noroeste). Muitos outros trabalhos taxonômicos envolvendo grupos específicos de macroalgas também foram feitos envolvendo a região noroeste do estado, entre eles: Necchi (1989, Rhodophyta) e Branco et al. (1999, Cyanophyta); Vieira et al. (2002, 2003, Characeae - Chlorophyta); Necchi et al. (2001 e 2002, gêneros Vaucheria Heterokonthophyta e Microspora - Chlorophyta, respectivamente).

Os remanescentes florestais da região noroeste são constituídos especialmente por Floresta Estacional Semidecidual, um tipo de floresta tropical seca, caracterizada pela ausência de coníferas e pela perda parcial das folhas, em decorrência da baixa precipitação pluviométrica no inverno (RAMBALDI \& OLIVEIRA, 2003). Além disso, ela é importante pela singularidade de espécies, pelo nível de destruição e pela importância econômica (RAMBALDI \& OLIVEIRA, 2003). De acordo com o Ministério do Meio Ambiente, grande parte das áreas consideradas como "de provável importância biológica, 
mas insuficientemente conhecida" é composta por remanescentes de Floresta Semidecidual (MAURY, 2002).

Embora muitos trabalhos envolvam comunidades de macroalgas da região noroeste, ainda não foi realizada qualquer abordagem sobre aspectos florísticos de macroalgas lóticas em fragmentos florestais remanescentes, aspecto mais relevante do estudo. Sendo assim, este trabalho teve como objetivo realizar o levantamento florístico das comunidades de macroalgas lóticas de fragmentos florestais remanescentes da região noroeste do estado de São Paulo.

Entre as regiões/biomas ocorrentes no estado de São Paulo (de acordo com NECCHI et al., 2000), presume-se que a região estudada apresente maior similaridade florística com Floresta Tropical, que é o ambiente mais próximo da região amostrada, além de ser composto também por Floresta Estacional Semidecidual.

\subsection{Materiais e Métodos}

A área de estudo e os procedimentos de amostragem das macroalgas, assim como os procedimentos tomados para medição das variáveis ambientais, substrato e sombreamento referentes ao presente trabalho, foram previamente detalhados nos materiais e métodos gerais do presente estudo.

Após coletadas as amostras em cada ponto de amostragem, os espécimes foram identificados em laboratório até o nível espécie, sempre que possível. Para todos os táxons foram feitas ilustrações (fotomicrografias), através de câmera de vídeo digital Leica DFC 320 e software de captura e análise de imagem (Leica IM50), acoplado ao microscópio Leica DM 5.000. Foram apresentadas, ainda, descrição e, quando necessário, considerações taxonômicas.

A preservação dos espécimes foi feita em solução de formaldeído 4\% (NECCHI, 2004). Os procedimentos para análise e identificação foram aqueles descritos nos trabalhos taxonômicos de macroalgas lóticas citados anteriormente. Conjuntos representativos de espécimes-testemunho foram incorporados no Herbário SJRP (HOLMGREN \& HOLMGREN, 1993).

\subsection{Resultados}

Descrição das espécies 


\section{Chlorophyta}

Microspora floccosa (Vaucher) Thuret.

Figs. 1-2

Ann. Sci. Nat., ser. Bot., 3(14): 221, 1850.

Basiônimo: Prolifera floccosa Vaucher, Histoire des conferves d'eau douce. pp. XV, 131132, pl. XIV: fig. 3, 1803.

Emaranhado de filamentos, verde-amarelados, filamentos levemente constritos, 10,5-13,0 $\mu \mathrm{m}$ diâm.; células cilíndricas ou doliformes, (9,5-)11,0-17,5 $\mu \mathrm{m}$ compr., 9,0-11,0 $\mu \mathrm{m}$ diâm., C/D 0,8-2,3; estruturas em H claramente visíveis; cloroplastos laminares, cobrindo a maior parte da célula.

Comentários: A relação C/D foi pouco maior do que a observada em trabalhos realizados no estado de São Paulo (NECCHI et al., 1997 e NECCHI et al., 2002, C/D=0,8-1,5). Entretanto, em estudo realizado na Mata Atlântica (BRANCO \& NECCHI, 1996) os indivíduos apresentaram células pouco mais longas, com 15,0-20,0 (22,5) $\mu \mathrm{m}$ compr., o que mostra que essa pequena variação no comprimento das células está dentro dos limites de variação e permite a identificação das populações como M. floccosa.

Condições ambientais: ( $\mathrm{n}=2$; P1 e P7-R2): Temperatura 22,1-22,5 ${ }^{\circ} \mathrm{C}(\mathrm{X}=22,3 \pm 0,2)$; Condutividade 6,0-10,0 $\mu{\mathrm{S} . \mathrm{cm}^{-1}}(\mathrm{X}=7,3 \pm 2,3)$; Turbidez 5,0-15,0 UNT (X=11,3 $\left.\pm 5,5\right)$; Velocidade da correnteza 1,6-70,2 cm.s ${ }^{-1}(X=32,1 \pm 17,6) ; \mathrm{pH}$ 6,7-6,9 (X=6,8 \pm 0,1); Oxigênio dissolvido 3,2-3,9 mg. $\mathrm{L}^{-1}(X=3,6 \pm 0,4)$; Profundidade 5,0-25,0 cm (X=11,3 \pm $4,7)$.

Microspora quadrata Hazen

Figs. 3-4

Mem. Torrey Bot. Cl. 11: 178, 1887.

Emaranhado de filamentos, verde-amarelados, filamentos levemente constritos, 7,5-9,5 $\mu \mathrm{m}$ diâm; células quadráticas, cilíndricas, ou levemente doliformes, 8,5-12,0 $\mu \mathrm{m}$ compr., 6,58,0 $\mu \mathrm{m}$ diâm., C/D 0,8-1,5; estruturas em H claramente visíveis; cloroplastos laminares, cobrindo a maior parte da célula.

Comentários: Estudo realizado no estado do Paraná (KRUPEK et al., 2007), registrou indivíduos com proporções semelhantes às do presente trabalho (células com 9,0-15,5 $\mu \mathrm{m}$ compr., 7,5- 9,0 $\mu \mathrm{m}$ diâm.), mas sem constrição nos septos. Entretanto, Necchi et al. (2002) encontraram indivíduos com e sem constrição nos septos, o que possibilita a identificação dos espécimes. 
Condições ambientais: $(n=1 ; \quad P 1)$ : Temperatura $22,1-22,5^{\circ} \mathrm{C} \quad(X=22,3 \quad \pm \quad 0,2)$; Condutividade 6,0-10,0 $\mu{\mathrm{S} . \mathrm{cm}^{-1}}(\mathrm{X}=7,3 \pm 2,3)$; Turbidez 5,0-15,0 UNT $(\mathrm{X}=11,3 \pm 5,5)$; Velocidade da correnteza 1,6-70,2 cm.s ${ }^{-1}(X=32,1 \pm 17,6)$; pH 6,7-6,9 (X=6,8 \pm 0,1); Oxigênio dissolvido 3,2-3,9 mg. $\mathrm{L}^{-1}(\mathrm{X}=3,6 \pm 0,4)$; Profundidade 8,0-25,0 $\mathrm{cm}(\mathrm{X}=11,3 \pm$ $4,7)$.

Nitella rosa-maria e Picelli-Vicentim

Figs. 5-7

Flora ficológica do estado de São Paulo - Charophyceae, 5: 64-65, 2004.

Plantas monóicas, ecorticadas, desprovidas de incrustação calcária; verticilos estéreis bem desenvolvidos; verticilos férteis reduzidos, formando capítulos desprovidos de muco; capítulos pedunculados; râmulos verticilados 3-4 furcados; dáctilos 3-5, 2-3 celulados; gametângios pedunculados, presentes na primeira furcação dos râmulos conjuntos ou sejuntos; núculas 1-2 por nó.

Comentários: Este táxon já foi registrado anteriormente para o estado de São Paulo, inclusive para a região noroeste (VIEIRA et al, 2002), embora não definido em nível específico (Nitella sp.), e a descrição concorda perfeitamente com os indivíduos amostrados no presente trabalho.

Condições ambientais: ( $\mathrm{n}=1 ; \quad \mathrm{P} 1)$ : Temperatura $22,1-22,5^{\circ} \mathrm{C} \quad(\mathrm{X}=22,3 \quad \pm \quad 0,2)$;

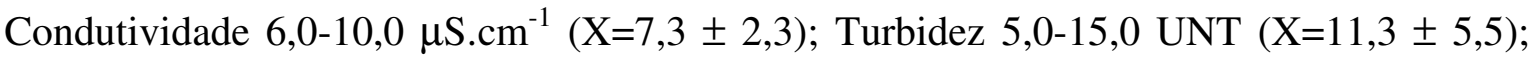
Velocidade da correnteza 1,6-70,2 cm.s ${ }^{-1}(X=32,1 \pm 17,6)$; pH 6,7-6,9 (X=6,8 \pm 0,1); Oxigênio dissolvido 3,2-3,9 mg. $\mathrm{L}^{-1}(\mathrm{X}=3,6 \pm 0,4)$; Profundidade 5,0-25,0 $\mathrm{cm}(\mathrm{X}=11,3 \pm$ $4,7)$.

Nitella subglomerata A. Braun

Figs. 8-10

Monatsberichte der Deutschen Akademie der Wissenchaft zu Berlin 1858: 356, 1859.

Plantas monóicas, ecorticadas, desprovidas de incrustação calcária; verticilos estéreis bem desenvolvidos, verticilos férteis reduzidos, formando capítulos frouxos e desprovidos de muco; capítulos pedunculados; râmulos verticilados estéreis 7-9, 1-furcado; dáctilos 3-5, 1celulado, acuminados; gametângios sésseis, raramente pedunculados, presentes na primeira furcação dos râmulos, conjuntos ou sejuntos, dentro ou fora dos capítulos; núculas 1-2 por nó;

Condições ambientais: ( $\mathrm{n}=1 ; \quad \mathrm{P} 7-\mathrm{R} 2)$ : Temperatura $18,8-18,9^{\circ} \mathrm{C} \quad(\mathrm{X}=18,8 \quad \pm$ 0,1);Condutividade 26,0 $\mu$ S.cm-1 ( $X=26,0 \pm 0,0)$; Turbidez 23,0 UNT (X=23,0 $\pm 0,0)$; 
Velocidade da correnteza 9,1-22,5 cm.s-1 (X=15,7 \pm 6,7); pH 6,7-6,9 (X=6,8 \pm 0,1); Oxigênio dissolvido 5,6 mg.L-1 (X=5,6 \pm 0,0); Profundidade 6,0-33,0 cm (X=14,7 \pm $15,9)$;

Oedogonium sp.1

Células cilíndricas, 18,5-32,0 $\mu$ m compr., 5,6-8,0 $\mu$ m diâm., C/D 2,9-4,7.

Comentários: Foram encontrados apenas espécimes estéreis nos pontos de amostragem, o que impossibilita a identificação em nível específico. Dessa forma, os espécimes foram divididos em 3 "grupos vegetativos" para permitir referência futura a essas populações em estudos ecológicos e taxonômicos da região. Essa divisão foi baseada no diâmetro das células: Oedogonium sp.1 (5-8 $\mu \mathrm{m})$, Oedogonium sp.2 (11-16 $\mu \mathrm{m})$, e Oedogonium sp.3 (20-34 $\mu \mathrm{m})$. Estes grupos não têm valor taxonômico formal.

Condições ambientais: ( $n=1 ; G 3)$ : Temperatura 20,5-20,8 ${ }^{\circ} \mathrm{C} \quad(X=20,6 \quad \pm \quad 0,2)$; Condutividade 1,0-3,0 $\mu \mathrm{S} . \mathrm{cm}^{-1}(\mathrm{X}=2,0 \pm 1,0)$; Turbidez 14,0-15,0 UNT (X=14,3 \pm 0,6); Velocidade da correnteza 0,0-63,4 cm.s ${ }^{-1}(X=18,9 \pm 22,5)$; pH 6,1-6,2 (X=6,2 \pm 0,1); Oxigênio dissolvido 7,3-7,9 mg. $\mathrm{L}^{-1}(\mathrm{X}=7,7 \pm 0,3)$; Profundidade 2,0-18,0 $\mathrm{cm}(\mathrm{X}=10,2 \pm$ $4,7)$.

Oedogonium sp.2

Fig. 12

Células cilíndricas, 32,0-48,0 (-56,0) $\mu \mathrm{m}$ compr., 11,0-16,0 $\mu \mathrm{m}$ diâm., C/D 1,8-4,0, com grânulos citoplasmáticos bem evidentes.

Condições ambientais: ( $n=2$; P1 e P7-R2): Temperatura 22,1-22,5 ${ }^{\circ} \mathrm{C}(\mathrm{X}=22,3 \pm 0,2)$; Condutividade 6,0-10,0 $\mu \mathrm{S} . \mathrm{cm}^{-1}(\mathrm{X}=7,3 \pm 2,3)$; Turbidez 5,0-15,0 UNT (X=11,3 $\left.\pm 5,5\right)$; Velocidade da correnteza 1,6-70,2 cm.s ${ }^{-1}(X=30,0 \pm 17,4) ; \mathrm{pH}$ 6,7-6,9 (X=6,8 \pm 0,1); Oxigênio dissolvido 3,2-3,9 mg. $\mathrm{L}^{-1}(\mathrm{X}=4,8 \pm 0,1)$; Profundidade 5,0-33,0 $\mathrm{cm}(\mathrm{X}=11,8 \pm$ $6,6)$.

Oedogonium sp.3

Fig. 13

Células cilíndricas, 32,0-50,0 $\mu$ m compr., 20,0-32,0 (-34,0) $\mu$ m diâm., C/D (0,8-) 1,1-4,5 $(-4,8)$, levemente constritas nos septos.

Condições ambientais: ( $\mathrm{n}=2$; G8-R1 e P7-R2): Temperatura $16,3-18,9{ }^{\circ} \mathrm{C}(\mathrm{X}=18,0 \pm 1,5)$; Condutividade 26,0-30,0 $\mu \mathrm{S} . \mathrm{cm}^{-1}(\mathrm{X}=27,3 \pm 2,3)$; Turbidez 23,0-25,0 UNT (X=23,7 \pm 
1,2); Velocidade da correnteza 0,0-38,5 cm.s ${ }^{-1}(X=17,8-13,1)$; pH 7,4-7,5 (X=7,4 $\left.\pm 0,1\right)$; Oxigênio dissolvido 4,8-6,4 mg. $\mathrm{L}^{-1}(\mathrm{X}=5,3 \pm 0,5)$; Profundidade 9,1-38,5 $\mathrm{cm}(\mathrm{X}=23,9 \pm$ $10,6)$.

Spirogyra sp.1

Fig. 14

Filamentos emaranhados, células cilíndricas, 106,5-269,5 $\mu \mathrm{m}$ compr., (23,0-) 26,0-28,0 $\mu \mathrm{m}$ diâm., C/D 2,1-3,9.

Comentários: Da mesma forma que Oedogonium spp., foram encontrados apenas espécimes estéreis nos pontos de amostragem. Estes foram divididos em 2 "grupos vegetativos" para permitir referência futura a essas populações em estudos ecológicos e taxonômicos da região. Essa divisão foi baseada no diâmetro das células: Spirogyra sp.1 (20,0-30,0 $\mu \mathrm{m})$ e Spirogyra sp.2 (45,0-60,0 $\mu \mathrm{m})$.

Condições ambientais: ( $\mathrm{n}=1$; P7-R2): Temperatura 18,9-18,8 ${ }^{\circ} \mathrm{C}(\mathrm{X}=18,8 \pm 0,1)$;

Condutividade 26,0 $\mu \mathrm{S} . \mathrm{cm}^{-1}(X=26,0 \pm 0,0)$; Turbidez 23,0 UNT $(X=23,0 \pm 0,0)$; Velocidade da correnteza 9,1-22,5 cm.s ${ }^{-1}(X=15,7 \pm 6,7)$; pH 6,7-6,9 (X=6,8 $\left.\pm 0,1\right)$; Oxigênio dissolvido 5,6 mg. $\mathrm{L}^{-1}(X=5,6 \pm 0,0)$; Profundidade 6,0-33,0 (X=14,7 \pm 15,9);

Spirogyra sp.2

Fig. 15

Filamentos emaranhados, células cilíndricas, 106,5-269,5 $\mu \mathrm{m}$ compr., 46,0-57,5 $\mu \mathrm{m}$ diâm., C/D 1,9-4,9.

Condições ambientais: ( $n=1 ; \quad P 1)$ : Temperatura $22,1-22,5 \quad{ }^{\circ} \mathrm{C} \quad(X=22,3 \quad \pm \quad 0,2)$; Condutividade 6,0-10,0 $\mu{\mathrm{S} . \mathrm{cm}^{-1}}(\mathrm{X}=7,3 \pm 2,3)$; Turbidez 5,0-15,0 UNT $(\mathrm{X}=11,3 \pm 5,5)$; Velocidade da correnteza 11,6-70,2 cm.s ${ }^{-1}(X=30,0 \pm 17,4)$; pH 6,7-6,9 (X=6,8 $\left.\pm 0,1\right)$; Oxigênio dissolvido 3,2-3,9 mg. $\mathrm{L}^{-1}(\mathrm{X}=4,8 \pm 0,1)$; Profundidade 5,0-33,0 $\mathrm{cm}(\mathrm{X}=11,8 \pm$ $6,6)$.

\section{Cyanophyta}

Geitlerinema splendidum (Gomont) Anagnostidis Figs. 16-17

Pl. Syst. Evol. 164: 33-46, 1989.

Basiônimo: Oscillatoria splendida Greville ex Gomont, Annales des Sciences Naturelles, Sér. 7, 16: 224, 1892. 
Tricomas emaranhados, retos ou flexuosos, distintamente atenuados, não constritos, curvos no ápice; células 3,0-5,0(-7,0) $\mu \mathrm{m}$ compr., 1,6-2,5 $\mu \mathrm{m}$ diâm, C/D 1,2-3,2(-3,5); conteúdo celular verde-azulado, homogêneo, septos granulados, 1 ou 2 grânulos de cada lado; células apicais capitadas.

Comentários: Nos indivíduos coletados no fragmento P6 não foram observados os grânulos; entretanto todas as outras características são compatíveis com a descrição da espécie (BRANCO et al., 1999).

Condições ambientais: ( $\mathrm{n}=3$; P2, P6 e G3): Temperatura 20,5-25,1 ${ }^{\circ} \mathrm{C}(\mathrm{X}=22,3 \pm 2,3)$;

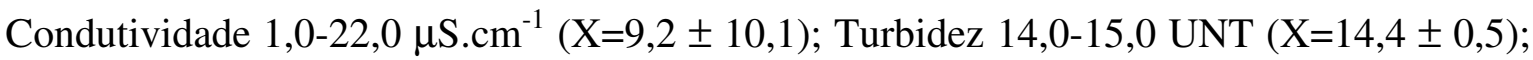
Velocidade da correnteza 0,0-63,4 cm.s ${ }^{-1}(X=13,8 \pm 17,0) ; \mathrm{pH}$ 6,1-7,2 (X=6,5 \pm 0,5); Oxigênio dissolvido 4,8-7,9 mg. $\mathrm{L}^{-1}(\mathrm{X}=6,5 \pm 1,6)$; Profundidade 2,0-25,0 $\mathrm{cm}(\mathrm{X}=9,6 \pm$ $5,9)$.

Jaaginema homogeneum (Frémy) Anagnostidis et Komárek Algolog. Stud. 50-53: 396, 1988.

Basiônimo: Oscillatoria homogenea Frémy, Arch. Bot. Mémoires 3(2): 1-508, 1930.

Filamentos levemente curvados, geralmente solitários, às vezes formando tufos, não atenuados nas extremidades; bainha na maioria das vezes ausente, raramente como mucilagem difusa e incolor ao redor dos tricomas; tricomas não constritos; células mais longas que largas, (4,0-)4,8-7,2 $\mu \mathrm{m}$ compr., 3,2-3,6(-4,0) $\mu \mathrm{m}$ diâm., C/D (1,2-)1,5-2,2; conteúdo celular verde-azulado, com grânulos protoplasmáticos; célula apical cilíndricoarredondada ou levemente cônico-arredondada, sem caliptra.

Comentários: Não foram observados grânulos nas paredes celulares, diferentemente do material descrito por Branco et al. (1999). Entretanto, Komárek \& Anagnostidis (2005) também descreveram a espécie sem grânulos, o que permite supor que esta não seja uma característica diagnóstica para a espécie. Anagnostidis \& Komárek (1988) levaram em conta que esta espécie não contém bainha ou qualquer mucilagem ao redor de seus tricomas. Tanto esse caráter quanto a disponibilidade de grânulos na espécie necessita ser revisado. A ausência de produção de hormogônios através de necrídeos é uma característica importante para distinguir esta espécie de P. willei (Gardner) Anagnostidis et Komárek (ANAGNOSTIDIS \& KOMÁREK, 1988). As células bastante longas também caracterizam o táxon melhor como sendo da família Pseudoanabaenaceae do que 
Phormidiaceae. Tendo em vista estas últimas características, mais as dimensões dos indivíduos, pôde-se indentificar o táxon como J. homogeneum.

Condições ambientais: $(n=1 ; \quad G 6)$ : Temperatura $17,6-17,7^{\circ} \mathrm{C} \quad(X=17,6 \pm 0,1)$; Condutividade 40,0-78,0 $\mu$ S.cm-1 (X=59,0 \pm 26,9); Turbidez 11,0 UNT (X=11,0 \pm 0,0); Velocidade de correnteza 2,0-85,8 cm.s ${ }^{-1}(X=57,8 \pm 19,5)$; pH 7,5-7,6 (X=7,5 \pm 0,0); Oxigênio dissolvido 5,2-5,8 mg. $\mathrm{L}^{-1}(X=5,5 \pm 0,4)$; Profundidade 8,0-208 (X=26,0 $\left.\pm 44,4\right)$;

Microcoleus subtorulosus Gomont

Fig. 19

Ann. Sci. Nat. Bot., Sér. 7, 15: 360,1892.

Basiônimo: Phormidium subtorulosum Brébisson 1845: (1845-49), 35.

Filamentos emaranhados, azul-acinzentado, não ramificado, 9,0-20,0 $\mu \mathrm{m}$ diâm.; bainha homogênea, levemente amarelada, não lamelada; 1-3 tricomas por filamento, constritos nos septos; células geralmente mais longas do que largas ou isodiamétricas, (4,0-)5,0-9,0

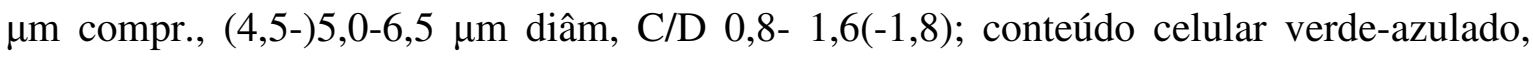
com grânulos protoplasmáticos; célula apical predominantemente cônico-arredondada ou cilíndrico-arredondada.

Comentários: As células do material examinado foram mais longas e estreitas se comparadas ao trabalho de Necchi et al., 1997 (3,1-6,3 $\mu \mathrm{m}$ compr., 6,5-8,2 $\mu \mathrm{m}$ diâm., C/D 0,4-1,0) e Branco et al., (1999, 4,5-8,2 $\mu \mathrm{m}$ compr., 6,2-8,0 $\mu \mathrm{m}$ diâm., C/D 0,4-1,1), realizados com material da região noroeste, e San't Anna \& Azevedo (1995) (3,1-6,3 $\mu \mathrm{m}$ compr, 6,5-8,2 $\mu \mathrm{m}$ diâm., C/D 0,4-1,0), com o material do estado de São Paulo. As menores dimensões no diâmetro das células, e principalmente do filamento $(15,0-115,0 \mu \mathrm{m}$ para os trabalhos citados), ocorreram também com Trichocoleus sociatus, que foi coletado no mesmo riacho. Isto sugere possível interferência do hábitat em sua morfologia.

Condições ambientais: ( $\mathrm{n}=1$; G5-R1): Temperatura 14,3-14,6 ${ }^{\circ} \mathrm{C}(\mathrm{X}=14,5 \pm 0,2)$; Condutividade 37,0-41,0 $\mu$ S.cm-1 (X=39,3 $\pm 2,1)$; Turbidez 2,0 UNT (X=2,0 \pm 0,0); Velocidade da correnteza 1,6-120,6 cm.s ${ }^{-1}(X=30,4 \pm 29,4) ; \mathrm{pH} 6,54-7,44(X=7,1 \pm 0,5)$; Oxigênio dissolvido 5,9-6,6 mg. $\mathrm{L}^{-1}(\mathrm{X}=6,2 \pm 0,4)$; Profundidade 7,0-27,0 $\mathrm{cm}(X=15,2-$ $5,5)$ 
Tricomas solitários, retos, não atenuados ou levemente atenuados no ápice, levemente constritos; células mais curtas do que largas, 2,0-4,0 $\mu \mathrm{m}$ compr., 11,0-12,0 $\mu \mathrm{m}$ diâm., C/D 0,2-0,3; conteúdo celular verde-azulado, com grânulos protoplasmáticos; célula apical cilíndrico-arredondada.

Comentários: Diferentemente de Sant'Anna (1988), que descreveu indivíduos não constritos e com granulações na parede, Komárek \& Anagnostidis (2005) reportaram indivíduos com e sem constrição nos septos e sem grânulos na parede, o que corrobora a descrição da população no presente estudo.

Condições ambientais: ( $\mathrm{n}=1$; P6): Temperatura 22,3-22, $6^{\circ} \mathrm{C} \quad(\mathrm{X}=22,4 \quad \pm \quad 0,2)$; Condutividade 6,0-8,0 $\mu{\mathrm{S} . \mathrm{cm}^{-1}}^{-}(\mathrm{X}=7,0 \pm 1,4)$; Turbidez 2,0 UNT $(\mathrm{X}=2,0 \pm 0,0)$; Velocidade da correnteza 0,0-1,7 cm.s ${ }^{-1}(X=0,2 \pm 0,6) ; \mathrm{pH}$ 6,6-7,4 (X=7,0 \pm 0,5); Oxigênio dissolvido 4,4-4,7 mg. $\mathrm{L}^{-1}(\mathrm{X}=4,6 \pm 0,2)$; Profundidade 4,0-25,0 $\mathrm{cm}(X=13,0 \pm$ $7,5)$.

Phormidium retzii (C. Agardh) Gomont

Fig. 21

Ann. Sci. Nat. Bot., Sér. 7, 16: 175, 1892.

Basiônimo: Oscillatoria retzii Agardh, Dispositio Algarum Sueciae, p.36, 1812. Filamentos em feixes emaranhados, prostrados, 6,0-9,0 $\mu \mathrm{m}$ diâm.; bainha delgada, hialina, não lamelada; tricomas não constritos; células 4,0-9,0 (-11,0) $\mu \mathrm{m}$ comp., (4,0-) 5,0-8,0 $\mu \mathrm{m}$ diâm, C/D 0,6-2,0; conteúdo celular verde-azulado, com grânulos protoplasmáticos; célula apical cilíndrica ou cônico arredondada; hormogônios e necrídeos presentes.

Comentários: Esta espécie apresenta considerável variabilidade nas características morfométricas, além de várias incertezas taxonômicas, sendo que esta seria na verdade um complexo de diferentes espécies (GEITLER, 1932; BRANCO et al., 1999). Nas amostras examinadas notou-se variação morfológica na célula apical: cilíndrica (em torno de $90 \%$ dos indivíduos) e cônico-arredondada (apenas 10\%). Esta espécie tem também ampla distribuição mundial, sendo considerada como a mais bem distribuída por Sheath \& Cole (1992), baseado no estudo de 1000 segmentos de riachos na América do Norte, e por Necchi et al. (2000), em trabalho conduzido em 172 riachos no estado de São Paulo.

Condições ambientais: ( $\mathrm{n}=6$; P1, P2, G1-R1, G6, G8-R1, G8-R2): Temperatura 16,3-25,1 ${ }^{\circ} \mathrm{C}(\mathrm{X}=20,0 \pm 2,7)$; Condutividade 1,0-78,0 $\mu{\mathrm{S} . \mathrm{cm}^{-1}}^{-}(\mathrm{X}=16,8 \pm 19,2)$; Turbidez 4,0-51,0 $\mathrm{UNT}(\mathrm{X}=16,2 \pm$ 
12,1); Velocidade da correnteza $0,0-85,8 \mathrm{~cm} \cdot \mathrm{s}^{-1}(\mathrm{X}=32,8 \pm 21,2)$; $\mathrm{pH}$ 6,1-7,6 (X=6,8 \pm 0,4); Oxigênio dissolvido 3,1-7,9 mg. $\mathrm{L}^{-1}(\mathrm{X}=5,6 \pm 1,4)$; Profundidade 2,0-208,0 $\mathrm{cm}(\mathrm{X}=$ $16,4-21,8)$.

Phormidium cf. retzii (C. Agardh) Gomont

Fig. 22

Ann. Sci. Nat. Bot., Sér. 7, 16: 175, 1892.

Basiônimo: Oscillatoria retzii Agardh, Dispositio Algarum Sueciae, p.36, 1812.

Filamentos em feixes emaranhados e prostrados, com bainha ausente ou bastante delgada, 6,0-6,5 $\mu$ m diâm.; conteúdo celular verde-azulado, com grânulos protoplasmáticos; tricomas não constritos, 5,0-9,0(-10,0) $\mu \mathrm{m}$ compr., 5,0-6,0 $\mu \mathrm{m}$ diâm, C/D (1,0-1,5)(-1,7); célula apical cilíndrica ou cônico arredondada. Hormogônios e necrídeos não observados.

Comentários: Essa população foi descrita à parte porque, apesar de todas as outras características corroborarem a descrição do táxon como $P$. retzii, esta apresenta diferença no comprimento das células, que são quadráticas ou mais longas que largas, e nunca mais curtas. O táxon analisado assemelha-se também a $P$. corium, embora este apresente diâmetro pouco menor de acordo com Komárek \& Anagnostidis (2005) [(2,8-)3,0-5,4 (8,0-10,0?) $\mu \mathrm{m}]$ e bem menor de acordo com Gomont (1892) (3,0-4,5 $\mu \mathrm{m})$. A célula apical obtusa também é uma característica que difere $P$. corium da população analisada no presente estudo.

Condições ambientais: ( $\mathrm{n}=1 ;$ P6): Temperatura $22,3-22,6^{\circ} \mathrm{C} \quad(\mathrm{X}=22,4 \quad \pm \quad 0,2)$; Condutividade 6,0-8,0 $\mu{\mathrm{S} . \mathrm{cm}^{-1}}^{-}(\mathrm{X}=7,0 \pm 1,4)$; Turbidez 2,0 UNT $(\mathrm{X}=2,0 \pm 0,0)$; Velocidade da correnteza 0,0-1,7 cm.s ${ }^{-1}(X=0,2 \pm 0,6) ; \mathrm{pH} 6,6-7,4(X=7,0 \pm 0,5)$;

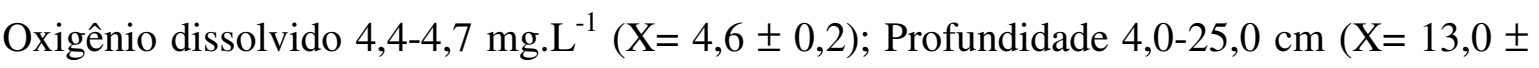
$7,4)$.

Scytonema arcangeli Bornet et Flahault

Figs. 23-25

Ann. Sci. Nat. Bot., Sér.7, 5: 92, 1886.

Filamentos agrupados formando tufos eretos, verde-azulados, 16,0-20,0 $\mu \mathrm{m}$ diâm.; ramificações falsas duplas abundantes e ramificações simples ocasionais; bainha hialina, geralmente incolor, às vezes amarelada, sem lamelação; tricomas predominantemente constritos, sem área meristemática definida, dispersas ao longo do filamento; células em sua maioria mais curtas do que largas, 8,0-12,0 $\mu \mathrm{m}$ compr., 12,0-16,0 $\mu \mathrm{m}$ diâm., C/D 0,5- 
0,8 (1,0); heterócitos bipolares, 8,0-14,0 $\mu \mathrm{m}$ compr., 12,0-18,0 $\mu \mathrm{m}$ diâm., C/D 0,5-1,0 $(1,2)$; hormogônios presentes.

Comentários: Os indivíduos amostrados assemelham-se aos reportados anteriormente para a região noroeste (BRANCO et al., 1999 e NECCHI et al., 1997) embora as células tenham diâmetro pouco menor ou próximo aos limites mínimos reportados por Branco et al. (1999)(15,0-31,0 ㅆm diâm.). Entretanto, apresentaram-se pouco mais curtas e mais largas se comparadas àqueles reportados por Sant'Anna (1988) (11,0-20,0 $\mu \mathrm{m}$ compr., 9,0-11,5 $\mu \mathrm{m}$ diâm.), o que sugere que esta variação não interfere na descrição do táxon. Em todas as descrições anteriores há grande variação quanto ao grau de constrição das células.

Condições ambientais: ( $\mathrm{n}=1 ; \mathrm{G} 3)$ : Temperatura $20,5-20,8^{\circ} \mathrm{C} \quad(X=20,6 \quad \pm \quad 0,2)$; Condutividade 1,0-3,0 $\mu{\mathrm{S} . \mathrm{cm}^{-1}}(\mathrm{X}=2,0 \pm 1,0)$; Turbidez 14,0-15,0 UNT (X=14,3 $\left.\pm 0,6\right)$; Velocidade da correnteza 0,0-63,4 cm.s ${ }^{-1}(X=18,9 \pm 22,5)$; pH 6,1-6,2 (X=6,2 \pm 0,1); Oxigênio dissolvido 7,3-7,9 mg. $\mathrm{L}^{-1}(\mathrm{X}=7,7 \pm 0,3)$; Profundidade 2,0-18,0 $\mathrm{cm}(X=10,2 \pm$ $4,7)$.

Trichocoleus sociatus (W. West et G.S. West) Anagnostidis

Figs. 26-27 Preslia, 73: 369, 2001.

Basiônimo: Microcoleus sociatus W. et G.S. West, J. Bot. 35: 272, 1897.

Filamentos não ramificados, longos, 11,0-30,0 $\mu \mathrm{m}$ diâm.; bainha firme, transparente ou castanha, aberta na extremidade, contendo 10-13 tricomas, emaranhados ou torcidos em espiral; tricomas verde-azulados, às vezes acinzentados, constritos nos septos, não granulados; células geralmente mais longas do que largas, 4,5-8,0 $\mu \mathrm{m}$ compr., (1,5-) 2,53,5 ㅆm diâm., C/D 1,0-3,0; célula apical cônico-arredondada, alongada, sem caliptra.

Comentários: Esta espécie já foi reportada para o estado de São Paulo por Sant'Anna \& Azevedo, 1995 (como Microcoleus sociatus), mas apresentando filamentos bem mais largos (35,0-40,0 $\mu \mathrm{m}$ diâm.) e células pouco mais longas (6,7-10,5 $\mu \mathrm{m}$ comp.; C/D 2,3-3,2) do que os encontrados no presente trabalho. Entretanto, a variação no diâmetro do filamento deve-se essencialmente ao tamanho da bainha, que pode variar conforme o ambiente. Essas diferenças, portanto, não comprometem a identificação da população.

Condições ambientais: ( $\mathrm{n}=1$; G5-R1): Temperatura 14,3-14,6 ${ }^{\circ} \mathrm{C}(\mathrm{X}=14,5 \pm 0,2)$; Condutividade 37,0-41,0 $\mu{\mathrm{S} . \mathrm{cm}^{-1}}(\mathrm{X}=39,3 \pm 2,1)$; Turbidez 2,0 UNT (X=2,0 \pm 0,0); Velocidade da correnteza 1,6-120,6 cm.s ${ }^{-1}(X=30,4 \pm 29,4)$; pH 6,54-7,44 (X=7,1 \pm 0,5); 
Oxigênio dissolvido 5,9-6,6 mg. $\mathrm{L}^{-1}(\mathrm{X}=6,2 \pm 0,4)$; Profundidade 7,0-27,0 cm (X=15,2$5,5)$.

\section{Heterokontophyta}

Vaucheria pseudogeminata Dangeard

Figs. 28-30

Botaniste 29: 216, 1939.

Talos formando tufos verdes sobre o substrato; sifão 30,0-40,0 $\mu \mathrm{m}$ diâm.; indivíduos monóicos; gametóforo com 2 oogônios laterais a um anterídio central; pedúnculo do gametóforo 100,0-260,0 $\mu \mathrm{m}$ compr., 32,0-44,0 $\mu \mathrm{m}$ diâm.; anterídio cilíndrico-circinado, 40,0-50,0 (-60,0) $\mu \mathrm{m}$ compr.,12,0-18,0 $\mu \mathrm{m}$ diâm.; pedicelo do anterídio ereto, levemente curvado; oogônios eretos, imaturos.

Comentários: Esta espécie se assemelha a Vaucheria geminata Vaucher, entretanto a última apresenta dimensões maiores: sifão: (48-)58,0-96,0 $\mu \mathrm{m}$ diâm.; pedúnculo do gametóforo: 172,0-364,0 $\mu \mathrm{m}$ comp., 48,0-84,0 $\mu \mathrm{m}$ diâm; anterídio: (60,0-)70,0-108,0 $\mu \mathrm{m}$ comp., 24,0-41,0 ㅆm diâm.) (ENTWISLE, 1988). Não foi possível especificar o tamanho dos oogônios e dos oósporos, por se encontrarem imaturos, bem como não foi possível distinguir a cavidade oogonial, que são características diagnósticas adicionais para a espécie. Entretanto, com base nas demais características, pôde-se identificar a amostra como Vaucheria pseudogeminata. Este é o primeiro registro da espécie no Brasil. Esta já foi registrada na Austrália (ENTWISLE, 1988), América do Norte (BLUM, 1972), Europa (DANGEARD, 1939) e Norte da África (GAUTHIER-LIEVRE, 1955).

Condições ambientais: ( $n=1$; G1-R2): Temperatura 19,0-19,4 ${ }^{\circ} \mathrm{C}(\mathrm{X}=19,2 \pm 0,2)$; Condutividade 7,0-8,0 $\mu{\mathrm{S} . \mathrm{cm}^{-1}}(\mathrm{X}=7,3 \pm 0,6)$; Turbidez 13,0-30,0 UNT (X=18,7 $\left.\pm 9,8\right)$; Velocidade da correnteza 3,0-52,4 cm.s ${ }^{-1}(X=30,0 \pm 13,1)$; pH 6,3-6,5 (X=6,4 \pm 0,1); Oxigênio dissolvido 5,0-6,1 mg. $\mathrm{L}^{-1}(\mathrm{X}=5,4 \pm 0,6)$; Profundidade 2,5-12,0 $\mathrm{cm}(\mathrm{X}=8,1 \pm$ 2,9).

\section{Rhodophyta}

Batrachospermum ambiguum Montagne

Figs. 31-33

Ann. Sci. Nat., Sér.3, 14: 296, 1850

Planta monóica, moderadamente mucilaginosa; ramificação irregular, abundante; verticilos doliformes, contíguos, 290-400 $\mu \mathrm{m}$ diâm.; internó com 135-350 $\mu \mathrm{m}$ compr.; ramos 
primários retos, com 9-11 células; células proximais cilíndricas a elípticas, células distais obovóides a esféricas; ramos secundários numerosos, retos, sobre toda a extensão do internó; espermatângios terminais, esféricos; ramo que sustenta o carpogônio torcido em hélice; tricogínio cilíndrico, pedicelado; carposporófito central, menor que o raio do verticilo.

Comentários: Os indivíduos amostrados concordam perfeitamente com a descrição de Necchi (1990, como B. bicudoi Necchi).

Condições ambientais: ( $\mathrm{n}=1$; G8-R2): Temperatura 16,5-16,8 ${ }^{\circ} \mathrm{C} \quad(\mathrm{X}=16,7 \pm 0,2)$;

Condutividade 19,0 $\mu \mathrm{S} . \mathrm{cm}^{-1}(\mathrm{X}=19,0 \pm 0,0)$; Turbidez 23,0-51,0 UNT (X=36,7 \pm 14,0); Velocidade da correnteza 0,0-93,8 cm.s ${ }^{-1}(X=27,9 \pm 27,8)$; pH 6,5-6,8 (X=6,7 \pm 0,2); Oxigênio dissolvido 6,1-6,4 mg. $\mathrm{L}^{-1}(\mathrm{X}=6,2 \pm 0,2)$; Profundidade 6,0-60,0 ( $\left.\mathrm{X}=15,9 \pm 1,6\right)$.

Compsopogon coeruleus (Balbis ex C. Agardh) Montagne

Figs. 34- 35

Algues Expl. Sc. Algerie, Bot. 1:154,1846.

Basiônimo: Conferva coerulea Balbis ex C Agardh, Sist. Alg. 122, 1824.

Filamentos corticados, com células axiais doliformes ou sub-esféricas; corticação formada verticalmente, através de divisões regulares das células axiais, sem filamentos rizoidais; células corticais externas geralmente poligonais; filamentos unisseriados com células terminais discóides;

Comentários: Os indivíduos amostrados concordam perfeitamente com a descrição de Necchi \& Dip (1992).

Condições ambientais: ( $\mathrm{n}=1 ; \mathrm{P} 4)$ : Temperatura $19,7-19,8 \quad{ }^{\circ} \mathrm{C} \quad(\mathrm{X}=19,7 \quad \pm \quad 0,1)$; Condutividade 35,0-37,0 $\mu$ S.cm ${ }^{-1}(X=35,7 \pm 1,2)$; Turbidez 9,0-10,0 UNT (X=9,7 $\left.\pm 0,6\right)$; Velocidade da correnteza 0,0-22,4 cm.s-1 (X=9,2 \pm 7,9); pH 7,7-7,8 (X=7,8 \pm 0,1); Oxigênio dissolvido 4,8-5,2 mg. $\mathrm{L}^{-1}(X=5,0 \pm 0,2)$; Profundidade 16,0-63,0 cm $(X=36,8 \pm$ $15,0)$.

macrospora "Chantransia"

Fig. 36

(Estágio 'Chantransia' de Batrachospermum spp.)

Filamentos verde-azulados, com o sistema basal formado por filamentos rizoidais bem desenvolvidos; filamentos compostos por células cilíndricas, (42,0-)52,0-90,0 $\mu \mathrm{m}$ compr., 
(16-)20,0-28,0 $\mu \mathrm{m}$ diâm.; ramos formando ângulo fechado com o ramo principal; monosporângios obovóides a esféricos, (18,0-) 26,0-28,0 $\mu$ m compr., 18,0-26,0 $\mu$ m diâm.

Comentários: Conforme recomendação de Zucchi \& Necchi (2003), associou-se a ocorrência da alga com uma das morfologias referidas para o estágio "Chantransia", neste caso, macrospora.

Condições ambientais: ( $n=2$; P4 e G8-R1): Temperatura $16,3-19,8{ }^{\circ} \mathrm{C}(\mathrm{X}=18,9 \pm 1,7)$; Condutividade 30,0-37,0 $\mu$ S.cm ${ }^{-1}$ (X=34,2 \pm 3,0); Turbidez 9,0-25,0 UNT (X=13,5 $\left.\pm 7,7\right)$; Velocidade da correnteza 0,0-38,5 cm.s $\mathrm{s}^{-1}(\mathrm{X}=6,9 \pm 8,0) ; \mathrm{pH} 7,4-7,8(\mathrm{X}=7,7 \pm 0,2)$;

Oxigênio dissolvido 4,8-5,2 mg.. $\mathrm{L}^{-1}(\mathrm{X}=4,9 \pm 0,2)$; Profundidade 16,0-63,0 cm $(\mathrm{X}=36,7 \pm$ $14,5)$.

\subsection{Discussão}

Nos 17 riachos amostrados foram encontradas 16 espécies de macroalgas, incluindo dois grupos vegetativos (Oedogonium spp. e Spirogyra spp.), pertencentes a 14 gêneros e distribuídos nos filos: Chlorophyta, Cyanophyta, Heterokonthophyta e Rhodophyta, sendo estes comumente reportados como típicos de ambientes lóticos (SHEATH \& COLE, 1992; NECCHI et al., 1997; KRUPEK et al., 2007; PERES et al., 2008; NECCHI et al., 2008). Em número de espécies, os grupos predominantes (Cyanophyta e Chlorophyta) concordam parcialmente com levantamentos anteriores (SHEATH \& BURKHOLDER, 1985; SHEATH et al., 1989; BIGGS, 1990; ENTWISLE, 1989; SHEATH \& COLE, 1992, 1996; NECCHI et al., 1997, 2000), exceto que o grupo melhor representado têm sido tipicamente Chlorophyta (37\% neste trabalho x 35\%-57\% nos anteriores), seguido de Cyanophyta (44\% x 17\%-35\%). Rhodophyta e Heterokonthophyta foram menos representativos (12\% e $6 \%$ respectivamente), o que ocorreu também em estudos anteriores no Brasil (NECCHI et al., 1997; BRANCO \& NECCHI, 1998; NECCHI et al., 2000; KRUPEK et al., 2007; PERES et al., 2008; 8\%-20\% e 3\%-11\% respectivamente).

O número global de espécies do presente estudo (16) foi baixo, comparado a estudos feitos com metodologia semelhante no estado de São Paulo: Branco \& Necchi (1996), realizado em 52 pontos de amostragem em região de Mata Atlântica (38 espécies) e Necchi et al. (1994b, 1997, 2000), em 22 pontos abrangendo a bacia de Rio Preto (27 espécies), em 50 pontos na região noroeste (44 espécies), e em 172 pontos de amostragem em diferentes biomas do estado (101 espécies), respectivamente. Esse valor baixo pode 
possivelmente ser atribuído ao substrato, que foi predominantemente arenoso $(65 \%)$ e à escassez de luz, já que os riachos se encontraram em sua maioria em trechos totalmente sombreados (53\%). O número de espécies relativo ao número de pontos de amostragem ( 0,9 neste trabalho) situou-se dentro dos limites dos valores referentes aos trabalhos mencionados (0,6-1,1). Entretanto, sabe-se que há uma tendência de diminuição do número de novas ocorrências com o aumento do número de amostragens, resultante da repetição de espécies (SHEATH \& COLE, 1992; BRANCO \& NECCHI, 1996; NECCHI et al., 2000). Trabalhos realizados no Parque Nacional de Itatiaia, MG/RJ (NECCHI et al., 2008), e na Serra da Canastra, MG (NECCHI et al., 2003), apresentaram valores bem superiores, tanto de número total de espécies (29 e 30, respectivamente) quanto de espécies em relação ao número de pontos de amostragem (2,1 e 2,5, respectivamente).

Os gêneros melhor representados foram Microspora (Chlorophyta) e Nitella (Chlorophyta), com duas espécies cada. Heterokontophyta foi representado por um único gênero e espécie: Vaucheria pseudogeminata. A maioria das espécies (69\%) foi encontrada exclusivamente em um único ponto de amostragem. Esta predominância de poucas espécies é um padrão frequentemente observado em comunidades de macroalgas lóticas (SHEATH \& BURKHOLDER, 1985; SHEATH et al., 1986, 1989; NECCHI et al., 1994b, 2000).

Phormidium retzii (Cyanophyta) foi a espécie mais frequente, ocorrendo em seis pontos de amostragem. Esta espécie tem sido reportada como cosmopolita e de ampla distribuição em vários estudos realizados no Brasil (BRANCO et al.,1999; NECCHI et al., 2000; KRUPEK et al., 2007), na América do Norte (SHEATH \& COLE, 1992), Ilhas Fiji (SHEATH \& COLE, 1996), Hawaí (VIS et al., 1994) e no Alaska (SHEATH et al., 1986). Algumas espécies encontradas (B. ambiguum, C. coeruleus e Nitella rosa-mariae) têm sido reportadas como predominantemente tropicais (NECCHI, 1991; NECCHI \& DIP, 1992; PICELLI-VICENTIM, 2004). Todas as espécies amostradas no presente estudo já foram reportadas para a região noroeste (NECCHI et al., 1991; NECCHI, 1993; NECCHI \& PASCOALOTO, 1993; NECCHI et al., 1994a, 1994b; NECCHI \& MOREIRA, 1995; BRANCO \& NECCHI, 1997; NECCHI et al, 1997; BRANCO \& NECCHI, 1998; BRANCO et al., 1999; NECCHI et al., 2000; BRANCO et al., 2001; BRANCO \& PEREIRA, 2002; NECCHI et al., 2002; VIEIRA et al., 2002, 2003; BRANCO et al., 2005), exceto Trichocoleus sociatus (Cyanophyta), que foi reportada pela primeira vez na região e Vaucheria pseudogeminata (Heterokontophyta), que representa a primeira ocorrência no Brasil. 
A proporção dos tipos morfológicos foi: filamentos livres (46\%), emaranhados de filamentos (40\%), filamentos gelatinosos e tufos (7\% cada). Estas proporções foram bastante distintas daquelas reportadas em estudos anteriores (SHEATH \& COLE, 1992; NECCHI et al., 2000, 2003), notadamente a frequiência bem maior neste estudo de filamentos livres (8\%-15\% nos anteriores), menor de filamentos gelatinosos (11\%-13\%) e ausência de incrustantes e colônias gelatinosas (1\%-2\% e 12\%-23\% respectivamente). A predominância de filamentos livres, seguida de emaranhado de filamentos, foi semelhante a estudos realizados no Parque Nacional de Itatiaia, RJ-MG (35\% e $24 \%$ respectivamente, NECCHI et al., 2008) e na região noroeste do estado de São Paulo (40\% e 31\%, NECCHI et al., 1997), que corresponde a região estudada no presente trabalho.

A composição florística de macroalgas lóticas dos fragmentos florestais do presente estudo foi similar àquela encontrada em estudo anterior na região noroeste (NECCHI et al., 1997), com 12 espécies em comum (75\%). Comparando a estudos realizados em diferentes regiões/biomas do estado de São Paulo (NECCHI et al., 2000), a flora do presente trabalho se assemelhou mais àquela de Floresta Tropical, com nove espécies em comum (56\%), seguida de Floresta Subtropical, com oito (50\%), Mata Atlântica, com sete (44\%) e região de águas duras, com seis espécies em comum (37\%). O bioma que apresentou a menor similaridade de espécies com os fragmentos da região noroeste foi o Cerrado, com a ocorrência de apenas duas espécies em comum (12\%). Essa baixa similaridade, entretanto, pode ser justificada pelo fato de o Cerrado ter sido, entre os biomas amostrados por Necchi et al. (2000), o que possuiu o menor número de espécies reportadas, reduzindo assim as chances de repetição de táxons entre os dois biomas.

A maior similaridade com Floresta Tropical, bioma mais próximo da região de estudo e composto também por Floresta Estacional Semidecidual confirma a hipótese apresentada no presente trabalho.

\section{Referências Bibiográficas}

ANAGNOSTIDIS, K.; KOMÁREK, J. Modern approach to the classification system of cyanophytes. 3. Oscillatoriales. Algological Studies, v. 50-53. P. 327-472, 1988.

BIGGS, B. J. F. Periphyton communities and their enviroments in New Zealand rivers. New Zealand Journal of Marine and Freshwater Research, v. 24, p. 367-386, 1990.

BIGGS, B. J. F.; PRICE, G. M. A. A survey of filamentous algal proliferations in New Zealand rivers. New Zealand Journal of Marine and Freshwater Research, v. 24, p. 367-386, 1987. 
BLUM, J. L., 1972. Vaucheriaceae. North American Flora série II, part..8, 1-64.

BRANCO, C. C. Z.; BRANCO, L. H. Z.; MOURA, M. O.; BERTUSSO, F. R. The succession dynamics of a macroalgal community after a flood disturbance in a tropical stream from São Paulo State, southeastern Brazil. Revista Brasileira de Botânica, v. 28, p. 267-275, 2005.

BRANCO, C. C. Z.; EMED, R. G.; NECCHI, O. Jr. Macroalgas de riachos da Floresta Nacional de Irati, região centro-sul do estado do Paraná, sul do Brasil. Acta Botanica Brasilica, v.22, p. 437-51, 2008.

BRANCO, C. C. Z.; KRUPEK, A. R.; PERES, C. K. Distribution of Stream Macroalgal Communities from the Mid-Western Region of Paraná State, Southern Brazil: Importance of Local Scale Variation. Brazilian Archives of Biology and Technology, v.52, p. 379386, 2009.

BRANCO, C. C. Z. \& NECCHI, O Jr. Distribution of stream macroalgae in the eastern Atlantic rainforest of São Paulo State, southeastern Brazil. Hydrobiologia, v. 333, p. 139$150,1996$.

BRANCO, L. H. Z. \& NECCHI, O. Jr. Seasonality of macroalgae in three tropical drainage basins in São Paulo State, southeastern Brazil. Archiv für Hydrobiologie, v. 141, p. 75-91, 1997.

BRANCO, L. H. Z. \& NECCHI, O. Jr. Distribution of stream macroalgae in three tropical drainage basins of southeastern Brazil. Archiv für Hydrobiologie, v.142, p. 241-256, 1998.

BRANCO, L. H. Z., NECCHI, O. Jr., BRANCO, C. C. Z. Cyanophyceae from lotic ecosystems of São Paulo State, southeastern Brazil. Algological Studies, v. 94, p. 63-87, 1999.

BRANCO, C. C. Z., KRUPEK, A. R., PERES, C. K.. Distribution of Stream Macroalgal Communities from the Mid-Western Region of Paraná State, Southern Brazil: Importance of Local Scale Variation. Brazilian Archives of Biology and Technology, v. 52, p.379386, 2009.

BRANCO, L. H. Z., NECCHI, O. Jr., BRANCO, C. C. Z. Ecological distribution of Cyanophyceae in lotic ecosystems of São Paulo State. Revista Brasileira de Botânica, v. 24, p. 99-108, 2001.

BRANCO, L. H. Z. \& PEREIRA, J. L. Evaluation of seasonal dynamics and bioindication potential of macroalgal communities in a polluted tropical stream. Archiv für Hydrobiologie, v. 155, p. 147-161, 2002.

DANGEARD, P. Le genre Vaucheria, spécialement dans la région du sud-ouest de la France. Botaniste, v. 29, p. 183-265, 1939.

ENTWISLE, T. J. A monograph of Vaucheria (Vaucheriaceae, Chrysophyta) in southeastern Mainland Australia. Australian Systematic Botany, v.1, p. 1-77, 1988. 
ENTWISLE, T. J. Macroalgae in Yarra River basin: flora and distribution. Proceedings of the Royal Society of Victoria, v. 101, p. 1-76, 1989.

ENTWISLE, T. J. Macroalgae in the upper Yarra and Watts River catchments: Distribution and Phenology. Australian Journal of Marine and Freshwater Research, v. 41, p. 505-522, 1990.

GAUTHIER-LIEVRE, L., 1955. Le genre Vaucheria en Afrique du Nord. Bull Soc Hist Nat Afrique Du Nord, v. 46, p. 301-31.

GEITLER, L. Cyanophyceae. In: RABENHORST, L. Kryptogamenflora von Deutschlands, Österreichs und der Schweiz, Leipzig: Akademische Verlagsgesellschft, 1196 p, 1932.

GOMONT, M. M. Monografie des oscillatoriées (Nostocacées homocystées). Annais du Sciences Naturelles. Botanique, v. 15, 16, p. 263-368, 91-264, 1892.

HOLMGREN, P. K. \& HOLMGREN, N. H.. Additions to Index Herbariorum (Herbaria), Taxon, v. 42, p. 489-505, 1993.

JOHANSSON, C. Attached algal vegetation in running water of Jamtland. Acta Phytogeographica, v.74, p. 1-84, 1982.

KAWECKA, B. Sessile algae in European mountain streams. 2. Taxonomy and autecology. Acta Hydrobiologica, v. 23, p. 17-46, 1981.

KOMÁREK, J.; ANAGNOSTIDIS, K. Cyanoprokaryota - 2. Teil: Oscillatoriales. Süsswasserflora von Mitteleuropa 19/2. Heidelberg, Germany: Elsevier/Spektrum, 2005. 759 p.

KRUPEK, R. A.; BRANCO, C. C. Z.; PERES, C. K. Levantamento florístico das comunidades de macroalgas da bacia do rio das Pedras, região centro-sul do Estado do Paraná, Sul do Brasil. Hoehnea, v. 35, p. 25-44, 2008.

KRUPEK, R. A.; BRANCO, C. C. Z.; PERES, C. K. Distribuição ecológica das comunidades de macroalgas da bacia de drenagem do rio das Pedras, região centro-sul do estado do Paraná, Sul do Brasil. Revista Brasileira de Botânica, v. 30, p. 173-182, 2007.

MAURY, C. (org.). Avaliação e identificação de áreas e ações prioritárias para a conservação, utilização sustentável e repartição dos benefícios da biodiversidade nos biomas brasileiros. Brasília: MMA/SBF, 2002. 404 p

NECCHI, O. Jr. Rhodophyta de água doce do Estado de São Paulo: levantamento taxonômico. Boletim de Botânica da Universidade de São Paulo, v. 11, p. 11-69, 1989.

NECCHI, O. Jr. Revision of the genus Batrachospermum Roth (Rhodophyta, Batrachospermales) in Brazil. Bibliotheca Phicologica, v. 84, p. 1-201, 1990.

NECCHI, O. Jr. The section Sirodotia of Batrachospermum (Rhodophyta, Batrachospermaceae) in Brazil. Algological Studies, v. 62, p. 17-30, 1991. 
NECCHI, O. Jr. Distribution and seasonal dynamics of Rhodophyta in the Preto River basin, southeastern Brazil. Hydrobiologia, v. 250, p. 81-90, 1993.

NECCHI, O. Jr. Amostragem de algas bentônicas. In: BICUDO, C.E.M.; BICUDO, D. C. (eds). Amostragem em limnologia, São Carlos: Ed. RIMA, p.167-177, 1996.

NECCHI O. Jr.; BRANCO, C. C. Z.; BRANCO, L. H. Z. Distribution of stream macroalgae in São Paulo State, Southeastern Brazil, Algological Studies , v. 97, p. 43-57, 2000.

NECCHI, O. Jr.; BRANCO, C. C. Z.; SIMÃO, R. C. G.; BRANCO, L. H. Z. Distribution of stream macroalgae in the northwest region of São Paulo State, southeastern Brazil. Hydrobiologia, v. 299, p. 219-230, 1995.

NECCHI, O. Jr.; BRANCO, L. H. Z.; BRANCO, C. C. Z. Ecological distribution of stream macroalgal communities from a drainage basin in the Serra da Canastra National Park, Minas Gerais, southeastern Brazil. Brazilian Journal of Biology, v. 63, p. 635-646, 2003.

NECCHI, O. Jr.; BRANCO, L. H. Z.; DIP, M. R. Uso de macroalgas para avaliação da poluição orgânica no Rio Preto, noroeste do estado de São Paulo. Anais da Academia Brasileira de Ciências, v. 66, p. 359-371, 1994a.

NECCHI, O. Jr.; BRANCO, L. H. Z.; PASCOALOTO, D., 1994b. Distribution of macroalgae in a tropical river basin from southeastern Brazil. Archiv für Hydrobiologie v. 129, p. $459-471,1994$ b.

NECCHI, O. Jr.; BRANCO, L. H. Z.; SPEZAMIGLIO, D. N. Ecological distribution of stream macroalgal communities from " Parque Nacional de Itatiaia", states of Minas Gerais and Rio de Janeiro, Brazil. Revista Brasileira de Botânica, v. 31, p. 135-145, 2008.

NECCHI, O. Jr.; DIP, M. R. The family Compsopogonaceae (Rhodophyta) in Brazil. Algological Studies, v. 66, p. 105-118, 1992.

NECCHI, O. Jr.; DIP, M. R.; GÓES, R. M. Macroalgae of a stream in southeastern Brazil: composition, seasonal variation and relation to physical and chemical variables. Hydrobiologia, v. 213, p. 241-250, 1991.

NECCHI, O. Jr. \& MOREIRA, J. C. L., 1995. Longitudinal distribution of macroalgae in two tropical lotic ecosystems from southeastern Brazil. Archiv für Hydrobiologie 135: 113-128.

NECCHI, O. Jr.; PASCOALOTO, D. Seasonal dynamics of macroalgal communities in the Preto River basin, São Paulo, southeastern Brazil. Archiv für Hydrobiologie, v. 129, p. 231-252.

NECCHI, O. Jr.; PASCOALOTO, D.; BRANCO, C. C. Z.; BRANCO, L. H. Z. Stream macroalgal flora from the northwest region of São Paulo State, Southeastern Brazil. Algological Studies, v. 84, p. 91-112, 1997. 
NECCHI, O. Jr.; SPEZAMIGLIO, D. N.; BRANCO, C. C. Z.; BRANCO, L. H. Z. Estudo taxonômico e distribuição ecológica do gênero Vaucheria (Xanthophyta, Vaucheriaceae) em ecossistemas lóticos do estado de São Paulo, Brasil. Hoehnea, v. 28, p. 231-242, 2001.

NECCHI, O. Jr.; SPEZAMIGLIO, D. N.; BRANCO, C. C. Z.; BRANCO, L. H. Z. Taxonomy and ecological distribution of the genus Microspora (Microsporaceae, Chlorophyta) in lotic ecosystems of São Paulo State, Southeastern Brazil. Algological Studies, v. 105, p. 39-50, 2002.

PERES, C. K.; BRANCO, C. C. Z.; KRUPEK, R. A.. Macroalgas de riachos da Serra da Prata, leste do estado do Paraná, Sul do Brasil. Acta Botanica Brasilica, v. 22, p. 333-344, 2008.

PICELLI-VICENTIM, M. M.; BICUDO, C. E. M.; BUENO, N. C. Flora ficológica do estado de São Paulo 5: Charophyceae. São Carlos: RiMa Editora, 2004. 124 p.

RAMBALDI, D. M.; OLIVEIRA, D. A. S. Fragmentação de ecossistemas: causas, efeitos sobre a biodiversidade e recomendações de políticas públicas. Brasília: Ministério do Meio Ambiente, 2003. 508 pp.

SANT'ANNA, C. L. Scytonemataceae (Cyanophyceae) from the State of São Paulo, Southern Brazil. Nova Hedwigia v. 46, p. 519-539, 1988.

SANT'ANNA, C. L.; AZEVEDO, M. T. P. Oscillatoraceae (Cyanophyceae) from São Paulo State, Brazil. Nova Hedwigia, v. 60, p. 18-58, 1995.

SHEATH, R. G.; BURKHOLDER, J. Characteristics of softwater streams in Rhode Island. II: Composition and seasonal dynamics of macroalgae communities. Hydrobiologia, v.128, p. 109-118, 1985.

SHEATH, R. G.; COLE, K. M. Biogeography of stream macroalgae in North America. Journal of Phycology, v. 28, p. 448-460, 1992.

SHEATH, R.G.; COLE, K. M. Stream macroalgae of the Fiji Islands: A preliminary study. Pacific Science, v. 50, p.46-54, 1996.

SHEATH, R. G.; HAMILTON, P. B.; HAMBROOK, J. A.; COLE, K. M. Stream macroalgae of the eastern boreal forest region of North America. Canadian Journal of Botany, v. 67, p. 3353-3362, 1989.

SHEATH, R. G.; MORINSON, M. O.; KORSH, J. E; KACZMARCZYK, D., COLE, K. M. Distribution of stream macroalgae in south-central Alaska. Hydrobiologia, v. 135, p. 259-269, 1986.

SHEATH, R.G.; MÜLLER, K. M. Distribution of stream macroalgae in four high arctic drainage basins. Arctic, v. 50, p. 355-364, 1997.

VAN DEN HOEK, C.; MANN, D. G.; JAHNS, H. M. Algae. An introduction to phycology. Cambridge: Cambridge University Press, 1995. 623 pp 
VIEIRA, J. Jr.; NECCHI O. Jr.; BRANCO, C. C. Z.; BRANCO, L. H. Z. Characeae (Chlorophyta) em ecossistemas lóticos do Estado de São Paulo, Brasil: gênero Nitella. Hoehnea, v. 29, p. 249-266, 2002.

VIEIRA, J. Jr.; NECCHI, O. Jr.; BRANCO, C. C. Z.; BRANCO, L. H. Z. Characeae (Chlorophyta) em ecossistemas lóticos do estado de São Paulo, Brasil: gênero Chara e distribuição ecológica. Hoehnea, v. 30, p. 53-70, 2003.

VIS, M. L.; SHEATH, R. G.; HAMBROOK, J. A.; COLE, K. M. Stream macroalgae of the Hawaiian islands: a preliminary study. Pacific Science, v. 48, p. 175-187, 1994.

WHITTON, B. A. Algae. In: WHITTON, B. A. (ed.). River ecology. Oxford: Blackwell Scientific Publishers, 1975. 725 p.

ZUCCHI, M. R.; NECCHI, O. Jr. Blue-greenish acrochaetioid algae in freshwater habitats are 'Chantransia' stages of Batrachospermales sensu lato (Rhodophyta). Cryptogamie $\begin{array}{lllll}\text { Algologie, } & \text { v. } & 24, & \text { p. } & 117-131,\end{array}$ 


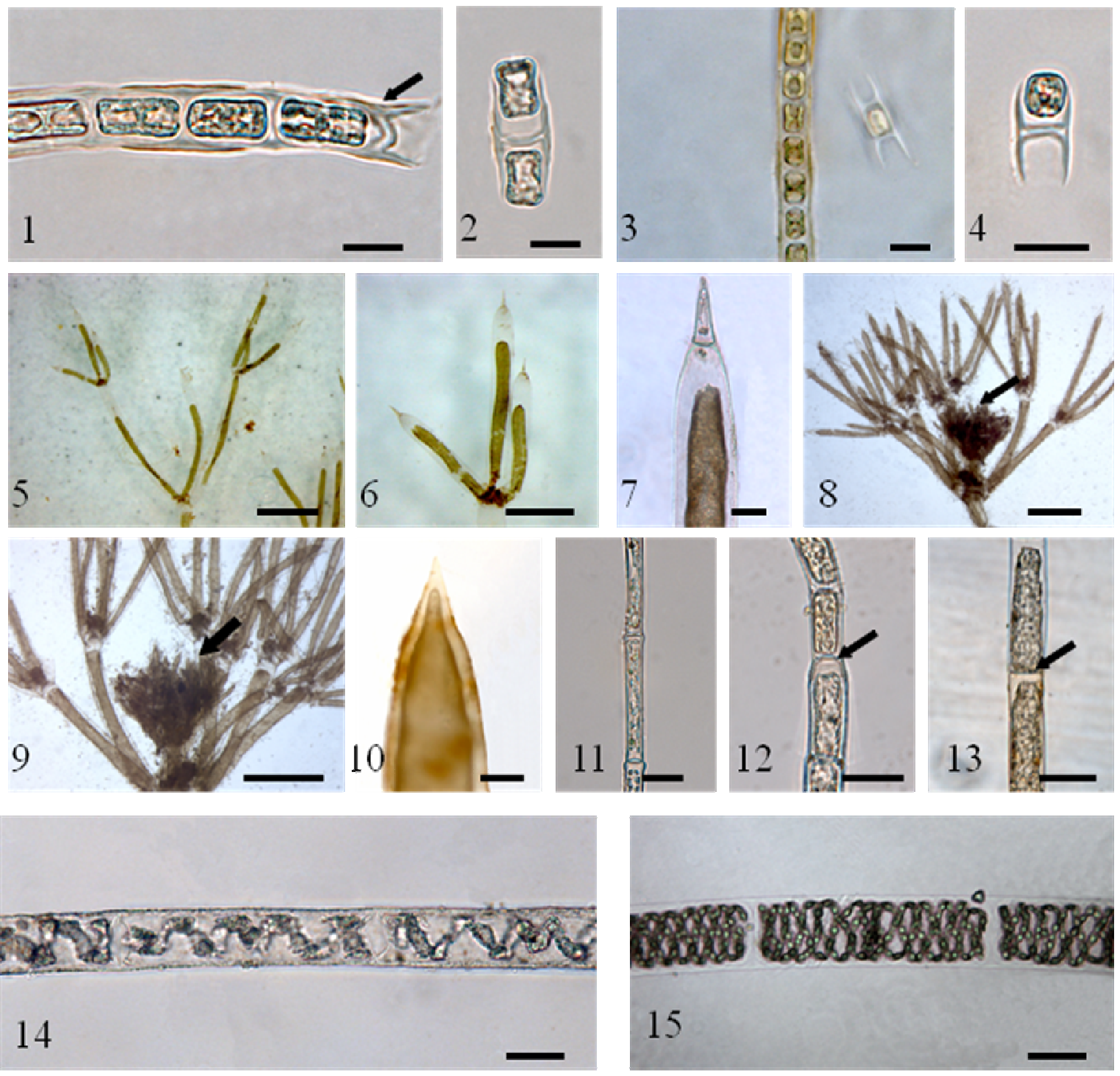

Figuras. 1-15. Fotomicrografias das espécies de Chlorophyta descritas. 1-2 - Microspora floccosa. 1 - Ápice do filamento evidenciando peça em H (seta). 2- Detalhe da parede em forma de H; 3-4 - Microspora quadrata. 3 - Ápice do filamento evidenciando peça em $\mathrm{H}$ (seta). 4 - Detalhe da parede em forma de H; 5-7 - Nitella rosa-maria. 5 - Aspecto geral do dáctilo. 6-7 - Dáctilos 2-celulados. 8-10 - Nitella subglomerata. 8-9 - Ápice da planta evidenciando os capítulos frouxos (setas). 10 - Dáctilo unicelulado acuminado. 11 Oedogonium sp.1. 12 - Oedogonium sp. 2. 13 - Oedogonium sp. 3. 14 - Spirogyra sp.1. 15 - Spirogyra sp. 2. (Escalas: Fig. 1-4, $11=10 \mu \mathrm{m} ; 12,14=25 \mu \mathrm{m} ; 7,13,15=50 \mu \mathrm{m}$; $10=100 \mu \mathrm{m} ; 6=0,5 \mathrm{~mm} ; 5,8,9=1 \mathrm{~mm})$. 

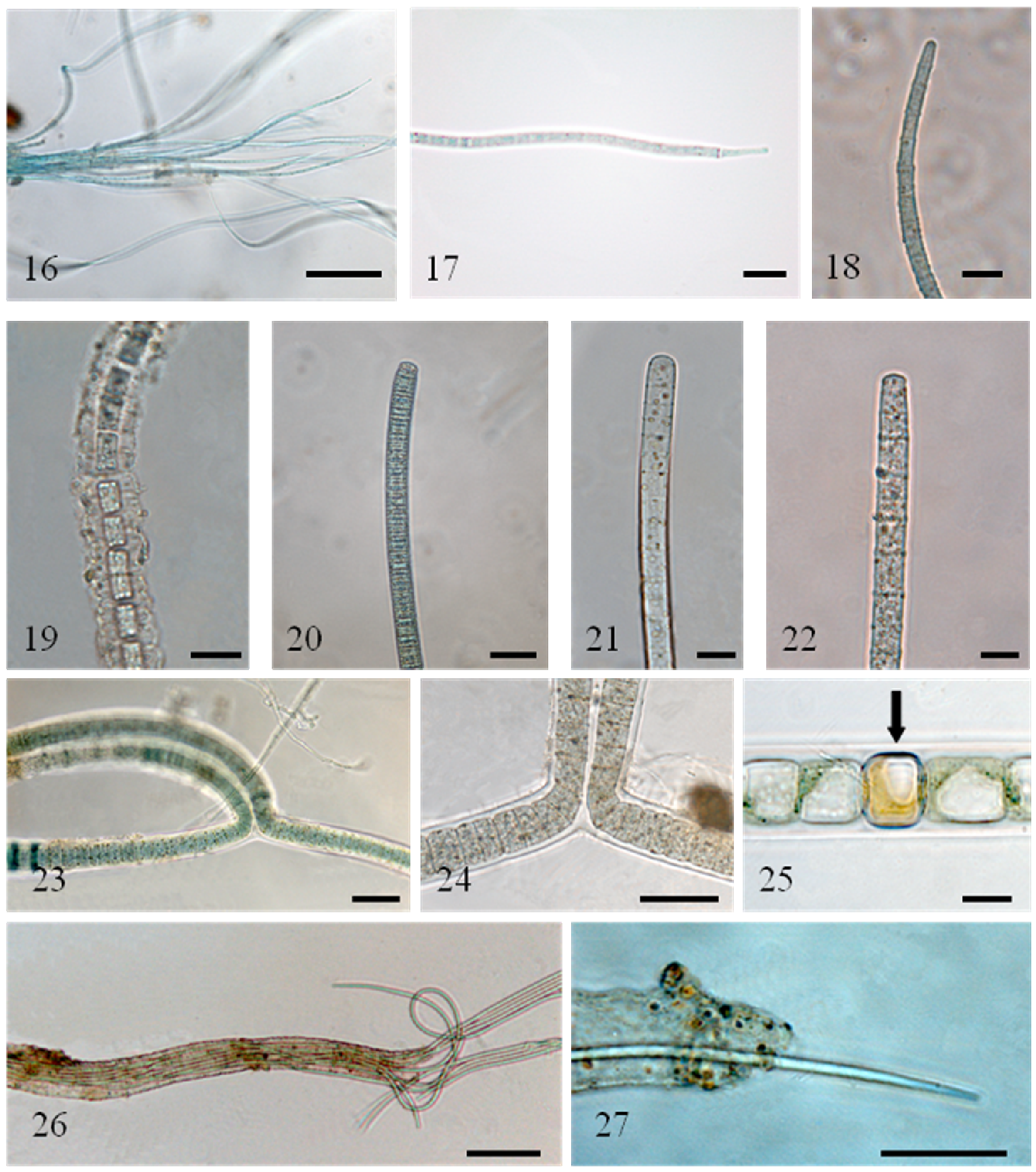

Figuras. 16-27. Fotomicrografias das espécies de Cyanophyta descritas. 16-17 Geitlerinema splendidum 16. Aspecto geral de um emaranhado de filamentos. 17 Filamento evidenciando célula apical capitada. 18 - Jaaginema homogeneum. 19 Microcoleus subtorulosus. 20 -Oscillatoria tenuis. 21 - Phormidium retzii. 22 - Phormidium cf. retzii. 23-25 - Scytonema arcangeli. 24 - Filamento evidenciando uma ramificação falsa dupla. 25 - Detallhe de um heterocito (seta). 26-27 - Trichocoleus sociatus. 26 - Filamento com muitos tricomas. 27 - Detalhe da extremidade de um filamento. (Escalas: 17-19, 21-22, $25=10 \mu \mathrm{m} ; 20,23-24,27=25 \mu \mathrm{m} ; 16,26=50 \mu \mathrm{m})$. 


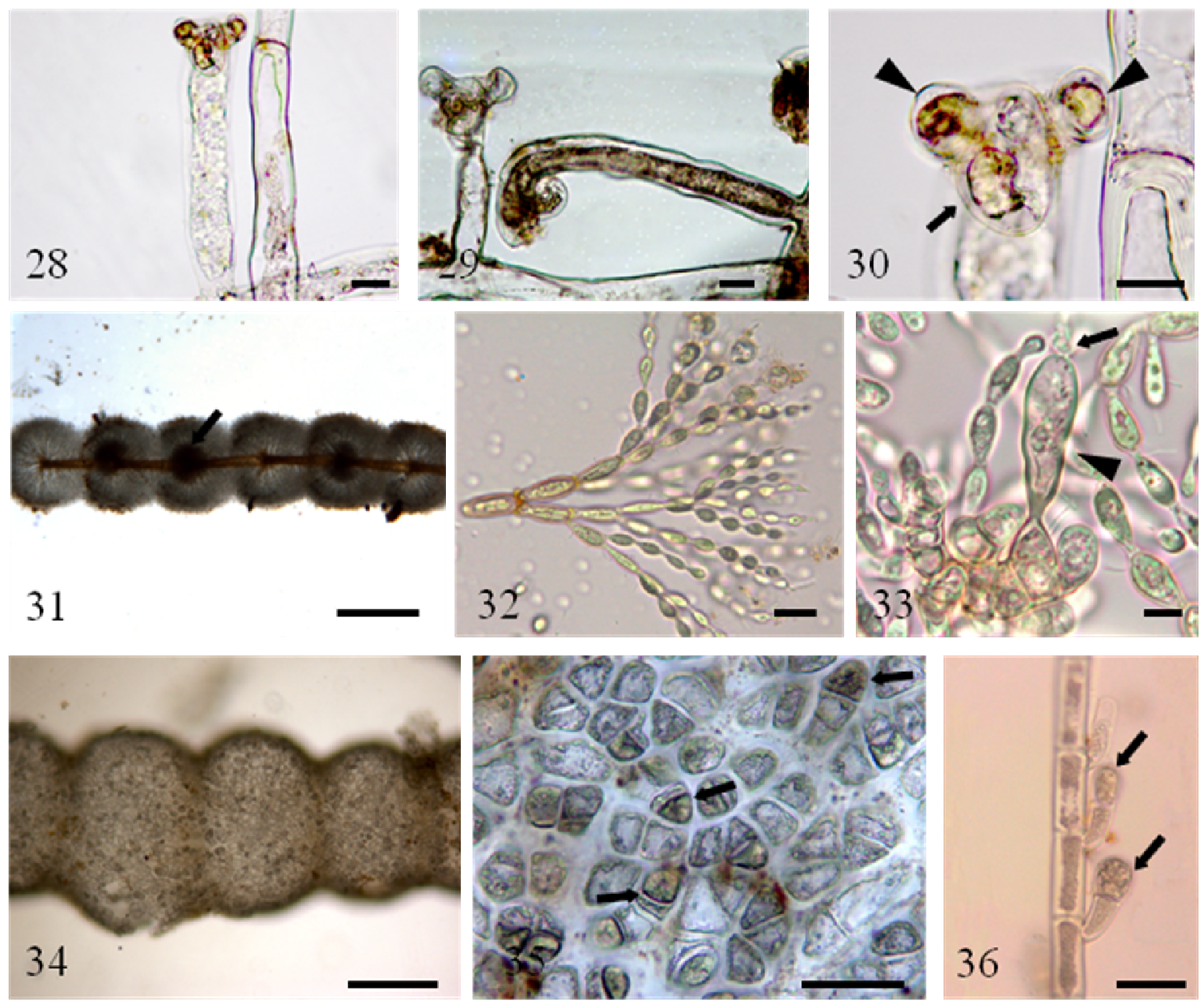

Figuras. 28-36. Fotomicrografias das espécies de macroalgas descritas. 28-30 - Vaucheria pseudogeminata (Heterokontophyta). 28-29 - Gametóforos pedunculados. 30 - Detalhe do gametóforo: anterídeo circinado (seta), com dois oogônios imaturos laterais (pontas de seta). 31-33 - Batrachospermum ambiguum (Rhodophyta). 31 - Aspecto geral dos verticilos, evidenciando carposporófito (seta). 32 - Ramo primário. 33 - Carpogônio fecundado, evidenciando tricogínio (ponta de seta) com espermácio (seta). 34-35 Compsopogon coeruleus (Rhodophyta). 34 - Aspecto geral de um filamento corticado. 35 Detalhe em vista superficial de um filamento corticado evidenciando células corticais e monosporângios (seta). 36 - Estágio "Chantransia" (macrospora 'Chantransia') (Rhodophyta). Filamento evidenciando monosporângios (setas). (Escalas: 32-33: $10 \mu \mathrm{m}$; $30,35-36=25 \mu \mathrm{m} ; 28-29=50 \mu \mathrm{m} ; 31,34=200 \mu \mathrm{m})$. 
Capítulo 2

\section{DISTRIBUIÇÃO ECOLÓGICA DAS COMUNIDADES DE MACROALGAS LÓTICAS DE FRAGMENTOS FLORESTAIS DA REGIÃO NOROESTE DE SÃO PAULO}




\section{RESUMO}

São muito raros estudos envolvendo a distribuição ecológica de macroalgas lóticas em fragmentos florestais remanescentes em escala global, sendo este o aspecto mais relevante do atual trabalho. O presente estudo teve como objetivos: (1) analisar a distribuição das comunidades de macroalgas e suas relações com as variáveis ambientais referentes aos respectivos riachos amostrados; (2) avaliar a influência das características dos fragmentos florestais e suas matrizes adjacentes, assim como da bacia de drenagem, sobre estas comunidades. A distribuição de macroalgas tem sido frequentemente relacionada a variáveis ambientais intrínsecas de cada corpo d'água. Presume-se, portanto, que estas variáveis exerçam maior influência na riqueza e abundância das comunidades do que parâmetros mais gerais relacionados com características do fragmento, ordem de grandeza do riacho amostrado e com a bacia de drenagem na qual se insere. A maioria dos rios/riachos apresentou apenas uma ou duas espécies $(53 \%)$ ou ainda ausência de macroalgas (29\%). Os principais fatores que pareceram ter determinado, tanto a riqueza quanto a abundância de espécies foram substrato e sombreamento. A riqueza global (16) e a riqueza por ponto de amostragem $(1,6 \pm 1,5)$, assim como a abundância $(1,8 \pm 3,1)$ de macroalgas foram baixas. Este fator foi atribuído à predominância de substrato areno-argiloso (65\% dos pontos), instável e prejudicial à colonização das macroalgas, e provavelmente à predominância de trechos sombreados $(53 \%)$, conseqüentes da redução da entrada de luz pela vegetação marginal devido à localização dos pontos dentro de fragmentos florestais. Tais condições caracterizam o ambiente como um ambiente severo para estas comunidades, o que pode explicar o fato de poucas espécies estarem aptas a colonizarem e crescerem nestes ambientes. Todas estas características condizem com a Hipótese do Distúrbio Intermediário, que prevê que em situações de frequiência e intensidade elevada de distúrbios muitas espécies tendem a não tolerar tal condição e acabam por extinguir-se do local. As comunidades de macroalgas apresentaram distribuição em mosaico e a maioria (69\%) das espécies foi encontrada em apenas um ponto de amostragem, ambos padrões frequentemente reportados para macroalgas lóticas. Características como forma e tamanho do fragmento, assim como sua matriz adjacente, ordem do riacho e sua posição no fragmento (borda/interior), assim como a respectiva bacia de drenagem não mostraram influência na comunidade de macroalgas. Estes resultados, aliados à ocorrência restrita de espécies, sugerem que as variáveis locais, especialmente substrato, e ainda sombreamento, característico de riachos localizados em fragmentos florestais, foram as variáveis de maior influência sobre a distribuição das comunidades de macroalgas. Estes dados confirmam a hipótese inicial. Por outro lado, recomenda-se que mais estudos sejam realizados para se entender melhor a distribuição das comunidades de macroalgas lóticas em fragmentos florestais, tendo em vista que são praticamente inexistentes estudos com esta abordagem no mundo. 


\subsection{Introdução}

Como os organismos planctônicos apresentam menor representatividade em ambientes lóticos, as algas bentônicas em geral, têm sido largamente descritas como componente produtor dominante para a maioria dos riachos e um dos principais elementos de sustentação da cadeia alimentar nestes ambientes (LAMBERTI, 1996). Mesmo em riachos com forte sombreamento, estas algas representam uma importante fonte de energia para determinados grupos de invertebrados (STEVENSON, 1996). A habilidade destas algas em crescerem e desenvolverem-se em ambientes de águas correntes está relacionada a uma série de complexos fatores que incluem interações entre hidrologia, qualidade da água e fatores bióticos (DeNICOLA, 1996). Além destes fatores, a estrutura do talo também representa uma adaptação a diferentes níveis de velocidade, sendo as estruturas em emaranhado, tufos ou gelatinosas consideradas melhor adaptadas ao estresse causado pela correnteza (SHEATH \& HAMBROOK, 1990; SHEATH \& COLE, 1992).

Estudos abordando aspectos relacionados à distribuição da comunidade de macroalgas lóticas tem sido desenvolvidos em diferentes partes do mundo (JOHN \& MOORE, 1985; SHEATH \& BURKHOLDER, 1985; SHEATH et al., 1986; ENTWISLE, 1989; BIGGS, 1990; SHEATH \& COLE, 1992; PFISTER, 1993; SHEATH et al., 1996; SHEATH \& MÜLLER, 1997). No Brasil, principalmente nas duas últimas décadas, estudos relevantes com esta abordagem também foram realizados. Entre eles, trabalhos feitos em campos de altitude, na região dos estados de Minas Gerais e Rio de Janeiro (NECCHI et al., 2003, 2008), em diferentes biomas nos estados do Paraná (BRANCO et al., 2008, 2009; KRUPEK et al., 2007) e de São Paulo (NECCHI et al., 1995; BRANCO \& NECCHI, 1996b; NECCHI et al., 2000).

Entre os estudos que abordam em algum grau a região noroeste do estado de São Paulo, estão aqueles realizados com macroalgas em geral (NECCHI et al., 1995, 2000) ou ainda abordando grupos específicos, entre eles: Cyanophyceae (BRANCO et al., 2001), Rhodophyta (NECCHI, 1993; NECCHI et al., 1999), Characeae (VIEIRA et al., 2002, 2003), Chaetophoraceae (BRANCO et al., 2002) e os gêneros Vaucheria (NECCHI et al., 2001) e Microspora (NECCHI et al., 2002). Também nesta região, foram feitos estudos abordando outros aspectos ecológicos destas comunidades, como sucessão ecológica (BRANCO et al., 2005; BORGES \& NECCHI, 2007) e macroalgas como indicadoras de poluição (NECCHI et al., 1994; BRANCO \& PEREIRA, 2002). Trabalhos com comunidades de macroalgas da região foram conduzidos também 
diferentes escalas espaciais, os quais abordaram: a distribuição em um único riacho (NECCHI et al., 1991), em uma bacia de drenagem (NECCHI, 1993; NECCHI \& PASCOALOTO, 1993; NECCHI et al., 1994), em dois rios de diferentes tamanhos (NECCHI \& MOREIRA, 1995); em três bacias de drenagens (BRANCO \& NECCHI, 1997, 1998) e em toda a região (NECCHI et al., 1995, 1997).

A distribuição das comunidades de algas presentes em águas correntes, de uma forma geral, tem sido freqüentemente relacionada com diversos fatores ambientais, intrínsecos de cada corpo d'água (NECCHI \& PASCOALOTO, 1993), entre eles algumas variáveis físicas e químicas: temperatura (WHITTON, 1975; SHEATH \& BURKHOLDER, 1985; SHEATH et al, 1986, 1989; BIGGS, 1990; ENTWISLE, 1990; SHEATH \& HAMBROOK, 1990), condutividade específica (BIGGS, 1990; SHEATH \& COLE, 1992; NECCHI et al., 1994, 1995), pH (SHEATH \& BURKHOLDER, 1985; SHEATH et al., 1989; SHEATH \& COLE, 1992), turbidez (SHEATH \& MÜLLER., 1997) e velocidade da correnteza (REITER \& CARLSON, 1986; NECCHI et al., 1991; SHEATH \& COLE, 1996; SHEATH \& MÜLLER., 1997). Estas variáveis são reflexos da qualidade da água e do clima, o que determinam, desta forma, as características particulares do local. A intensa e rápida flutuação das condições de um riacho tem sido apontada como o principal fator na determinação da riqueza e abundância destas comunidades (SHEATH \& BURKHOLDER, 1985).

Para macroalgas lóticas de clima tropical, as melhores condições para o desenvolvimento ocorrem sob menores valores de precipitação pluviométrica, turbidez, velocidade da correnteza e temperatura, que correspondem à estação seca do ano (NECCHI \& PASCOALOTO, 1993). No entanto, em âmbito mundial, muitos estudos não apontam um padrão de variáveis físico-químicas favoráveis ou desfavoráveis à comunidade de macroalgas (NECCHI et al., 1999, 2000; HU \& XIE, 2006; KRUPEK et al., 2007; BRANCO et al., 2009), podendo estar o substrato (BIGGS, 1990; GORDON et al., 1992; SHEATH \& MÜLLER, 1997; KRUPEK et al., 2007), irradiância (STEINMAN \& MCINTIRE, 1986; STEINMAN et al., 1989; DeNICOLA et al., 1992; VERB \& VIS, 2001) e/ou precipitação (PFISTER, 1993; VERB \& VIS, 2001) entre as variáveis de maior influência direta ou indireta sobre a distribuição destes organismos. Além disso, a influência das variáveis ambientais pode também variar entre os filos, sendo riachos sombreados de regiões de floresta, por exemplo, sugeridos como benéficos para Rhodophyta (BRANCO \& NECCHI, 1996b; SHEATH \& COLE, 1992), enquanto no bioma Tundra, região de baixa temperatura e elevada radiação, Cyanophyta 
tende a predominar, pois apresenta adaptações a estas condições (SHEATH et al., 1996).

Alguns padrões tem sido consistentemente verificados em relação à distribuição de macroalgas lóticas (SHEATH et al. 1986, 1989; SHEATH \& COLE, 1992; NECCHI et al., 1995; BRANCO \& NECCHI, 1996b, 1998; NECCHI et al., 2000; BORGES \& NECCHI, 2006): 1. Dominância quantitativa e predominância por poucas espécies; 2. Pré-ocupação de nicho, no qual uma ou poucas espécies ocupam a maior parte do recurso (por exemplo, substrato) e as outras espécies competem pelos recursos restantes. 3. Distribuição em mosaico, no qual as comunidades mais abundantes são também as mais ricas. Estes padrões parecem representar um consenso geral e sugerem que poucas espécies estão aptas a colonizarem e se manterem em ambientes com elevada instabilidade e alteração recorrente de suas características, condições que prevalecem em ambientes lóticos (BRANCO \& NECCHI, 1996b, 1998; NECCHI et al., 1995, 2000; SHEATH \& COLE, 1992; SHEATH et al., 1986, 1989).

A região noroeste de São Paulo é considerada uma área fortemente afetada pela fragmentação de hábitats, possuindo apenas $9 \%$ de sua área florestal original, tendo sido substituída por áreas de pastagem, monoculturas e urbanas (PROBIO, 1998). O processo de fragmentação é caracterizado pela alteração na configuração espacial e funcional de um determinado hábitat, que após intervenções, geralmente antrópicas, tende a apresentar formato, área e funcionamento diferentes da sua condição original (LOMOLINO \& PERAUT, 2001).

Apesar de estudos variados envolvendo a distribuição ecológica das macroalgas lóticas, inclusive na região noroeste de São Paulo, são muito raros, de forma global, estudos envolvendo a distribuição destes organismos em fragmentos florestais remanescentes, principalmente no Brasil (BRANCO et al., dados não publicados), sendo este o aspecto mais relevante do presente trabalho. Considerando esta escassez de informações, o presente estudo teve como objetivo: 1. Analisar a distribuição das comunidades de macroalgas e suas relações com as variáveis ambientais de riachos pertencentes a fragmentos florestais remanescentes da região noroeste do estado de São Paulo; 2. Avaliar a influência das características dos fragmentos florestais e suas matrizes adjacentes, assim como da bacia de drenagem e da ordem de grandeza do riacho sobre estas comunidades.

Entre as variáveis que podem influenciar a distribuição dos organismos, pressupõe-se que as variáveis intrínsecas de cada corpo d'água (BRANCO \& NECCHI, 
1997, 1998; NECCHI et al. 1994, 1995, 2000; NECCHI \& MOREIRA, 1995) exerçam maior influência na riqueza e abundância das comunidades de macroalgas do que parâmetros mais gerais relacionados com características do fragmento, ordem de grandeza do riacho e com a bacia de drenagem na qual este riacho se insere.

\subsection{Materiais e Métodos}

A área de estudo e os procedimentos de amostragem das macroalgas, assim como os procedimentos tomados para medição das variáveis da água, substrato e sombreamento, foram detalhados nos materiais e métodos gerais do presente trabalho. A abundância das macroalgas foi estimada em termos de porcentagem de cobertura (SHEATH \& BURKHOLDER, 1985) em cada unidade amostral, através da técnica de estimativa visual (NECCHI, 1993). Esta técnica tem sido freqüentemente utilizada como um método não-destrutivo na determinação da abundância em estudos ecológicos de algas de ambientes lóticos (ENTWISLE, 1990; SHEATH e COLE, 1992; NECCHI et al., 1995; BRANCO \& NECCHI, 1996a; NECCHI et al., 2000).

Os resultados numéricos foram submetidos inicialmente à estatística descritiva e, posteriormente, foram calculados os seguintes índices para cada comunidade de macroalgas, com o intuito de comparar estas comunidades: índice de diversidade de Shannon-Wiener (H') (KREBS, 1989), para calcular a diversidade $\alpha$; índice de equitabilidade (J') (PIELOU, 1984), para avaliar a homogeneidade da comunidade e índice de dominância de Simpson (D) (KREBS, 1989), para avaliar a dominância de uma ou poucas espécies de macroalgas.

O coeficiente de correlação de Spearman (ZAR, 1999), utilizado para dados não paramétricos, foi aplicado com o intuito de avaliar a associação entre as variáveis biológicas (riqueza e abundância) e as variáveis ambientais (variáveis fisico-químicas da água, velocidade, profundidade e substrato).

Em seguida, através do Critério de Seleção de Akaike (CIA) (AKAIKE, 1974) foi selecionado o modelo que melhor explica a distribuição das macroalgas. O CIA é uma ferramenta que vem sendo bastante utilizada porque não lida com testes de hipóteses como faz a "stepwise selection" da regressão múltipla e pode trazer resultados mais próximos da realidade (BURNHAM \& ANDERSON, 2004). Este teste foi realizado com o auxilio do software Spatial Analysis in Macroecology (SAM), (versão 3.0, RANGEL, et al., 2006); (www.ecoevol.ufg.br/sam). 
Para avaliar a ocorrência de diferenças significativas entre a riqueza e abundância de macroalgas lóticas de fragmentos com diferentes características (posição do riacho no fragmento, tamanho, forma, matriz adjacente), assim como de riachos com diferentes ordens de grandeza, bacias de drenagens e níveis de sombreamento, foi aplicado o teste $t$ de student para variáveis dependentes (ZAR, 1999). O teste $t$ e a correlação foram feitos com o auxílio do software Statistica (versão 6.0, Statsoft).

As associações entre os pontos de amostragens, com base composição, riqueza, abundância e diversidade de espécies e nas variáveis ambientais, foram determinadas através de análise de grupamento e componentes principais (DIGBY \& KEMPTON, 1987). Na análise de grupamento, para verificar a similaridade dos pontos de amostragem com base na presença/ausência de macroalgas, foi aplicado o índice de Jaccard e para verificar a distância dos pontos com base na abundância (\% de cobertura) das macroalgas foi utilizado o índice de Bray-Curtis. A Análise de Componentes Principais (ACP) foi conduzida a partir da matriz formada com os dados biológicos e ambientais referentes aos pontos amostrados. A matriz foi padronizada pelo valor máximo ("ranging"), e depois foi gerada uma matriz de similaridade. Foram eliminadas as variáveis que tiveram forte colinearidade (DIGBY \& KEMPTON, 1987), número baixo de amostras e aquelas cujos vetores apresentaram valores muito baixos: temperatura, $\mathrm{pH}$, oxigênio dissolvido, profundidade e substrato do tipo seixo. Os testes estatísticos multivariados acima citados foram realizados com o uso do pacote estatístico "Multivariate Statistical Package" (MVSP) (versão 3.1, Kovach Computing Services).

A partir dos dados obtidos por Necchi et al. (1997), que representam o pool de espécies da região noroeste, foi calculado o Índice de Distintividade Taxonômica (CLARKE \& WARWICK, 2001), que fornece a medida do grau de relacionamento médio dos indivíduos de uma mesma assembléia de organismos, conceito introduzido por Warwick \& Clarke (1995). O índice é subdividido em duas análises: 1. distintividade taxonômica média (Average Taxonomic Distinctness, AvTD ou $\Delta^{+}$), que é o calculo da soma dos caminhos que conectam cada par de espécies em uma árvore taxonômica dividido pelo número de caminhos. Tais caminhos são assumidos como sendo os passos entre cada nível hierárquico: espécie para gênero, gênero para família, até o nível em comum do par de espécies; 2. Variação da distintividade taxonômica (Variation in Taxonomic Distinctness, VarTD ou $\Lambda^{+}$), que calcula a variância do 
caminho percorrido entre os pares de espécies de uma árvore taxonômica. Não entraram na análise os pontos que não tiveram ocorrência de macroalgas

\subsection{Resultados}

Os valores de condutividade e turbidez se mostraram bastante variáveis, sendo os primeiros baixos de forma geral $\left(17,9 \pm 16,4 \mu \mathrm{S}_{\mathrm{cm}} \mathrm{cm}^{-1}\right)$ e os últimos moderados $(16,1 \pm$ 10,6 UTN). Os valores de $\mathrm{pH}$ situaram-se próximos ao neutro $(6,9 \pm 0,4)$ (tabela 1). Velocidade e profundidade também apresentaram valores muito variáveis $\left(25,7 \mathrm{~cm} . \mathrm{s}^{-1} \pm\right.$ 21,8 e $17,1 \mathrm{~cm} \pm 17,5$ respectivamente) (tabela 2).

O substrato foi composto predominantemente por areia-argilla (65\%), seguido por "litter" (20\%) e outros (15\%) (tabela 2). A maioria dos pontos situou-se em trechos sombreados $(53 \%)$ ou parcialmente sombreados $(41 \%)$, sendo apenas um ponto localizado em segmento aberto (tabela 2).

Nos 17 riachos amostrados foram encontradas 16 espécies de macroalgas, incluindo dois grupos vegetativos (Oedogonium spp. e Spirogyra spp.) (tabela 3), pertencentes a 14 gêneros e distribuídos nos filos: Cyanophyta (44\%), Chlorophyta (37\%), Rhodophyta (12\%) e Heterokontophyta (6\%). O riacho do fragmento P1 foi o que apresentou maior riqueza de espécies (seis), seguido por P7(R1) (cinco), G3 e P6 (três espécies cada) (tabela 3). Os demais rios/riachos tiveram apenas uma ou duas espécies (53\%) ou ainda ausência de macroalgas (29\%) (tabela 3). A maioria (69\%) das espécies foi encontrada em apenas um ponto de amostragem (tabela 3). Em cinco riachos $(29 \%)$ não houve ocorrência de macroalgas. Em relação à abundância, o riacho com maior valor foi G8(R2) $(9,8 \%)$, seguido por G3 (6,7\%) e P1 (5,7\%) (tabela 4). As espécies de macroalgas mais abundantes foram Batrachospermum ambiguum (Rhodophyta) (7,1\%), presente em G8(R2), seguida por Scytonema arcangeli (Cyanophyta) (5,4\%), presente em G3 (tabela 4). Nos riachos com dados quantitativos para macroalgas houve dominância de uma $(67 \%)$ ou duas espécies $(16 \%)$ em relação às outras espécies presentes (tabela 4).

Nos trechos sombreados houve predominância de Cyanophyta (58\%) em relação aos outros grupos (14\% cada filo), o que não ocorreu em trechos parcialmente sombreados (50\% Cyanophyta e 50\% Chlorophyta). Nos riachos com substrato composto em sua maioria por areia-argila, houve também forte predominância de 
Cyanophyta (80\%), diferentemente dos riachos com predominância de outros substratos (42\% Cyanophyta, 42\% Chlorophyta, 16\% Rhodophyta e Heterokontophyta).

Os valores de abundância (cobertura percentual) e índice de diversidade de Shannon-Wiener (H') por ponto de amostragem variaram de 0 a 9,8\% $(1,8 \% \pm 3,1 \%)$ e 0 a 0,41 (0,23 $\pm 0,14)$, respectivamente (tabela 4). O índice de equitabilidade de Pielou (J') e de dominância de Simpson (D) variaram de 0,40 a 1,00 (0,47 $\pm 0,36)$ e 0,45 a 0,85 $(0,48 \pm 0,32)$, respectivamente (tabela 4$)$. Os valores de riqueza de espécies variaram de 0 a 6 por ponto de amostragem $(1,6 \pm 1,5)$ (tabela 4$)$ e o número de espécies relativo ao número de pontos de amostragens foi 0,9 .

$\mathrm{O}$ teste $t$ não apontou diferenças significativas $(\mathrm{p}<0,05)$ para nenhuma das variáveis ambientais e biológicas de riachos de fragmentos com diferentes características, tais como posição do riacho no fragmento (interior x borda), tamanho (pequeno x grande), matriz (cana x pastagem), além da UGRHI na qual o riacho se insere (Turvo Grande x Baixo-Tietê) e sombreamento (sombreado x parcialmente sombreado).

O teste de correlação de Spearman revelou correlação positiva significativa $(\mathrm{p}<$ $0,05)$ entre as variáveis biológicas: riqueza x abundância $(r=0,95)$; riqueza $\times H^{\prime}(r=$ 0,70); abundância x H' $(\mathrm{r}=0,58)$ e entre riqueza e o substrato "litter" $(\mathrm{r}=0,58)$. Para as seguintes variáveis foi encontrada correlação negativa significativa $(\mathrm{p}<0,05)$ : riqueza $\mathrm{x}$ condutividade $(r=-0,58)$; abundância $x$ condutividade $(r=-0,58)$; riqueza $\times \mathrm{pH} \quad(r=-$ $0,56)$; abundância $\times \mathrm{pH}(\mathrm{r}=-0,62)$; riqueza $\mathrm{x}$ substrato areia-argila $(\mathrm{r}=-0,60)$; abundância x substrato areia-argila $(r=-0,63)$.

Apesar da correlação de $\mathrm{pH}$ e condutividade com as variáveis biológicas, o Critério de Seleção de Akaike revelou que os modelos que melhor explicam as variáveis biológicas referem-se unicamente ao tipo de substrato, sendo $58 \%$ da riqueza de macroalgas explicada apenas pelo substrato "litter" $\left(r^{2}=0,58 ; \mathrm{AIC}=49,6\right)$ e $30 \%$ da abundância por areia-argila $\left(\mathrm{r}^{2}=0,30 ; \mathrm{AIC}=77,9\right)$.

A análise de grupamento para dados qualitativos revelou baixa similaridade entre os pontos de amostragem, sendo formados apenas dois grupos relevantes $(>50 \%)$ : P2 e P6; G1(R1) e G6 (figura 1). Além dos poucos grupos formados, estes ainda ocorreram devido à presença de apenas duas (Geitlerinema splendidium e Phormidium retzii) ou uma (Phormidium retzii) espécie em comum, respectivamente (tabela 3). A análise quantitativa mostrou a formação de um único grupo, composto por P2 e P6, com proximidade considerável (>90\%) (figura 2), e este se fez devido à presença de dados 
quantitativos semelhantes, nos dois pontos, para Geitlerinema splendidium (Cyanophyta) e Phormidium retzzi (Cyanophyta) (tabela 4).

A análise dos componentes principais (ACP) apresentou uma explicabilidade de $61 \%$ em relação à variação total (tabela 5). A análise mostrou uma tendência de separação dos fragmentos grandes e pequenos em relação ao eixo 1 (figura 3), sendo os fragmentos grandes (maioria na metade esquerda do eixo) correlacionados positivamente com área e negativamente com o substrato "litter", e os pequenos (maioria na metade direita) com correlação inversa (tabela 5). Os pontos P4, P9, G3 e G8-R2 constituíram exceção por apresentarem maiores (fragmentos grandes) ou menores (fragmentos pequenos) valores para as variáveis biológicas (tabela 4), ambos com tendência inversa em relação aos respectivos grupos. Em relação ao eixo 2 (figura 3), os pontos situados em fragmentos pequenos mostraram correlação negativa com velocidade e o substrato cascalho e positiva com areia-argila (tabela 5), sendo a única exceção o riacho de $\mathrm{P} 1$, com tendência inversa em relação aos riachos de outros fragmentos pequenos.

No Índice de Distintividade Taxonômica (figura 4), a comparação entre o $\Delta^{+}$ observado e os limites esperados mostrou que, entre os pontos considerados, a maioria $(66 \%)$ situou-se no intervalo de confiança de $95 \%$. Os pontos que se encontraram fora deste intervalo foram: P4, G1(R1), G1(R2), e G8(R1), que tiveram a ocorrência de apenas uma espécie.

\subsection{Discussão}

A riqueza global de espécies nos fragmentos amostrados (16), de forma geral, apresentou-se baixa se comparada a estudos feitos com metodologia semelhante no estado de São Paulo: Branco \& Necchi (1996a), em estudo feito no bioma de Mata Atlântica (38 espécies); Necchi et al. (1997), realizado na região noroeste (27 espécies); e Necchi et al. (2000), realizado em diferentes biomas no estado de São Paulo (101 espécies). A riqueza por ponto de amostragem variou de 0 a 6 espécies $(1,6 \pm 1,5)$, o que também representou valores baixos se comparados a alguns estudos realizados com a mesma abordagem em diferentes regiões do mundo: 0-11 (SHEATH et al., 1986 e SHEATH \& COLE, 1992); 1-11 (SHEATH et al., 1989); 2-17 (NECCHI et al., 1994); 1-9 (NECCHI et al., 2003). Vis et al. (1994), Branco \& Necchi (1996b), Necchi et al. (2000), Krupek et al. (2007), Necchi et al. (2008) e Branco et al. (2009) encontraram amplitude semelhante à do presente estudo (1-7; 0-6;0-7; 0-7; 0-5 e 0-6, 
respectivamente), entretanto todos estes trabalhos, assim como os anteriores, apresentaram os valores médios de espécies por ponto superiores $(2,6-8,0)$.

A abundância (cobertura percentual) das comunidades apresentou valores baixos (0 a 9,8\%) comparada a estudos relevantes feitos com macroalgas lóticas: <1 a 90\% (SHEATH et al., 1986); <1 a ca. 60\% (SHEATH et al., 1989); <1 a 51,9\% (NECCHI et al., 1991); 0 a aprox.100\% (SHEATH \& COLE, 1992); 5 a 85\% (NECCHI et al., 1994); 1 a 76\% (VIS et al., 1994); 0 a 70\% (BRANCO \& NECCHI, 1996b); 1 a 76\% (SHEATH \& COLE, 1996); 0 a 75\% (SHEATH \& MÜLLER, 1997); 0 a 70\% (NECCHI et al., 2000); 0 a 60\% (NECCHI et al., 2003); 0 a 35\% (NECCHI et al., 2008); 0 a 35\% (KRUPEK et al., 2007); 0 a 23,1\% (BRANCO et al., 2009). Notou-se também que a abundância média no presente estudo $(1,8 \%)$ apresentou valor muito baixo se comparada a muitos destes trabalhos: Sheath \& Cole, $1992(15,0 \%)$; Necchi et al., 1994 (52,0\%); Vis et al., 1994 (27,0\%) Branco \& Necchi, 1996b (15,5\%); Necchi et al., 2000 (15,0\%); Necchi et al., 2003 (13,0\%); Kuprek et al., 2007 (5,0\%); Necchi et al., 2008 (14,0\%); Branco et al., 2009 (5,7\%).

As correlações das variáveis biológicas com condutividade e $\mathrm{pH}$, encontradas no presente estudo, já foram reportadas em trabalhos anteriores com macroalgas lóticas: Sheath \& Burkholder (1985), Sheath et al. (1989), Biggs (1990), Sheath \& Cole (1992), Necchi et al. (1994, 1995). Apesar destas variáveis mostrarem-se relacionadas às variáveis biológicas, o principal fator que determinou, tanto a riqueza quanto a abundância de espécies neste trabalho, foi o substrato e aparentemente o sombreamento. O substrato já foi reportado em outros estudos como uma variável que afeta diretamente a comunidade de macroalgas lóticas (BIGGS, 1990; GORDON et al., 1992; NECCHI et al., 1994, 2003; BRANCO et al., 2009). Muitos estudos tem relacionado o substrato rochoso como favorável às comunidades de macroalgas lóticas (STOCK \& WARD, 1991; NECCHI \& MOREIRA, 1995; NECCHI et al., 2004), pois estas fixam-se a este substrato através de rizóides ou estruturas filamentosas (BURKHOLDER, 1996). Por outro lado, o substrato arenoso, que foi predominante no presente estudo, tem sido apontado como desfavorável à colonização e permanência destas macroalgas no ambiente (BRANCO et al., 2009). Sheath \& Müller (1997) também atribuiram a baixa diversidade e abundância de macroalgas ao predomínio de substrato instável. O processo de sedimentação, que inclui a deposição de areia no fundo do riacho, prejudica a fixação destes organismos, além de dificultar a entrada de luz para a realização de fotossíntese (SHEATH \& HAMBROOK, 1990). 
Sabe-se que a vegetação marginal de um riacho limita substancialmente a entrada de luz no corpo d'água (TRISKA et al., 1983; STANFORD, 1998), e pelo fato de o estudo ter sido feito em fragmentos florestais, a maioria dos segmentos de riachos foi sombreado (53\%), o que pareceu ter afetado negativamente as comunidades de macroalgas. A vegetação marginal é responsável por uma seleção dos comprimentos de onda que atingem o corpo d'água, o que reduz especialmente a incidência na faixa do vermelho e do azul (EVANS, 1966). Este fator sugere melhor adaptação do grupo das Cyanophyta em relação às Cholorophyta, grupos mais abundantes, nos ambientes sombreados (SHEATH \& BURKHOLDER, 1985; BRANCO \& NECCHI, 1998). Sabese também que Chlorophyta é um grupo bem adaptado a ambientes com maior disponibilidade de radiação (SHEATH \& BURKHOLDER, 1985; NECCHI, 2004), o que pode explicar a maior proporção destes organismos nos riachos parcialmente sombreados em relação aos sombreados.

Alguns trabalhos já relataram a radiação como fator relacionado à distribuição de macroalgas (SHEATH \& BURKHOLDER, 1985; BRANCO \& NECCHI, 1996b; VERB \& VIS, 2001; BRANCO et al., 2009). Neste estudo, o único trecho amostrado que apresentou elevada irradiância (aberto), foi também o único com a presença de matacão e seixo como substrato predominante (juntos representando 61\%) (G8-R2). Este ponto foi justamente aquele com maior abundância de macroalgas $(9,8 \%)$, o que também pode representar um indício da interferência destas variáveis na comunidade.

A correlação positiva entre riqueza e abundância de espécies, de forma geral, indica que as comunidades mais abundantes são aquelas com o maior número de espécies, o que caracteriza um padrão de distribuição em mosaico. Este padrão tem sido frequentemente evidenciado para macroalgas lóticas em estudos na América (SHEATH et al., 1986, 1989; SHEATH \& MÜLLER, 1997), sendo muitos destes realizados no Brasil (NECCHI et al., 1995; BORGES \& NECCHI, 1996; BRANCO \& NECCHI, 1996b, 1998; NECCHI et al., 2000, 2003; KRUPEK et al., 2007; NECCHI et al., 2008; BRANCO et al., 2009).

Ainda em relação à distribuição das espécies, notou-se também que a maioria (69\%) foi exclusiva de um único ponto de amostragem. Este padrão de ocorrência restrita tem sido comumente reportado em estudos com macroalgas lóticas. Sheath \& Burkholder (1985) e Sheath et al. (1986, 1989), em trabalhos realizados em diferentes biomas da América do Norte, encontraram 44\%, 55\% e 45\% dos táxons, respectivamente, em no máximo 5\% dos pontos de a amostragem. Em estudos feitos no 
Brasil, Necchi et al. (1994) encontraram $47 \%$ das macroalgas em menos de $10 \%$ dos pontos e Necchi et al. (1995) registraram 55\% dos táxons em menos de 5\% dos pontos. Branco \& Necchi (1996b) e Branco et al.(1999, 2009) também registaram 49\%, 65\% e $52 \%$ das espécies de macroalgas, respectivamente, em apenas um único ponto de amostragem.

Entre os pontos amostrados que tiveram a ocorrência de mais de um táxon, quatro (67\%) apresentaram uma grande dominância quantitativa por apenas uma espécie (72-92\% da abundância total do ponto) em relação às outras, e em um ponto (16\%) houve dominância por duas espécies (somando 95\% da abundância total do ponto), totalizando, portanto, $83 \%$ destes pontos apresentando forte dominância quantitativa por poucas espécies, o que caracteriza o padrão de pré-ocupação de nicho, no qual uma ou poucas espécies ocupam maior parte dos recursos, no caso substrato, e as outras competem pelos recursos restantes (BORGES \& NECCHI, 2006).

Muitos estudos ecológicos ressaltam a fragmentação de hábitats como a maior ameaça para a manutenção da biodiversidade e apontam o tamanho da área de estudo como proporcional a sua diversidade biológica (SCHOENER, 1976; PRIMACK \& RODRIGUES, 2001; KRAUSS et al., 2004; CAGNOLO et al., 2006). Um dos fatores considerados responsáveis por esta relação (espécies/área) é a maior heterogeneidade de hábitats encontrada em áreas maiores (KOHN \& WALSH, 1994; ROSENZWEIG, 1995; KOCHY \& RYDIN, 1997). De acordo com a Teoria da Biogeografia de Ilhas (riachos isolados) (MACARTUR \& WILSON, 1967), os efeitos do tamanho da área podem resultar em altas taxas de extinção em hábitats pequenos, assim como uma reduzida capacidade de migração. No entanto, no atual trabalho, realizado dentro de fragmentos florestais, não houve diferenças na riqueza, abundância e/ou diversidade das comunidades de macroalgas entre fragmentos de diferentes tamanhos. Este fato sugere que fatores intrínsecos de cada corpo d'água atuem mais intensamente sobre as comunidades destes organismos.

A predominância do substrato areno-argiloso e possivelmente o elevado grau de sombreamento dos riachos foram os principais fatores responsáveis pela baixa riqueza e abundância das macroalgas amostradas. Tais condições caracterizam o ambiente como um ambiente severo para estas comunidades, o que pode explicar o fato de poucas espécies estarem aptas a colonizarem e crescerem nestes ambientes. Todas estas características condizem com a Hipótese do Distúrbio Intermediário (CONNEL, 1978), que prevê que a diversidade será maior em ambientes com níveis intermediários de 
distúrbios, sendo que em ambientes com distúrbios pouco frequentes ou de baixa intensidade, as espécies mais competitivas tendem a dominar e eliminar as espécies restantes. Em contrapartida, em situações de freqüência e intensidade elevada de distúrbios, como parece ser o caso do ambiente amostrado, muitas espécies tendem a não tolerar tal condição e acabam por extinguir-se do local (COLLINS \& GLENN, 1997). Sob um nível moderado de perturbação a comunidade se distribui em um mosaico de partes de hábitats, o que favorece uma maior diversidade de espécies (RICKLEFS, 2003).

O ambiente amostrado pareceu ter favorecido, portanto, a ocupação essencialmente de espécies tolerantes a distúrbios intensos (ambientes sombreados e substratos instável) e bem adaptadas às características locais e a elevada flutuação das condições físicas e químicas da água, típica de ambientes lóticos (SHEATH \& BURKHOLDER, 1985).

Diferentemente das características locais, parâmetros mais gerais dos fragmentos e da bacia de drenagem não influenciaram a distribuição da comunidade. Esse fato, aliado à ocorrência restrita das espécies, sugere que as variáveis locais, especialmente substrato, e ainda sombreamento, que é característico de riachos localizados em fragmentos florestais, são mais influentes na comunidade que parâmetros mais gerais relacionados ao fragmento, ordem de grandeza do riacho e sua respectiva bacia de drenagem. Estes dados condizem perfeitamente com o esperado no presente estudo.

Por outro lado, recomenda-se que mais estudos sejam feitos para se entender melhor a distribuição das comunidades de macroalgas lóticas em fragmentos florestais, tendo em vista que são praticamente inexistentes trabalhos com esta abordagem no mundo.

\section{Referências bibliográficas}

AKAIKE, H.. A new look at the statistical model identification. IEEE Transactions on Automatic Control, v.19, p. 716-723, 1974.

BIGGS, B. J. F. Periphyton communities and their enviroments in New Zealand rivers. New Zealand Journal of Marine and Freshwater Research, v. 24, p. 367-386, 1990.

BORGES, F. R.; NECCHI, O. Jr. Patterns of spatial distribution in macroalgal communities from tropical lotic ecosystems. Revista Brasileira de Botânica, v. 29, p. 669-680, 2006. 
BORGES, F. R.; NECCHI, O. Jr. Short-term successional dynamics of a macroalgal community in a stream from northwestern SãoPaulo State, Brazil. Acta Botanica Brasilica, v. 22, p. 453-463, 2008.

BRANCO, C. C. Z.; BRANCO, L. H. Z.; MOURA, M. O.; BERTUSSO, F. R. The succession dynamics of a macroalgal community after a flood disturbance in a tropical stream from São Paulo State, southeastern Brazil. Revista Brasileira de Botânica, v. 28, p. 267-275, 2005.

BRANCO, C. C. Z.; EMED, R. G.; NECCHI, O. Jr. Macroalgas de riachos da Floresta Nacional de Irati, região centro-sul do estado do Paraná, sul do Brasil. Acta Botanica Brasilica, v. 22, p. 437-51, 2008.

BRANCO, C. C. Z.; KRUPEK, A. R.; PERES, C. K. Distribution of Stream Macroalgal Communities from the Mid-Western Region of Paraná State, Southern Brazil: Importance of Local Scale Variation. Brazilian Archives of Biology and Technology, v. 52, p. 379-386, 2009.

BRANCO, C. C. Z.; NECCHI, O. Jr. Survey of stream macroalgae of eastern Atlantic rainforest of São Paulo State, southeastern Brazil. Archiv für Hydrobiologie, v. 112, p. 35-57, 1996a.

BRANCO, C. C. Z.; NECCHI, O Jr. Distribution of stream macroalgae in the eastern Atlantic rainforest of São Paulo State, southeastern Brazil. Hydrobiologia, v. 333, p. 139-150, 1996b.

BRANCO, L. H. Z.; NECCHI, O. Jr. Seasonality of macroalgae in three tropical drainage basins in São Paulo State, southeastern Brazil. Archiv für Hydrobiologie, v. 141, p. 75-91, 1997.

BRANCO, L. H. Z.; NECCHI, O. Jr. Distribution of stream macroalgae in three tropical drainage basins of southeastern Brazil. Archiv für Hydrobiologie, v.142, p. 241-256, 1998.

BRANCO, L. H. Z.; NECCHI, O. Jr.; .BRANCO, C. C. Z. Ecological distribution of Cyanophyceae in lotic ecosystems of São Paulo State. Revista Brasileira de Botânica, v. 24, p. 99-108, 2001.

BRANCO, C. C. Z.; NECCHI, O. Jr.; BRANCO, L. H. Z. Taxonomy and ecological distribution of Chaetophoraceae (Chaetophorales, Chlorophyta) in lotic ecosystems from São Paulo State, southeastern Brazil. Algological Studies, v. 106, p. 43-75, 2002.

BRANCO, L. H. Z., PEREIRA, J. L. Evaluation of seasonal dynamics and bioindication potential of macroalgal communities in a polluted tropical stream. Archiv für Hydrobiologie, v. 155, p. 147-161, 2002.

BURKHOLDER, J. M. Interactions of benthic algae with their substrata. In: STEVENSON, R. J., BOTHWELL, M. L.; LOWE, R. L. (eds.), Algal Ecology: Freshwater Benthic Ecosystems. San Diego: Academic Press, p. 3-30, 1996. 
CAGNOLO, L.; CABIDO, M.; VALLADARES, G. Plant species richness in the Chaco Serrano Woodland from central Argentina: Ecological traits and habitat fragmentation effects. Biological Conservation, v. 132, p. 510-519, 2006

CLARKE, K. R.; WARWICK, R. M.. A further biodiversity index applicable to species lists: variation in taxonomic distinctness. Marine Ecology Progress Series, v. 216, p. 265-278, 2001.

CONNELL, J. H. Diversity in tropical rain forests and coral reefs. Science, v.199, p. 1302-1310, 1978.

COLLINS, S. L.; GLENN, S. M. Intermediate disturbance and its relationship to within-and between-patch structure. New Zealand Journal of Ecology, v. 21, p.103$110,1997$.

DeNICOLA, D. M.; HOGLAND, K. D.; ROEMER, S. C. Influence of canopy cover on spectral irradiance and periphyton assemblages in a prairie stream. Journal of the North American Benthological Society, v.11, p. 391-404, 1992.

DeNICOLA, D. M. Periphyton responses to temperature at different ecological levels. In: STEVENSON, R. J.; BOTHWELL, M. L.; LOWE, R. L. (eds): Algal ecology freshwaterbenthic ecosystems. San Diego: Academic Press. p. 150-181, 1996.

DIGBY, P. G. N.; KEMPTON. R. A. Multivariate analysis of ecological communities. London: Chapman and Hall, 1987. 205p.

ENTWISLE, T. J. Macroalgae in Yarra River basin: flora and distribution. Proceedings of the Royal Society of Victoria, v. 101, p. 1-76, 1989.

ENTWISLE, T. J. Macroalgae in the upper Yarra and Watts River catchments: Distribution and Phenology. Australian Journal of Marine and Freshwater Research, v. 41, p. 505-522, 1990.

EVANS, G. C. Model and measurement in the study of woodland light climates. In: BAINBRIDGE, R.; EVANS, G. C.; RACKMAN, O. (Eds). Light as an Ecological Factor. Oxford: Blackwell Scientific Publishers, p. 53-76, 1966.

GORDON, N. D.; McMAHON, T. A.; FINLAYSON, B. L. Stream hydrology, an introduction for ecologists. Chichester: John Wiley \& Sons, 1992. $526 \mathrm{p}$

HU, B. F.; XIE, S. L. Effect of seasonality on distribution of macroalgae in a streamsystem (Xin`an Spring) in Shanxi Province, North China. Journal of Integrative Plant Biology, v. 48, p. 889- 896, 2006.

JOHN, D. M.; MOORE, J. A. Observation on phytobenthos of freshwater Thames I. The environment, floristic composition and distribution of macrophytes (principally macroalgae). Archiv für Hydrobiologie, v.102, p. 435-459, 1985.

KOHN, D. D., WALSH, D. M. Plant species richness: the effect of island size and habitat diversity. Journal of Ecology, v.82, p. 367-377, 1994. 
KOCHY, M.; RYDIN, H. Biogeography of vascular plants on habitat islands, peninsulas and main lands in an east-central Swedish agricultural landscape. Nordic Journal of Botany, v. 17, p. 215-223, 1997.

KRAUSS, J.; KLEIN, A.; STEFFAN-DEWENTER, I.; TSCHARNTKE, T. Effects of habitat area, isolation, and landscape diversity on plant species richness of calcareous grasslands. Biodiversity and Conservation, v.13, p. 1427-1439, 2004.

KREBS, C. J. Ecological methodology. New York: Harper \& Row, 1989. 654 p.

KRUPEK, R. A.; BRANCO, C. C. Z.; PERES, C. K. Distribuição ecológica das comunidades de macroalgas da bacia de drenagem do rio das Pedras, região centro-sul do estado do Paraná, Sul do Brasil. Revista Brasileira de Botânica, v. 30, p.173-182, 2007.

LAMBERTI, G.A. The role of periphyton in benthic food webs. In: STEVENSON, R.J.; BOTHWELL, M.; LOWE, R.L. (eds.). Algal Ecology: freshwater benthic ecossystems. San Diego: Academic Press, p. 533-564, 1996.

LOMOLINO, M. V.; PERAULT, D. R. Island biogeography and landscape ecology of mammals inhabiting fragmented, temperate rain forests. Global Ecology and Biogeography, v. 10, p. 113-132, 2001.

MACARTHUR, R.H.; WILSON, E.O. The theory of Island Biogeography. Princeton: Princeton University Press, 1967. 224 p.

MAGURRAN, A.E. Ecological diversity and its measurement. New Jersey: Princeton University Press, 1988. 179 p.

NECCHI, O. Jr. Distribution and seasonal dynamics of Rhodophyta in the Preto River basin, southeastern Brazil. Hydrobiologia, v. 250, p. 81-90, 1993.

NECCHI, O. Jr. Amostragem de algas bentônicas. In: BICUDO, C.E.M.; BICUDO, D. C. (eds). Amostragem em limnologia. São Carlos: Ed. RIMA, p.167-177, 2004.

NECCHI, O. Jr.; BRAGA, M. R. A. J.; MOULTON, T. P. Survey and distribution of Rhodophyta from Cardoso Island, Sao Paulo State, Southeastern Brazil. Algological Studies, v. 88, p. 111-124, 1988.

NECCHI, O. Jr.; BRANCO, C. C. Z.; BRANCO, L. H. Z. Distribution of Rhodophyta in streams from São Paulo State, southeastern Brazil. Archiv für Hydrobiologie, v. 147, p. 73-89, 1999.

NECCHI O. Jr.; BRANCO, C. C. Z.; BRANCO, L. H. Z. Distribution of stream macroalgae in São Paulo State, Southeastern Brazil. Algological Studies, v. 97, p. 43$57,2000$.

NECCHI, O. Jr.; BRANCO, C. C. Z.; SIMÕES, R. C. G.; BRANCO, L. H. Z. Distribution of stream macroalgae in northwest region of São Paulo State, southeastern Brazil. Hydrobiologia, v. 299, p. 219-230, 1995. 
NECCHI, O. Jr.; BRANCO, L. H. Z.; BRANCO, C. C. Z. Ecological distribution of stream macroalgal communities from a drainage basin in the Serra da Canastra National Park, Minas Gerais, southeastern Brazil. Brazilian Journal of Biology, v. 63, p. 635646, 2003.

NECCHI, O. Jr.; BRANCO, L. H. Z.; DIP, M. R. Uso de macroalgas para avaliação da poluição orgânica no Rio Preto, noroeste do estado de São Paulo. Anais da Academia Brasileira de Ciências, v. 66, p. 359-371, 1994.

NECCHI, O. Jr.; BRANCO, L. H. Z.; SPEZAMIGLIO, D. N. Ecological distribution of stream macroalgal communities from " Parque Nacional de Itatiaia", states of Minas Gerais and Rio de Janeiro, Brazil. Revista Brasileira de Botânica, v. 31, p. 135-145, 2008.

NECCHI, O. Jr.; DIP, M. R.; GÓES, R. M. Macroalgae of a stream in southeastern Brazil: composition, seasonal variation and relation to physical and chemical variables. Hydrobiologia, v. 213, p. 241-250, 1991.

NECCHI, O. Jr.; MOREIRA, J. C. L. Longitudinal distribution of macroalgae in two tropical lotic ecosystems from southeastern Brazil. Archiv für Hydrobiologie, v. 135, p. 113-128, 1995.

NECCHI, O. Jr.; PASCOALOTO, D. Seasonal dynamics of macroalgal communities in the Preto River basin, São Paulo, southeastern Brazil. Archiv für Hydrobiologie, v. 129, p. 231-252, 1993.

NECCHI O. Jr.; PASCOALOTO, D.; BRANCO, C. C. Z.; BRANCO, L. H. Z. Stream macroalgal flora from the northwest region of São Paulo State, Southeastern Brazil. Algological Studies, v. 84, p. 91-112, 1997.

NECCHI, O. Jr., SPEZAMIGLIO, D. N., BRANCO, C. C. Z., BRANCO, L. H. Z. Estudo taxonômico e distribuição ecológica do gênero Vaucheria (Xanthophyta, Vaucheriaceae) em ecossistemas lóticos do estado de São Paulo, Brasil. Hoehnea, v. 28, p. 231-242, 2001.

NECCHI, O. Jr.; SPEZAMIGLIO, D. N.; BRANCO, C. C. Z.; BRANCO, L. H. Z. Taxonomy and ecological distribution of the genus Microspora (Microsporaceae, Chlorophyta) in lotic ecosystems of São Paulo State, Southeastern Brazil. Algological Studies, v. 105, p. 39-50, 2002.

PFISTER, P. Seasonality of macroalgal distribution pattern whitin the reach of a gravel stream (Isar, Tyrol, Austria). Archiv für Hydrobiologie, v. 129, p. 89-107, 1993.

PIELOU, E. C. The interpretation of Ecological Data: A primer on classification and ordination. New York: Wiley, 1984. 263 p.

PRIMACK, R. B. \& RODRIGUES, E. Biologia da conservação. Londrina: Vida, 2001. $328 \mathrm{p}$. 
PROBIO. Áreas de domínio do cerrado no estado de São Paulo. São Paulo: Imprensa Oficial, Secretaria do Meio Ambiente de São Paulo, 1998. 84 p.

RANGEL, T. F. L. V. B.; DINIZ-FILHO, J. A. F.; BINI, L. M. Towards an integrated computational tool for spatial analysis in macroecology and biogeography. Global Ecology and Biogeography, v. 15, p. 321-327, 2006.

REITER, M. A.; CARLSON, R. E. Current velocity in streams and the composition of benthic algal mats. Canadian Journal of Fisheries and Aquatic Sciences, v. 43, p. 1156-1162, 1986.

RICKLEFS, R.; SCHLUTER, D. Species diversity in ecological communities. Chicago: University of Chicago Press, 1993. 414 p.

ROSEENZWEIG, M. L. Species diversity in space and time. Cambridge: Cambridge University Press, 1995. 458 p.

SHEATH, R. G.; BURKHOLDER, J. Characteristics of softwater streams in Rhode Island. II: Composition and seasonal dynamics of macroalgae communities. Hydrobiologia, v. 128, p. 109-118, 1985.

SHEATH, R. G.; COLE, K. M. Biogeography of stream macroalgae in North America. Journal of Phycology, v. 28, p. 448-460, 1992.

SHEATH, R. G.; COLE, K. M. Stream macroalgae of the Fiji Islands: A preliminary study. Pacific Science, v. 50, p. 46-54, 1996.

SHEATH, R. G.; HAMBROOK, J. A. Freshwater ecology. In: COLE, K. M.; SHEATH, R. G. (eds.). Biology of red algae, p. 423-453, 1990.

SHEATH, R. G.; HAMILTON, P. B.; HAMBROOK, J. A.; COLE, K. M. Stream macroalgae of the eastern boreal forest region of North America. Canadian Journal of Botany, v. 67, p. 3353-3362, 1989.

SHEATH, R. G.; MORINSON, M. O.; KORSH, J. E.; KACZMARCZYK, D.; COLE, K. M. Distribution of stream macroalgae in south-central Alaska. Hydrobiologia, v. 135, p. 259-269, 1986.

SHEATH, R. G.; MÜLLER, K. M. Distribution of stream macroalgae in four high arctic drainage basins. Arctic, v. 50, p. 355-364, 1997.

SHEATH, R.G.; VIS, M. L.; HAMBROOK, J. A.; COLE, K. M. Tundra stream macroalgae of North America: composition, distribution and physiological adaptations. Hydrobiologia, v. 336, p. 67-82, 1996.

SCHOENER, T. W. The species-area relation within archipelagoes: models and evidence from island land birds. In: FIRTH, H.J.; CALABY, J.H. Proceedings of the XVI International Ornithological Congress. p. 629-642, 1976. 
STANFORD, J. A. Rivers in the landscape: introduction to the special issue on riparian and groundwater ecology. Freswater Biology, v. 40, p. 402-406, 1998.

STEINMAN, A. D.; McINTIRE, C. D. Effects of current velocity and light energy on the structure of periphyton assemblages in laboratory streams. Journal of. Phycology, v. 22, p. 352-361, 1986.

STEINMAN, A. D. McINTIRE, C. D.; GREGORY, S. V. L.; LAMBERTI, G. A. Effects of irradiance and grazing on lotic algal assemblages. Journal of. Phycology, v. 25, p. 478-485, 1989.

STEVENSON, R. J. An introduction to algal ecology in freshwater benthic habitats. In: STEVENSON, R. J.; BOTHWELL, M. L.; LOWE, L. (eds). Algal ecology: Freshwater benthic ecosystems. New York: Academic Press, p. 3-30, 1996.

STOCK, M.S.; WARD, A. K. Blue-green algal mats in a small stream. Journal of Phycology, v. 27, p. 692-698, 1991.

TRISKA, F. J.; KENNEDY, C. V.; AVANZINO, R. J.; REILLY, B. N. Effect of simulated canopy cover on regulation of nitrate uptake and primary production by natural periphyton communities. In: FONTAINE, T. D.; Bartell, S. M. (eds.). Dynamics of Lotic Ecosystems. Ann Arbor: Ann Arbor Scientific Publications, 1983. 494 p.

VERB, R. G.; VIS, M. L. Macroalgal communities from a acid mine drainage impacted watershed. Aquatic Botany, v. 71, p. 93-107, 2001.

VIEIRA J. Jr.; NECCHI O. Jr.; BRANCO, C. C. Z.; BRANCO, L. H. Z. Characeae (Chlorophyta) em ecossistemas lóticos do Estado de São Paulo, Brasil: gênero Nitella. Hoehnea, v. 29, p. 249-266, 2002.

VIEIRA, J. Jr.; NECCHI, O. Jr.; BRANCO, C. C. Z.; BRANCO, L. H. Z. Characeae (Chlorophyta) em ecossistemas lóticos do estado de São Paulo, Brasil: gênero Chara e distribuição ecológica. Hoehnea, v. 30, p. 53-70, 2003.

VIS, M. L.; SHEATH, R. G.; HAMBROOK, J. A.; COLE, K. M. Stream macroalgae of the Hawaiian islands: a preliminary study. Pacific Science, v. 48, p. 175-187, 1994.

WARWICK, R. M.; CLARKE, K. R. New 'biodiversity' measures reveal a decrease in taxonomic distinctness with increasing stress. Marine Ecology Progress Series, v. 129, p. 301-305, 1995.

WHITTON, B. A. Algae. In: WHITTON, B. A. (ed.). River ecology. Oxford: Blackwell Scientific Publishers, 1975. 725 p.

ZAR, J. H. Biostatistical Analysis, fourth edition. Upper Saddle River: Prentice Hall, 1999. 
苞

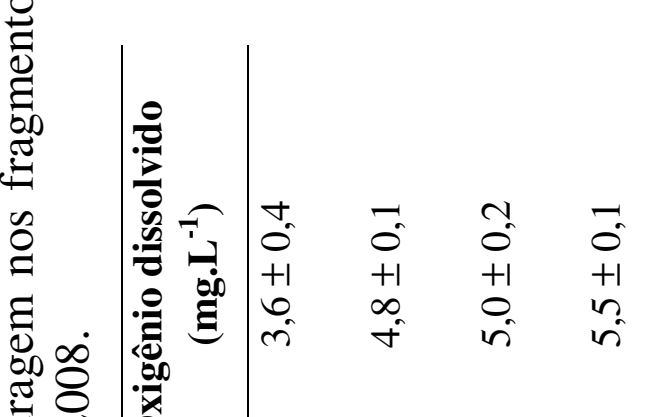

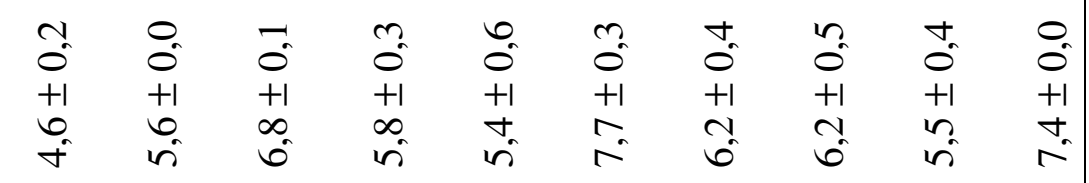
苋

隶

0

ฮิ

유

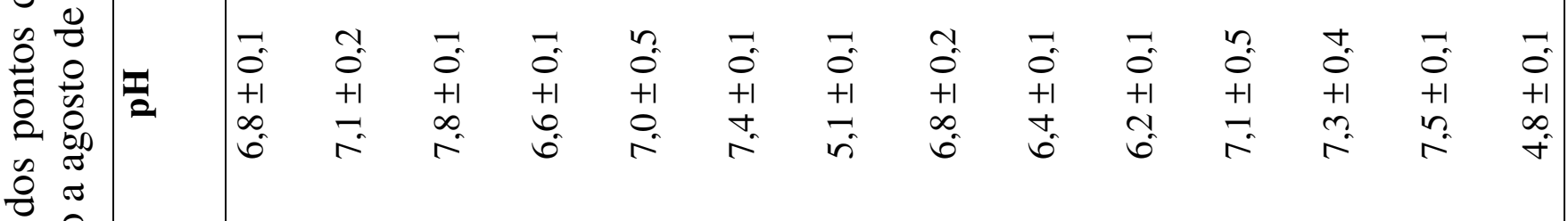

ส

琶

严

() 응

ฮี

总 $\begin{array}{cccc}n & n & 0 & 0 \\ n & 0 & 0 & 0 \\ +1 & +1 & +1 & +1\end{array}$

$\begin{array}{ccccccc}0 & 0 & 0 & 0 & \infty & 0 & 0 \\ 0 & 0 & 0 & i & 0 & 0 & 0 \\ +1 & +1 & +1 & +1 & +1 & +1 & +1\end{array}$

$\begin{array}{cccc}0 & 0 & 0 & \infty \\ 0 & i & 0 & i \\ +1 & +1 & +1 & +1\end{array}$

in

$\frac{\infty}{2} \frac{0}{2}$

菉

$>£$

สิ

กิI $\frac{0}{\sqrt{*}}$

ᄋิ

音

=

ఫ్ర

$\stackrel{0}{\circ} \frac{0}{2}$

बै

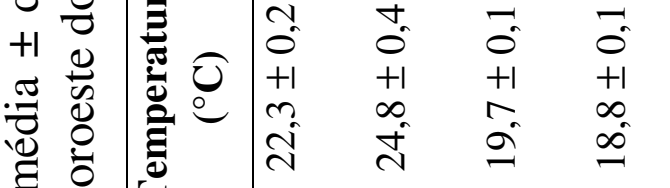

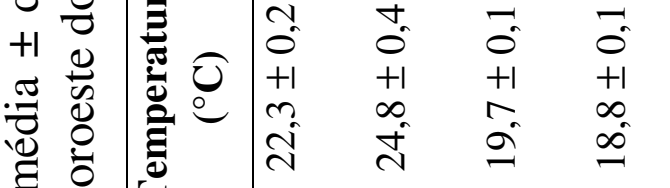

$\Xi \Xi$

옹

T⿱⺈

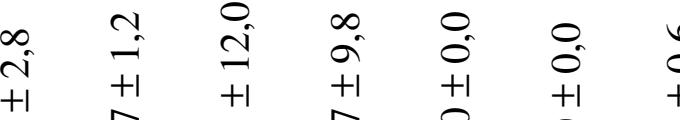

ते nं हैं

气̂

+1
0
0
0

an

0

in

0
0
+1
$m$

-

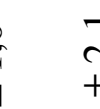

$\vec{a}+\bar{a}$

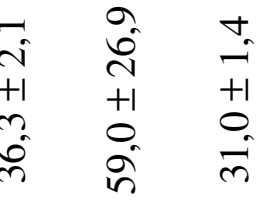

ชิ เి

을

$>\frac{\pi}{2}$

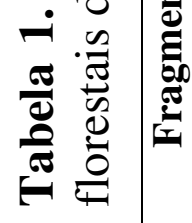

శิ

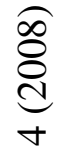

$\begin{array}{lllllll}-1 & 0 & n & \pi & n & \tilde{0}\end{array}$

$+1+$

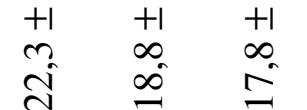

aे

กิ

în

+1
$n$
\pm

$\begin{array}{ccc}r & \overrightarrow{0} & \overrightarrow{0} \\ 0 & +1 & +1 \\ +1 & +1 & 0 \\ 0 & 0 & 0 \\ n & \tilde{0} & 0\end{array}$

$\sqrt[5]{2}$

\&

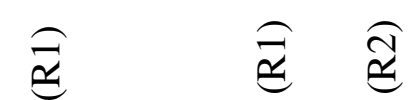

ฮู

$\frac{\widehat{\theta}}{0}$

$\widehat{\approx}$

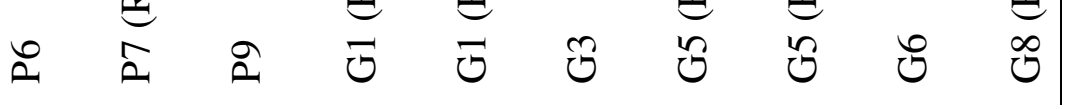


6

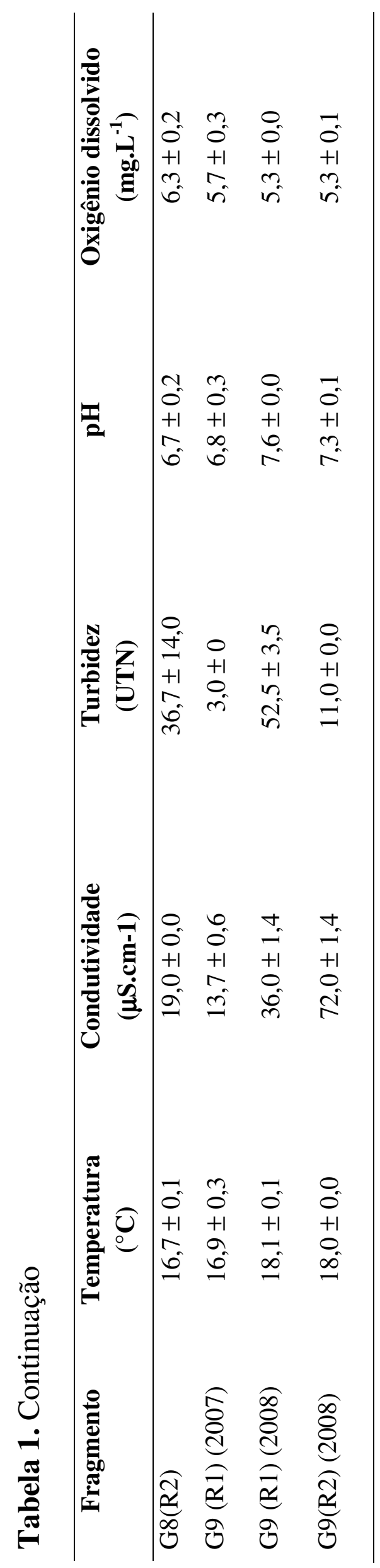


8

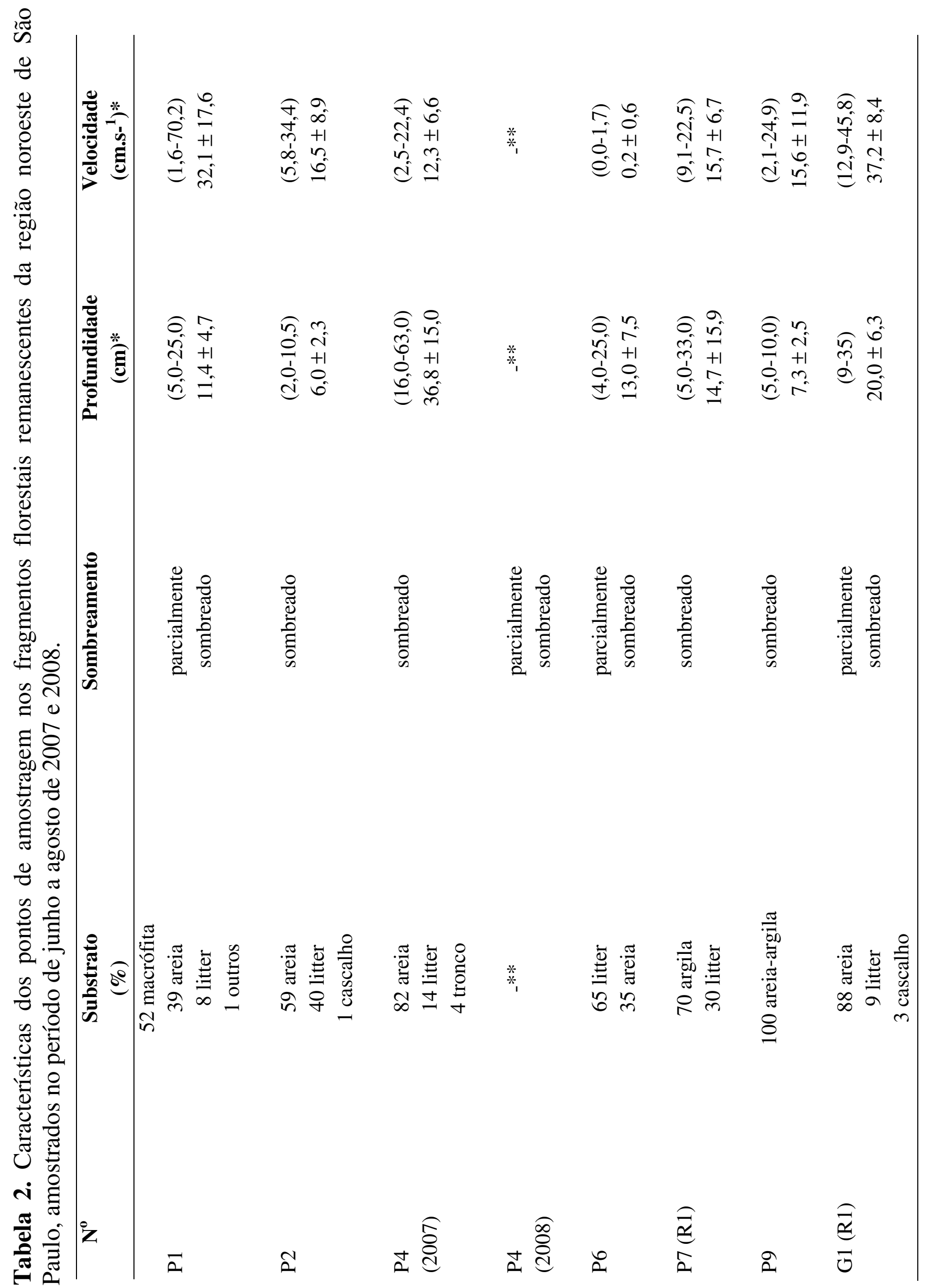


5

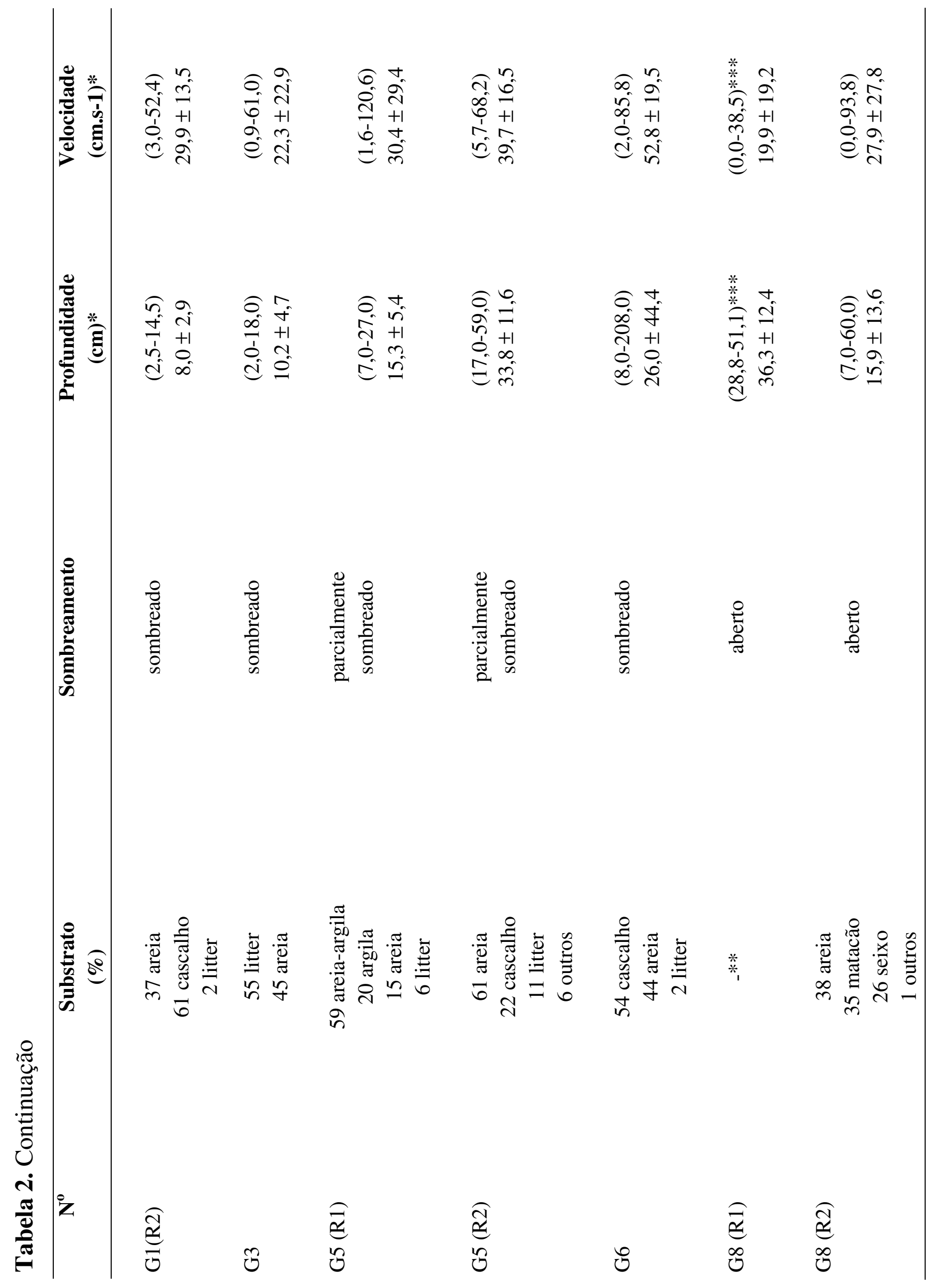


$\infty$

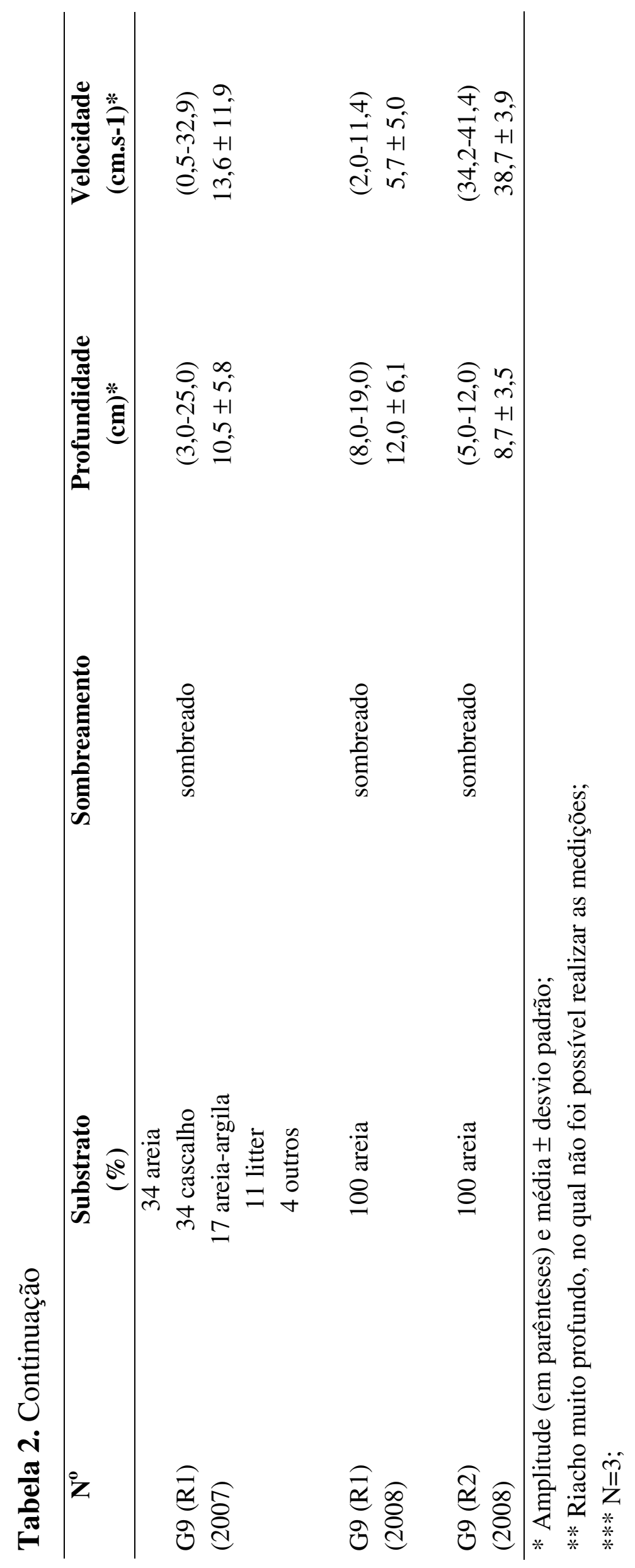




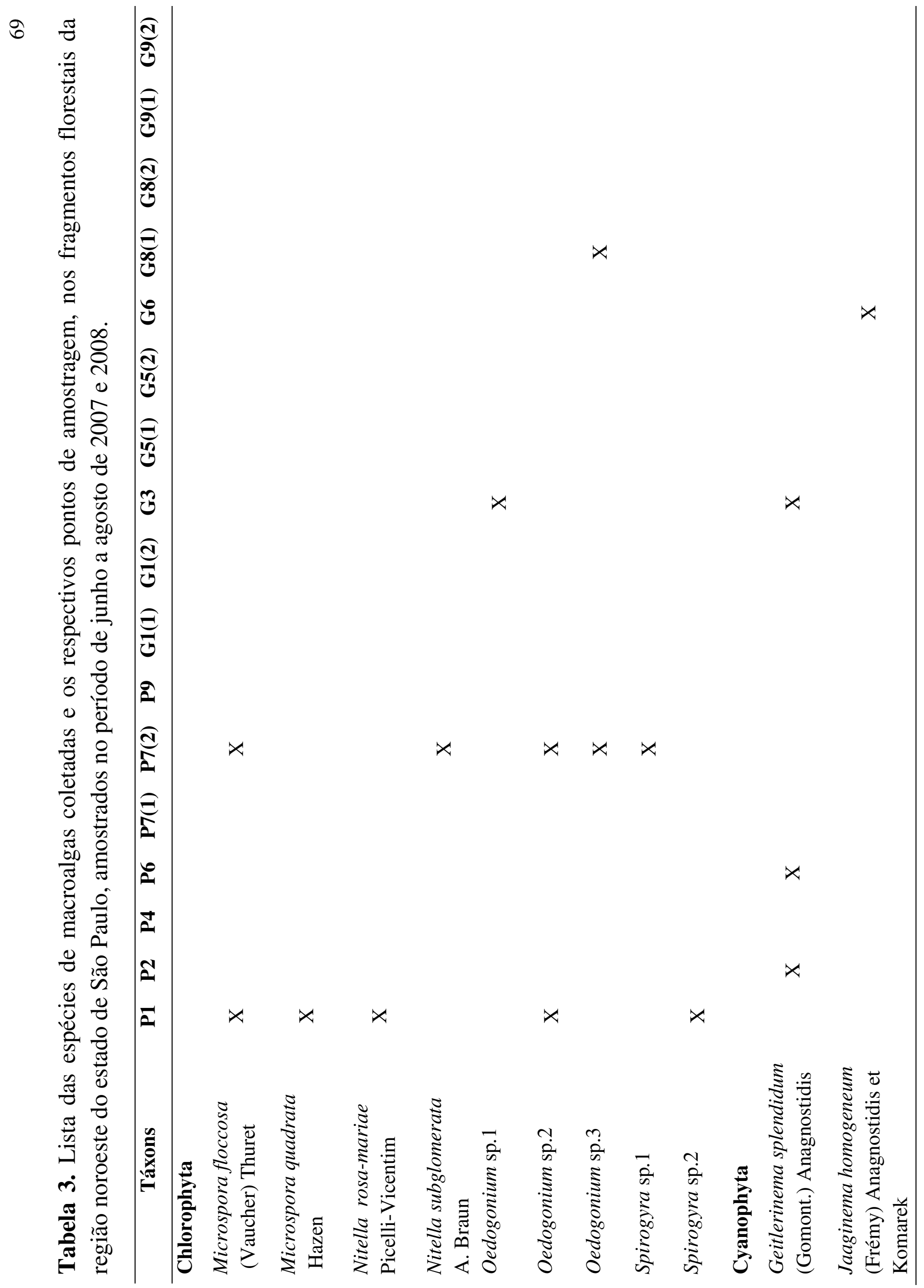




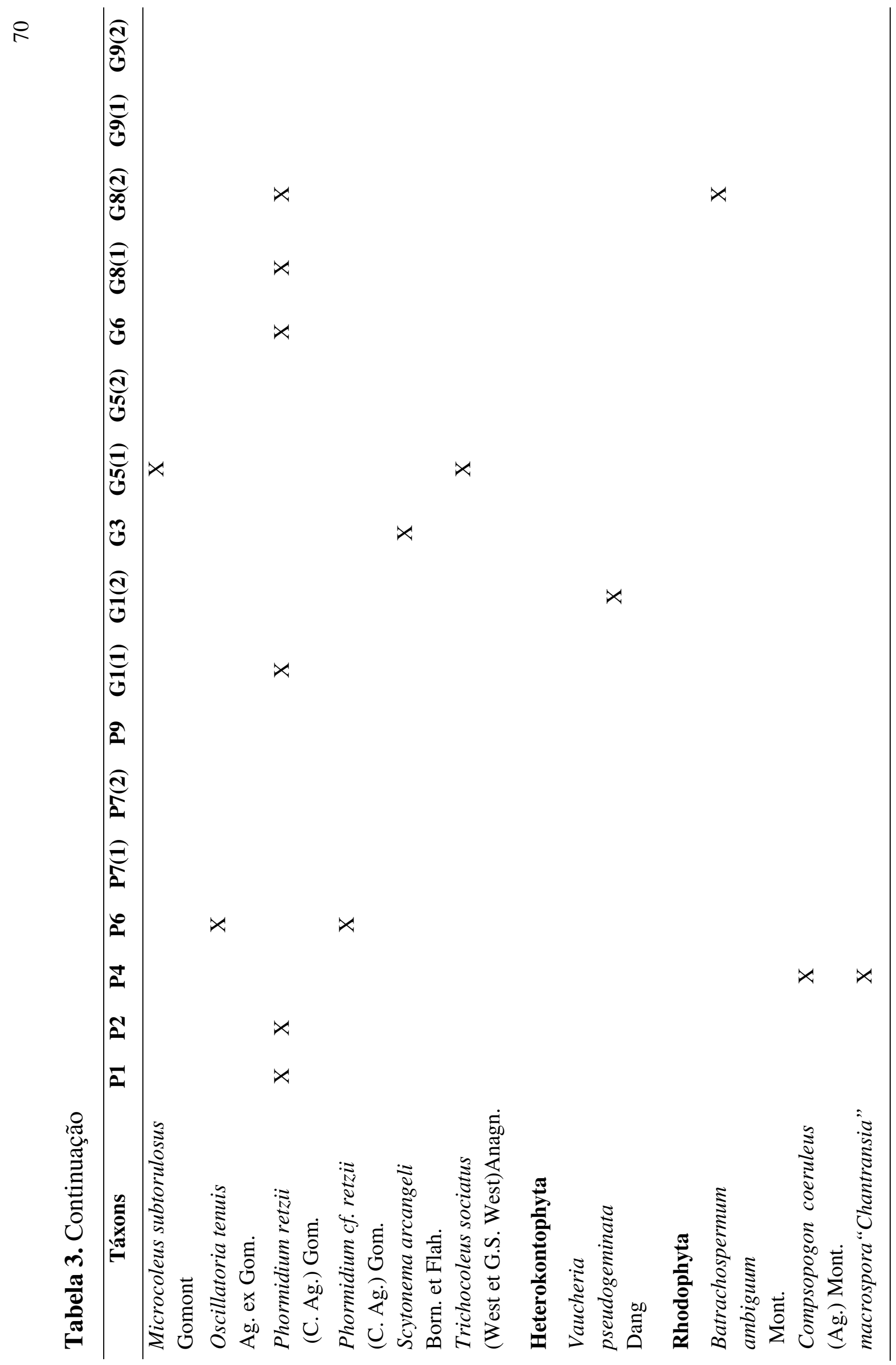




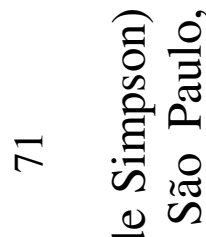

0
0
0
0
0
0
0
0
0
0
0
0
0
0
0
0
0
0
0
0
0
0
0
0
0
0
0
0
0
0
0
0
0
0
0
0
0
0
0
0
0
0
0
0
0
0
0
0
0
0
0
0
0

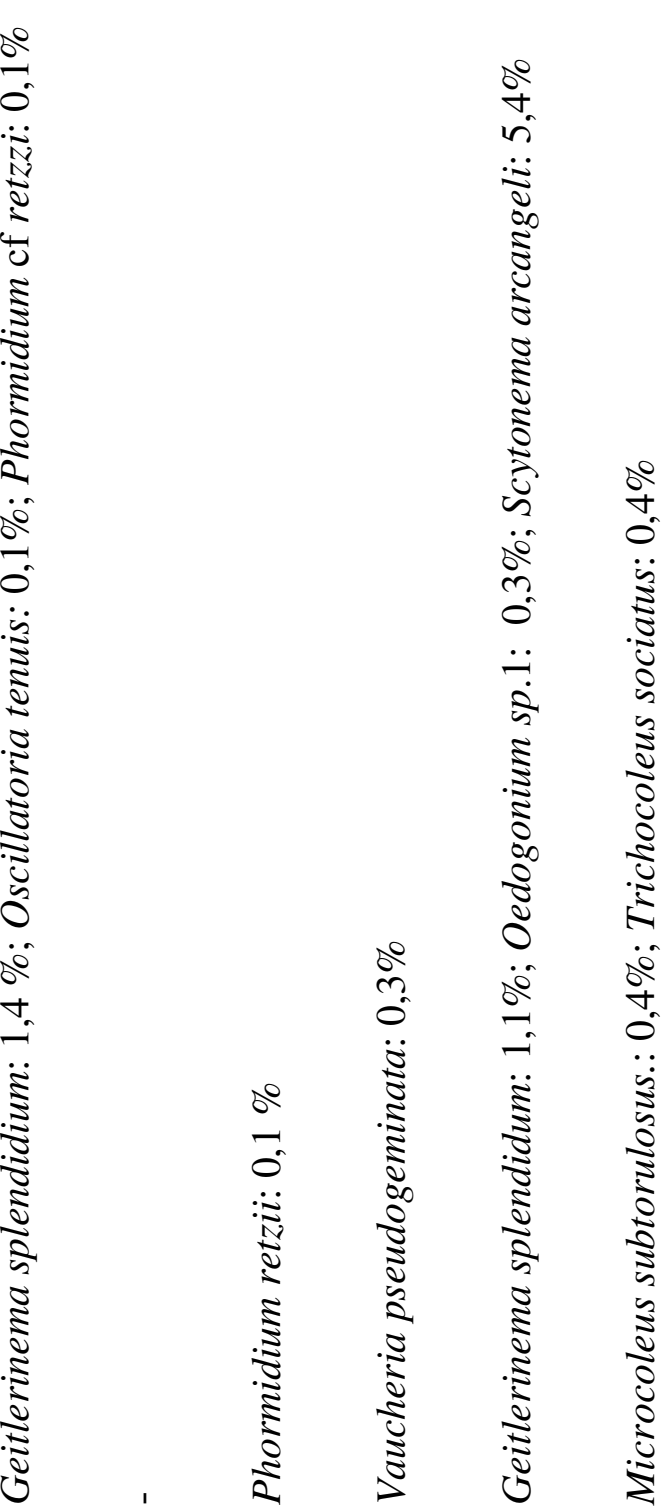

$\approx$ ช

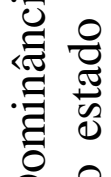

ค...

产

ก ?

0

胥

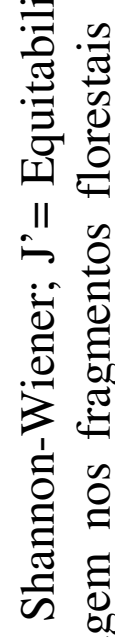

II

¿

吾的

ठ ซ 0

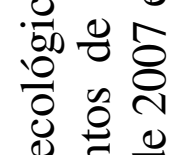

ช $\stackrel{0}{0}$

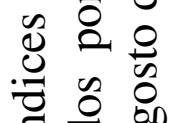

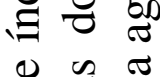

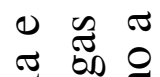

苞

突 它

ㅇำ

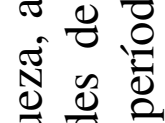

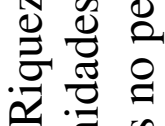

+

๘

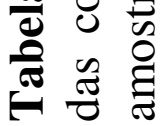

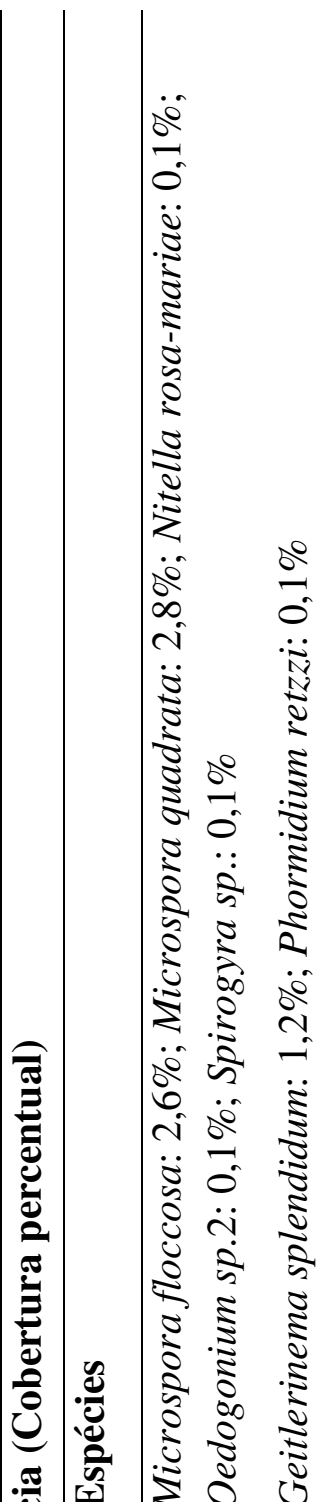


N

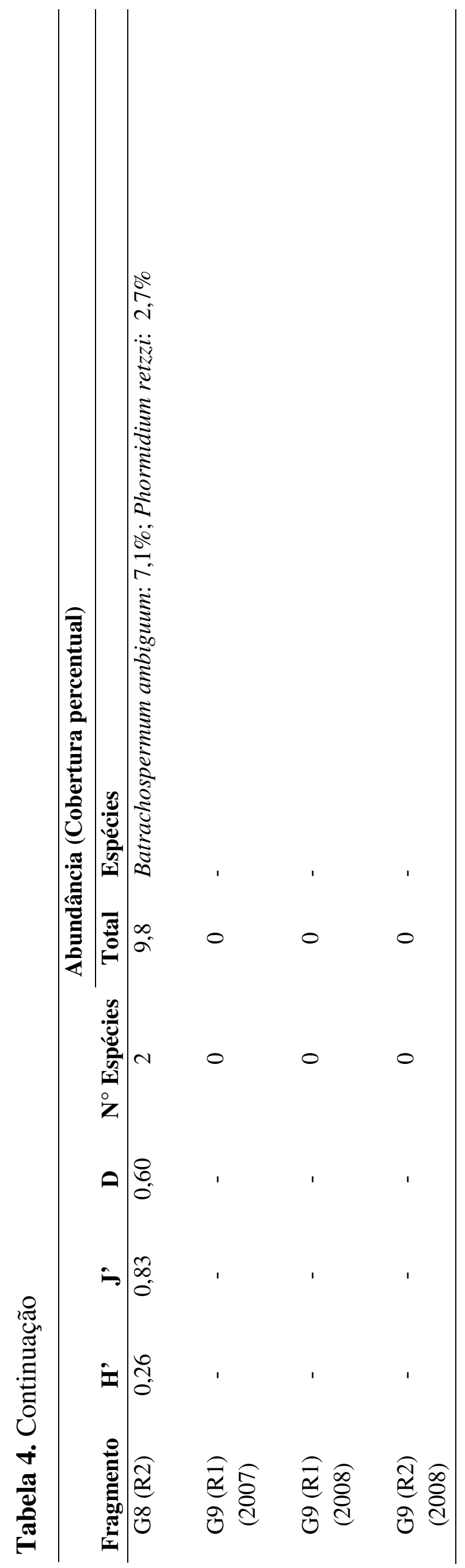


Tabela 5. Resultados da Análise dos Componentes Principais (ACP) incluindo variáveis (biológicas e ambientais) dos fragmentos florestais da região noroeste do estado de São Paulo, amostrados no período de junho a agosto de 2007 e 2008 e a correlação de cada variável com os dois primeiros eixos. Valores significativos estão grafados em negrito.

\begin{tabular}{lcc}
\hline Variáveis/Resultados & Eixo 1 & Eixo 2 \\
\hline Autovalores & 0,41 & 0,18 \\
Variação explicada (\%) & 42,6 & 18,6 \\
Variação cumulativa (\%) & 42,6 & 61,1 \\
Riqueza & 0,355 & 0,187 \\
Abundância (\%) & 0,295 & 0,230 \\
H' & 0,331 & 0,103 \\
Condutividade & $-0,314$ & 0,071 \\
Turbidez & $-0,115$ & $-0,191$ \\
Velocidade & $-0,151$ & $\mathbf{0 , 4 8 6}$ \\
Área & $\mathbf{- 0 , 4 4 0}$ & 0,084 \\
Areia-argila & $-0,237$ & $\mathbf{- 0 , 4 1 1}$ \\
Litter & $\mathbf{0 , 5 1 5}$ & $-0,086$ \\
Cascalho & $-0,166$ & $\mathbf{0 , 6 6 4}$ \\
\hline
\end{tabular}




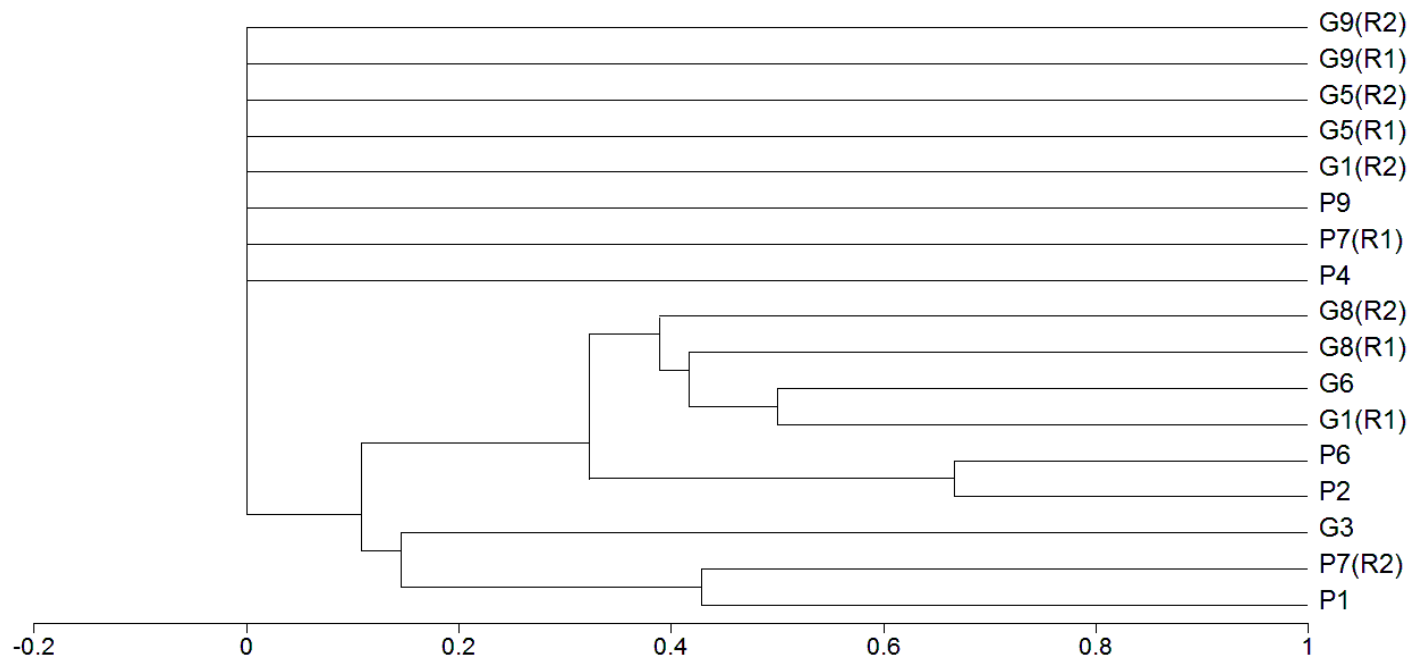

Figura 1. Dendrograma dos pontos de amostragem com base na presença/ausência de macroalgas (Jaccard) nos fragmentos florestais da região noroeste do estado de São Paulo, amostrados no período de junho a agosto de 2007 e 2008.

P6

P2

P1

Figura 2. Dendrograma dos pontos de amostragem com base na $\%$ de cobertura de macroalgas (Bray-curtis) nos fragmentos florestais da região noroeste do estado de São Paulo, amostrados no período de junho a agosto de 2007 e 2008. 


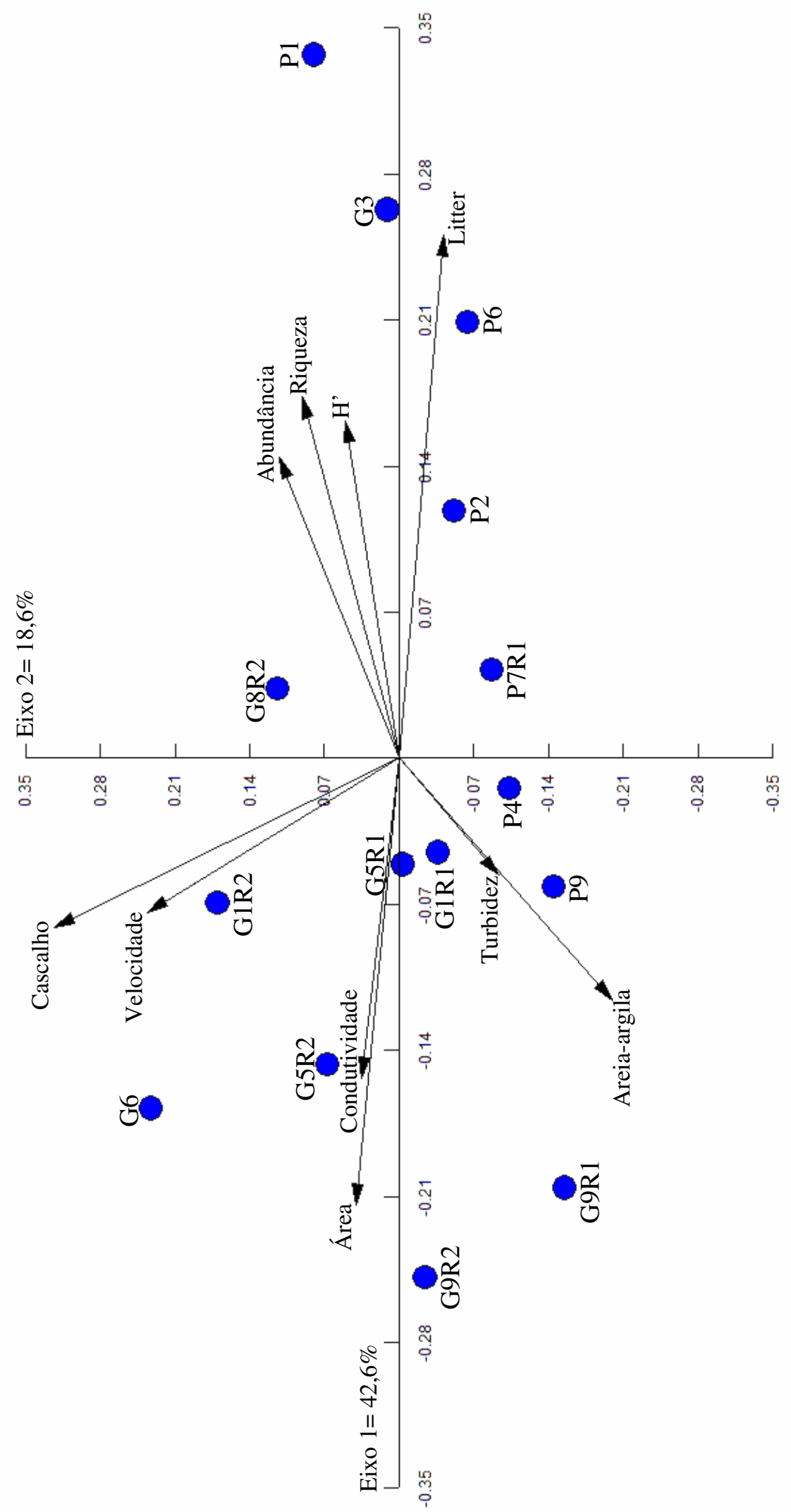

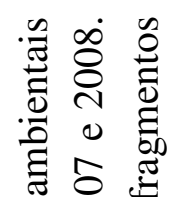

कू ते

突 ष

के 을

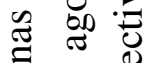

范

吉

$0 \%$

흐용

胥

की 20

宊

ษ :

苋 苛

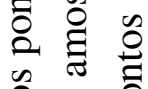

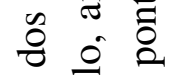

टि है

\零?

品 夆

离 胥

过 岂

苋造

言

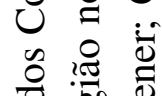

-

总

¿ 矛芯

은

茄 各 :

论

政

$\bar{\nabla} \Xi$

苛 है \&

๘.

ल

동

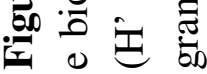




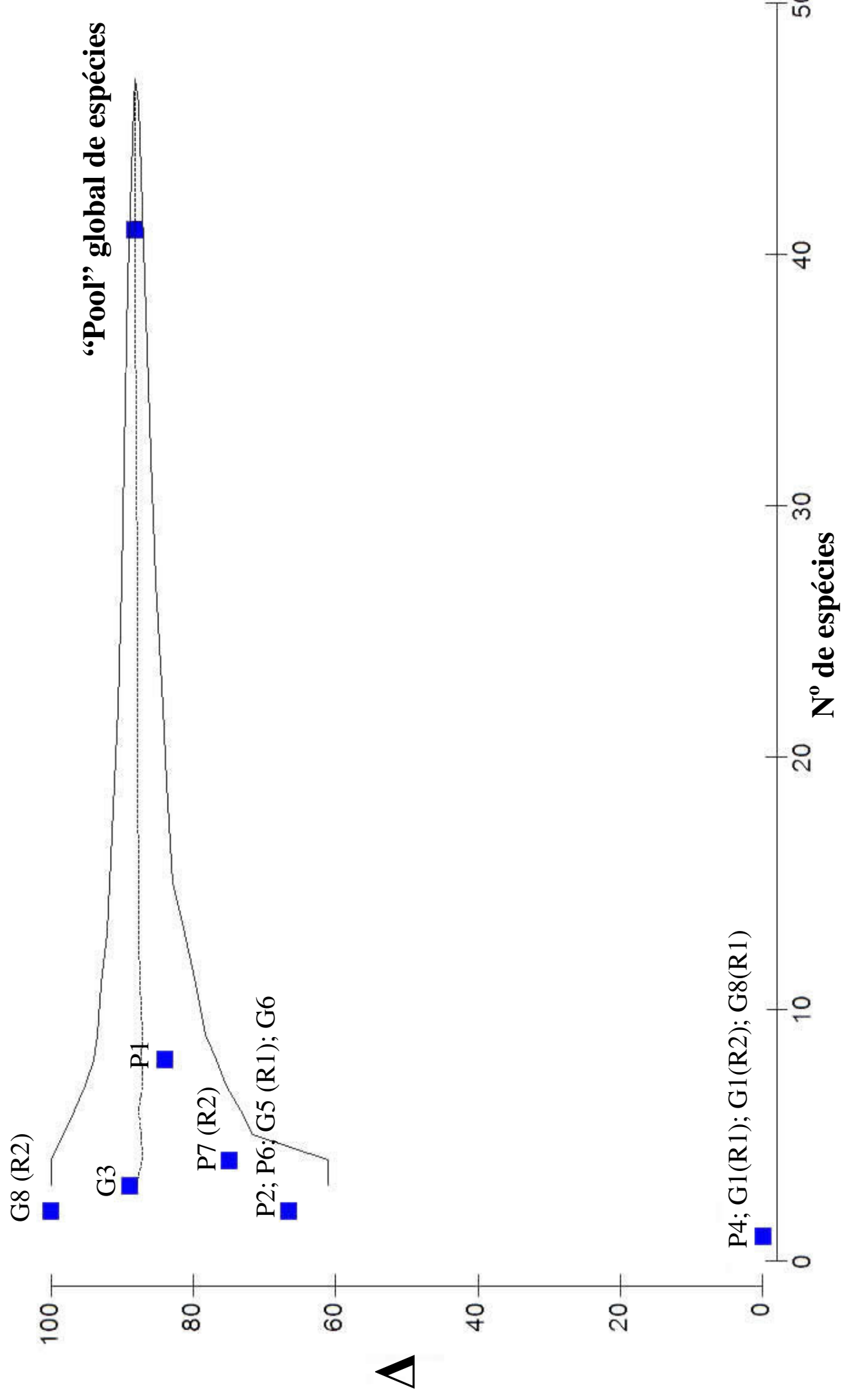

용 용

$\begin{array}{ll}0 & 0 \\ 0 & 0 \\ 0 & 0 \\ 0 & 0 \\ 0 & 0\end{array}$

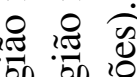

50

의 홍

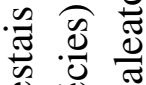

के क्षे

o 웡

항 용

क्ष

표

क

$\frac{\pi}{2}$

요

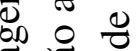

:

들

ช

卷

ㅇ น

\%

ชู

흐을

定

ส

을 울

要声

正

음

敋

สิ 


\section{CONSIDERAÇÕES FINAIS}




\section{Considerações finais}

A região noroeste do estado de São Paulo é provavelmente a região brasileira mais intensamente estudada sobre a flora e aspectos ecológicos de comunidades de macroalgas lóticas (NECCHI et al., 1991; NECCHI, 1993; NECCHI et al., 1994, 1995, 1997; BRANCO \& NECCHI, 1998; NECCHI et al., 2000). Entretanto, nunca foi realizado estudo sobre as comunidades de macroalgas lóticas em fragmentos florestais remanescentes da região, que é o aspecto mais relevante deste estudo. Phormidium retzii, que apresenta ampla distribuição mundial, e é considerada como a mais frequente em muitos estudos (SHEATH et al., 1986; SHEATH \& COLE, 1992; VIS et al., 1994; SHEATH \& COLE, 1996; BRANCO et al.,1999; NECCHI et al, 2000; KRUPEK et al., 2007), também foi a espécie com maior frequência no presente trabalho. Todas as espécies inventariadas já foram reportadas anteriormente na região noroeste, exceto Trichocoleus sociatus (Cyanophyta), que foi reportado pela primeira vez na região, e Vaucheria pseudogeminata (Heterokontophyta), que representa a primeira ocorrência no Brasil.

A correlação positiva encontrada entre riqueza e abundância de espécies, de forma geral, indica que as comunidades mais abundantes foram também aquelas com maior riqueza de espécies, o que caracteriza um padrão de distribuição em mosaico. Ainda em relação à distribuição das espécies, notou-se também que a maioria (69\%) foi exclusiva de um único ponto de amostragem. Tanto a distribuição em mosaico das comunidades de macroalgas (SHEATH et al., 1986, 1989; SHEATH \& MÜLLER, 1997; NECCHI et al., 1995; BRANCO \& NECCHI, 1996, 1998; NECCHI et al., 2000, 2003; KRUPEK et al., 2007; NECCHI et al., 2008; BRANCO et al., 2009), quanto o padrão de ocorrência restrita de espécies (SHEATH \& BURKHOLDER,1985; SHEATH et al., 1986, 1989; NECCHI et al.,1994, 1995; BRANCO \& NECCHI, 1996b; BRANCO et al.,1999, 2009) tem sido padrões consistentemente reportados para macroalgas lóticas.

A flora de macroalgas de fragmentos florestais remanescentes da região noroeste assemelhou-se mais a de Floresta Tropical, em comparação com outras regiões/biomas no estado e São Paulo (NECCHI et al., 2004). O estudo mostrou também que características locais, principalmente substrato (SHEATH \& HAMBROOK, 1990; STOCK \& WARD, 1991; NECCHI \& MOREIRA, 1995; SHEATH \& MÜLLER, 1997; NECCHI et al., 2004) e possivelmente sombreamento (SHEATH \& BURKHOLDER, 1985; BRANCO \& NECCHI, 1996b ; VERB \& VIS, 2001; BRANCO et al., 2009), atuaram de forma mais evidente sobre a comunidade das macroalgas, do que características mais gerais de cada fragmento, matriz 
adjacente, ordem de grandeza do riacho e sua respectiva bacia de drenagem. Ambas confirmam as hipóteses iniciais apresentadas no atual estudo.

Este trabalho, que integra o projeto temático "Fauna e flora de fragmentos florestais remanescentes do noroeste paulista: base para estudos de conservação da biodiversidade", dentro do programa BIOTA/FAPESP, Instituto Virtual da Biodiversidade (PROC. 04/048203), complementará e integrará base de dados importantes do ponto de vista da biodiversidade e dinâmica desses ecossistemas, fornecendo subsídios essenciais para estudos posteriores na área e iniciativas futuras visando à elaboração de estratégias para a conservação e manejo da área. Os resultados apontam, portanto, a necessidade de se preservar maior número de corpos d'água, levando em consideração suas características intrínsecas, especialmente a ocorrência de espécies exclusivas de cada corpo d'água. Recomenda-se que mais estudos sejam realizados para se entender melhor a distribuição das comunidades de macroalgas em fragmentos florestais, tendo em vista que são praticamente inexistentes trabalhos com esta abordagem no mundo.

\section{Referências Bibiográficas}

BRANCO, C. C. Z.; KRUPEK, A. R.; PERES, C. K. Distribution of Stream Macroalgal Communities from the Mid-Western Region of Paraná State, Southern Brazil: Importance of Local Scale Variation. Brazilian Archives of Biology and Technology, v. 52, p. 379-386, 2009.

BRANCO, C. C. Z.; NECCHI, O Jr. Distribution of stream macroalgae in the eastern Atlantic rainforest of São Paulo State, southeastern Brazil. Hydrobiologia, v. 333, p. 139$150,1996 b$.

BRANCO, L. H. Z.; NECCHI, O. Jr. Distribution of stream macroalgae in three tropical drainage basins of southeastern Brazil. Archiv für Hydrobiologie, v.142, p. 241-256, 1998.

BRANCO, L. H. Z.; NECCHI, O. Jr.; BRANCO, C. C. Z. Cyanophyceae from lotic ecosystems of São Paulo State, southeastern Brazil. Algological Studies, v. 94, p. 63-87, 1999.

KRUPEK, R. A.; BRANCO, C. C. Z.; PERES, C. K. Distribuição ecológica das comunidades de macroalgas da bacia de drenagem do rio das Pedras, região centro-sul do estado do Paraná, Sul do Brasil. Revista Brasileira de Botânica, v. 30, p.173-182, 2007.

NECCHI O. Jr.; BRANCO, C. C. Z.; BRANCO, L. H. Z. Distribution of stream macroalgae in São Paulo State, Southeastern Brazil. Algological Studies, v. 97, p. 43-57, 2000. 
NECCHI, O. Jr.; BRANCO, C. C. Z.; SIMÕES, R. C. G.; BRANCO, L. H. Z. Distribution of stream macroalgae in northwest region of São Paulo State, southeastern Brazil. Hydrobiologia, v. 299, p. 219-230, 1995.

NECCHI, O. Jr.; BRANCO, L. H. Z.; BRANCO, C. C. Z. Ecological distribution of stream macroalgal communities from a drainage basin in the Serra da Canastra National Park, Minas Gerais, southeastern Brazil. Brazilian Journal of Biology, v. 63, p. 635-646, 2003.

NECCHI, O. Jr.; BRANCO, L. H. Z.; PASCOALOTO, D., 1994b. Distribution of macroalgae in a tropical river basin from southeastern Brazil. Archiv für Hydrobiologie v. 129, p. 459471, 1994.

NECCHI, O. Jr.; BRANCO, L. H. Z.; SPEZAMIGLIO, D. N. Ecological distribution of stream macroalgal communities from " Parque Nacional de Itatiaia", states of Minas Gerais and Rio de Janeiro, Brazil. Revista Brasileira de Botânica, v. 31, p. 135-145, 2008.

NECCHI, O. Jr.; DIP, M. R.; GÓES, R. M. Macroalgae of a stream in southeastern Brazil: composition, seasonal variation and relation to physical and chemical variables. Hydrobiologia, v. 213, p. 241-250, 1991.

NECCHI O. Jr.; PASCOALOTO, D.; BRANCO, C. C. Z.; BRANCO, L. H. Z. Stream macroalgal flora from the northwest region of São Paulo State, Southeastern Brazil. Algological Studies, v. 84, p. 91-112, 1997.

SHEATH, R. G.; BURKHOLDER, J. Characteristics of softwater streams in Rhode Island. II: Composition and seasonal dynamics of macroalgae communities. Hydrobiologia, v. 128, p. 109-118, 1985.

SHEATH, R. G.; COLE, K. M. Biogeography of stream macroalgae in North America. Journal of Phycology, v. 28, p. 448-460, 1992.

SHEATH, R. G.; COLE, K. M. Stream macroalgae of the Fiji Islands: A preliminary study. Pacific Science, v. 50, p. 46-54, 1996.

SHEATH, R. G.; HAMILTON, P. B.; HAMBROOK, J. A.; COLE, K. M. Stream macroalgae of the eastern boreal forest region of North America. Canadian Journal of Botany, v. 67, p. 3353-3362, 1989.

SHEATH, R. G.; MORINSON, M. O.; KORSH, J. E; KACZMARCZYK, D., COLE, K. M. Distribution of stream macroalgae in south-central Alaska. Hydrobiologia, v. 135, p. 259269, 1986.

SHEATH, R.G.; MÜLLER, K. M. Distribution of stream macroalgae in four high arctic drainage basins. Arctic, v. 50, p. 355-364, 1997.

VIS, M. L.; SHEATH, R. G.; HAMBROOK, J. A.; COLE, K. M. Stream macroalgae of the Hawaiian islands: a preliminary study. Pacific Science, v. 48, p. 175-187, 1994. 